\title{
L'établissement enclos de La Métairie de la Lande à Guérande (Loire-Atlantique) : une possible ferme aristocratique du second âge du Fer
}

The enclosed settlement of La Métairie de La Lande in Guérande (Loire-

Atlantique): a possible aristocratic farm from the second Iron age

Das grabenumhegte Gehöft von La Métairie de la Lande bei Guérande (Loire-

Atlantique): ein aristokratisches Gehöft der jüngeren Eisenzeit?

El recinto de La Métairie de la Lande en Guérande (Loire-Atlantique): un posible establecimiento rural aristocrático de la Segunda Edad del Hierro

Patrick Bellanger, Joël Cornec et Rémy Arthuis

\section{OpenEdition}

Journals

Édition électronique

URL : https://journals.openedition.org/rao/6963

DOI : $10.4000 /$ rao.6963

ISSN : 1775-3732

Éditeur

Presses universitaires de Rennes

Édition imprimée

Date de publication : 21 décembre 2021

Pagination : 171-208

ISBN : 978-2-7535-8668-0

ISSN : 0767-709X

\section{Référence électronique}

Patrick Bellanger, Joël Cornec et Rémy Arthuis, «L'établissement enclos de La Métairie de la Lande à Guérande (Loire-Atlantique) : une possible ferme aristocratique du second âge du Fer », Revue archéologique de l'Ouest [En ligne], 37 | 2021, mis en ligne le 21 décembre 2021, consulté le 11 octobre 2022. URL : http://journals.openedition.org/rao/6963 ; DOI : https://doi.org/10.4000/rao.6963 


\title{
L'établissement enclos de La Métairie de la Lande à Guérande (Loire-Atlantique) :
} une possible ferme aristocratique du second âge du Fer

\author{
The enclosed settlement of La Métairie de La Lande in Guérande (Loire-Atlantique): \\ a possible aristocratic farm from the second Iron age
}

\author{
Patrick Bellanger \\ Inrap Grand Ouest, 4 rue du Tertre, 44470 Carquefou (patrick.bellanger@inrap.fr) \\ Joël Cornec \\ Inrap Grand Ouest, 4 rue du Tertre, 44470 Carquefou (joel.cornec@inrap.fr) \\ Rémy Arthuis \\ Inrap Grand Ouest, 4 rue du Tertre, 44470 Carquefou (remy-arthuis@inrap.fr)
}

\begin{abstract}
Résumé : L'établissement de La Lande, implanté sur le bord oriental du plateau de Guérande et sur la rive droite d'une amorce de vallon, a fait l'objet d'une fouille préventive en 2009, conduite sur une surface de $19500 \mathrm{~m}^{2}$. Huit phases d'occupations anciennes s'échelonnant entre le $\mathrm{IV}^{\mathrm{e}} \mathrm{s}$. av. J.-C. et le début du $\mathrm{II}^{\mathrm{e}} \mathrm{s}$. apr. J.-C. ont été identifiées. La première phase correspond à un probable petit habitat ouvert daté de la fin de La Tène ancienne ou du début de La Tène moyenne. Au cours des quatre phases suivantes, entre La Tène moyenne et La Tène finale, une vaste ferme couvrant une superficie d'environ 1,4 ha et de plan pentagonal est bâtie, et connaît de multiples réaménagements. Cet établissement est ceinturé par une double enceinte sur les flancs nord et nord-ouest, triplée sur les autres côtés. L'enclos possède dès sa création une entrée orientale dotée d'un porche. À l'intérieur s'observent de nombreux fossés de partition structurant l'espace en modules communiquant entre eux et dont les passages sont le plus souvent munis de portails. La structuration du site à cette période est telle que la question de son statut, alors potentiellement aristocratique, se pose. La cinquième phase, attribuable à La Tène finale, semble marquer un déclin du statut de la ferme. Bien que modifié sur sa façade sud, l'établissement reste utilisé durant les deux phases suivantes, datées du $\mathrm{I}^{\text {er }}$ s. apr. J.-C., avant d'être abandonné vers la fin du $\mathrm{I}^{\mathrm{er}}$ s. au profit d'un enclos à vocation de type agro-pastoral, chevauchant l'ancienne façade orientale.
\end{abstract}

\begin{abstract}
The La Lande settlement, located on the eastern edge of the Guérande plateau and on the right bank of a small valley, was excavated in 2009, covering an area of 19,500 $\mathrm{m}^{2}$. Eight occupation phases dating from the 4 th century $B C$ to the beginning of the $2 n d$ century AD, were identified. The first phase corresponds to a probable small open settlement dated to the late Early La Tène or early Middle La Tène. During the next four phases, between the Middle and Final La Tène periods, a vast farmhouse covering an area of about 1.4 ha and with a pentagonal plan was built and underwent multiple redevelopments. This settlement is surrounded by a double enclosure on the north and north-west flanks, tripled on the other sides. From the outset, the enclosure had an eastern entrance with a porch. Inside, there are numerous partition ditches that organise the space in modules that communicate with each other and whose passages are usually equipped with portals. The structuring of the site during this period is such that the question of its status, which was potentially aristocratic at the time, arises. The fifth phase, attributable to the Late La Tène period, seems to mark a decline in the status of the farm. Although modified on its southern façade, the settlement remained in use during the next two phases, dated to the 1st century $A D$, before being abandoned towards the end of the 1st century in favour of an agro-pastoral enclosure built on the former eastern façade.
\end{abstract}

Mots clés: Loire-Atlantique, âge du Fer, Haut-Empire, céramique.

Keywords: Loire-Atlantique, Iron Age, Early Empire, ceramic. 


\section{Présentation}

Située dans la partie occidentale et littorale de la cité des Namnètes (Lorho et Monteil, 2013), au nord de l'estuaire de la Loire, la commune de Guérande se trouve sur une ligne de crête s'étendant de Saint-Nazaire à Piriac-surMer, qui domine à la fois la côte atlantique et les marais de la Grande Brière (fig. 1).

\section{Contexte de la découverte}

Le site de La Lande a fait l'objet d'une fouille préventive en 2009. L’opération archéologique réalisée par l'Inrap, sur une surface de près de 2 ha, a permis la mise au jour d'un enclos complexe renfermant une grande quantité de structures fossoyées (fossés, fosses, trous de poteau) témoignant d'une occupation s'échelonnant entre le $\mathrm{III}^{\mathrm{e}} \mathrm{s}$. av. J.-C. et le début du II ${ }^{\mathrm{e}}$ s. apr. J.-C. (Bellanger, 2013).

Le plan général montre un grand système d'enclos emboîtés qui occupe la majeure partie du terrain. Les multiples fossés relevés, tant à l'intérieur qu'à l'extérieur, traduisent quant à eux une évolution de l'organisation interne des enclos et de leurs abords. Neuf phases correspondant à des réaménagements successifs du site ont été identifiées. Les cinq premières phases s'échelonnent entre La Tène moyenne et La Tène finale. Les phases 6 à 8 datent du Haut-Empire et la dernière phase concerne des fossés de parcellaire d'époque moderne.

Les reprises successives occasionnées par une relativement longue durée d'occupation, environ quatre siècles, faisant disparaître nombre de relations stratigraphiques, n'ont pas facilité le phasage du site. Toutefois, des décalages de tracés ont permis la préservation au moins ponc-
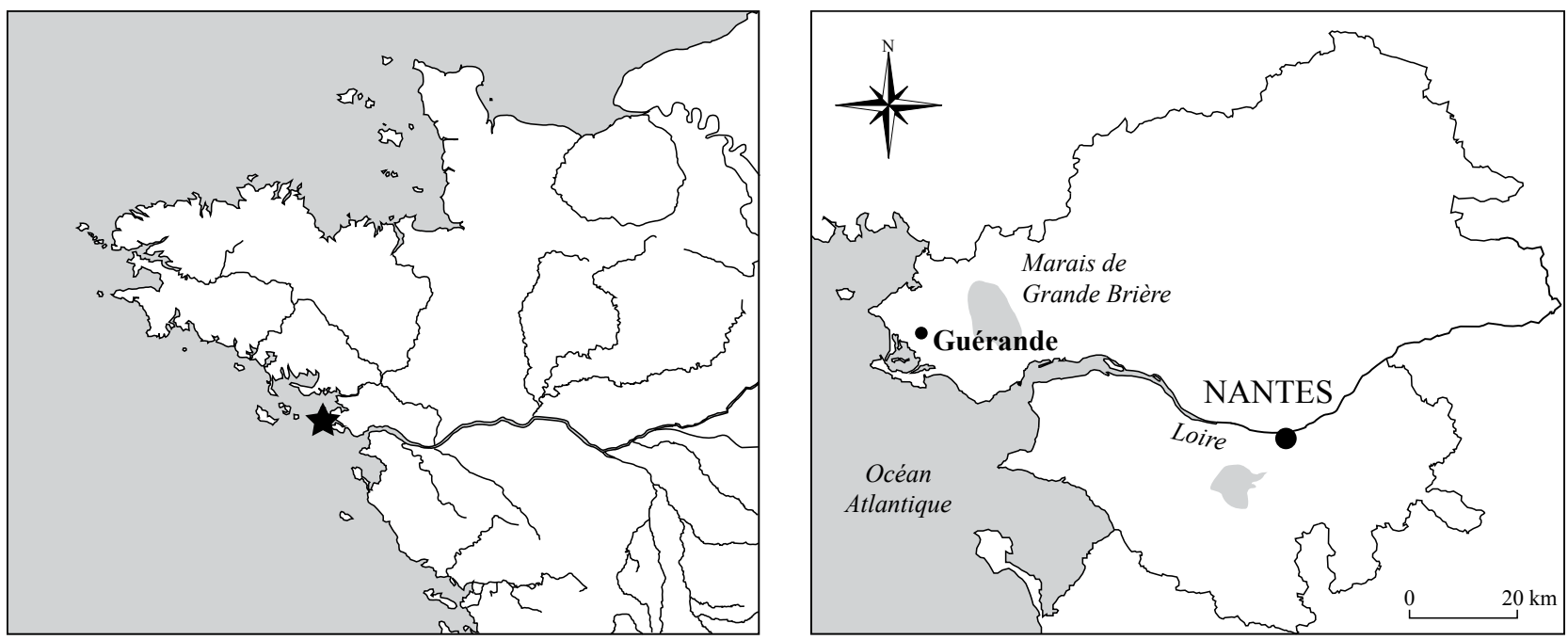

tuelle de vestiges significatifs en termes de chronologie relative qui, alliés à l'étude des intersections, à une logique spatiale et au mobilier recueilli au sein des comblements, permettent de proposer une interprétation de l'évolution du gisement de La Lande.

\section{Contextes géographique et géologique}

Le site archéologique est localisé à l'ouest de Guérande sur un vaste plateau incliné vers le nord-est, du côté des marais de Brière. Dans la direction opposée, en bordure de l'océan, à $1 \mathrm{~km}$ environ du site archéologique, le plateau à son point culminant (60 m NGF) décroche brutalement d'une hauteur de $45 \mathrm{~m}$ par un talus rectiligne orienté NO/SE. La base de ce talus est recouverte de dépôts de versant ou ennoyée dans une sédimentation argileuse de type lagunaire ou marine, mise en place durant la transgression flandrienne. Ces dépôts servent de socle aux marais salants. Le talus bordier est échancré par quelques vallées étroites et peu développées.

L'essentiel du réseau hydrographique se développe vers l'arrière-pays en suivant l'inclinaison nord-est du plateau. Les vallées sont peu hiérarchisées et faiblement incisées.

Le terrain décapé lors de la fouille archéologique est situé sur les versants d'un vaste amphithéâtre qui correspond aux limites extrêmes d'une tête de vallon. Le tracé linéaire du vallon se développe vers le nord-est, à l'ouest du site fouillé. Le substrat est composé d'un granite clair, généralement assez grossier, nettement feuilleté ou orienté. Il est traversé de quelques filons quartzeux orientés sud-est/nord-ouest et présente localement d'abondantes paillettes de mica blanc. Le granite relativement sain affleure localement (fig. 2). Ailleurs, il se présente très

Figure 1 : Guérande, « La Lande » : localisation géographique. DA0 : P. Bellanger 
altéré sous la forme d'une arène plus ou moins argileuse. Au sommet du substrat, des quartz plus ou moins émoussés sont redistribués sur les versants. Lorsqu'ils n'ont pas été tronqués par les labours, des limons de plateau sont conservés sur le substrat. Cette configuration stratigraphique se retrouve, sous le décapage, à l'échelle du chantier de fouille : à l'ouest où le substrat affleure, il s'agit d'une arène ou ponctuellement d'un granite relativement sain, tandis qu'à l'est, il est recouvert de limons de plateau plus ou moins argilisés.

\section{Un contexte archéologique particulièrement riche}

La presqu'île guérandaise et particulièrement le territoire communal de Guérande présentent une importante densité de gisements archéologiques.

De nombreux vestiges d'occupation datés de l'âge du Fer, enclos et habitats ouverts, ont été identifiés au cours de diagnostics et fouilles entrepris au préalable des travaux d'aménagement de la périphérie de la ville, essentiellement au nord et à l'est de celle-ci (fig. 3). On citera notamment des vestiges datant du Hallstatt et/ou de La Tène ancienne, souvent associés à de la production salicole, à Trébissin (Le Boulaire, 2009a, 2009b), à Villejames (Devals, 1995), à Kerhaut (Devals, 1998), au Parc Savari sur la ZAC de Bréhadour (Bellanger, 2010) et à La Maison Neuve, zone A (Pirault, 2019).

D'autres gisements correspondent à des habitats et/ ou des enclos attribuables à La Tène moyenne à finale, à Bréhadour (Devals, 1994), à La Lande (Bellanger, 2013) et à Villejames (Devals, 1995, 2009; Pirault, 2010), ou encore à un possible secteur à vocation rituelle au Clos Flaubert (Pirault, 1996). La production de sel est attestée pour cette période par la découverte de fours à grille à Villejames, à La Maison Neuve, zone A et à Léchet (La Maison Neuve, zone B : Bellanger, 2019).

Dans sa thèse soutenue en 2017, J. Rémy souligne que la quantité de vestiges mis au jour autour du Moulin de Beaulieu et l'apparente absence d'enclos délimitant cette occupation pourraient suggérer l'existence d'une

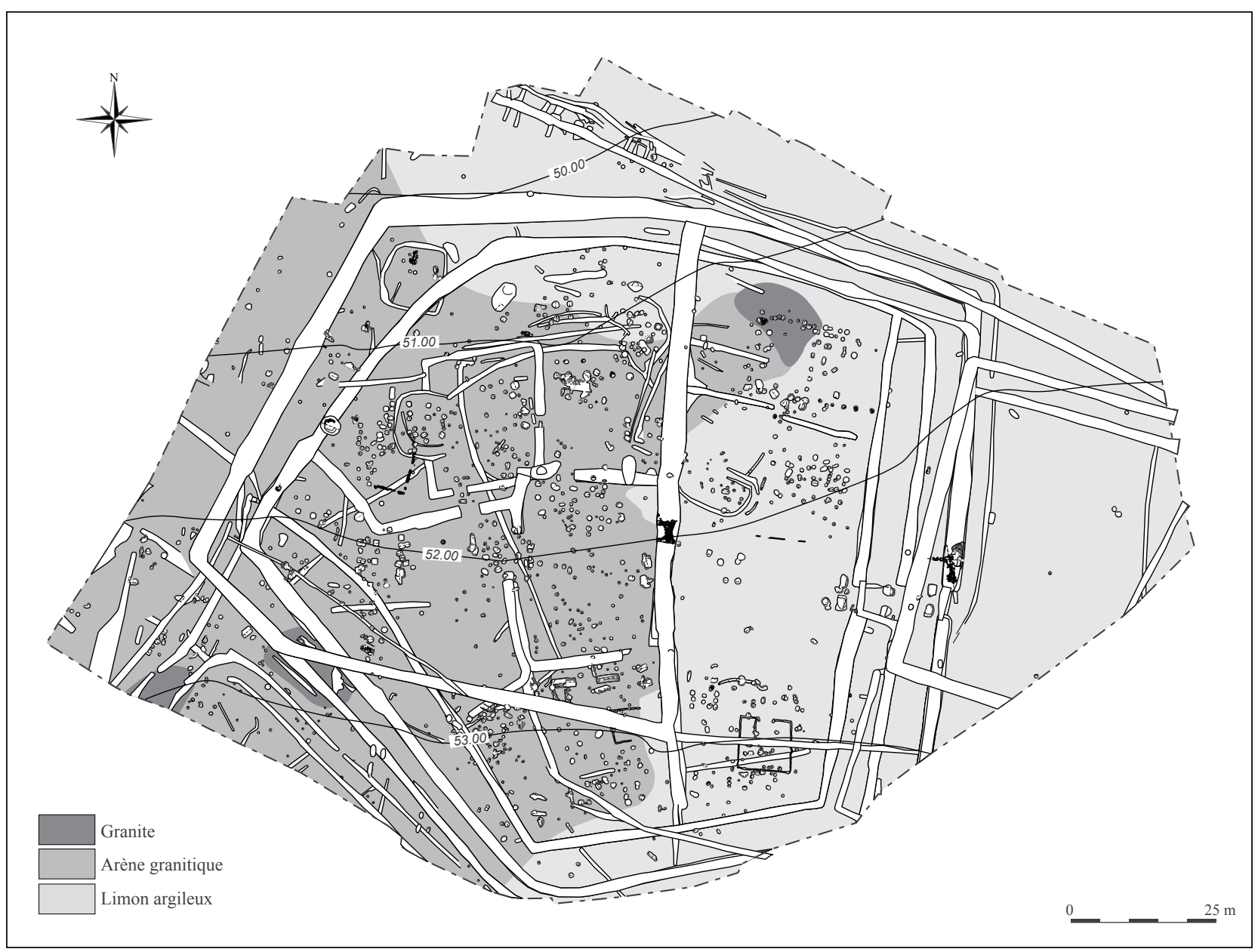

Figure 2 : Guérande, " La Lande » : géologie du site. DAO : P. Bellanger

Figure 2: Geology of the site. Realisation: P. Bellanger. 


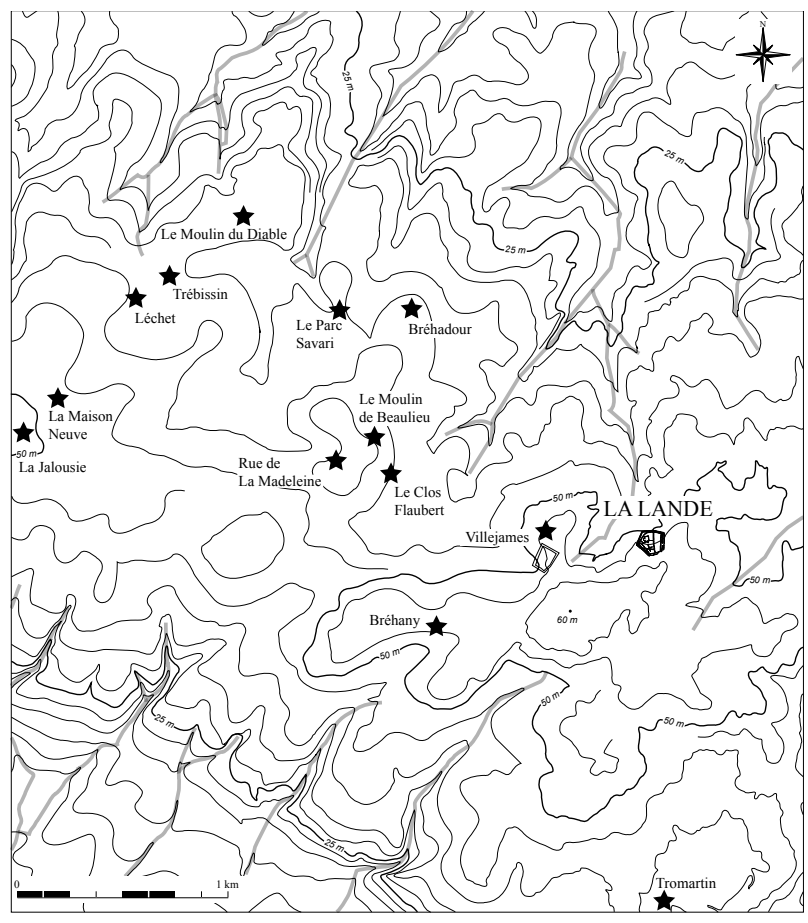

Figure 3 : Guérande, « La Lande » : environnement archéologique et topographique du site. DAO : P. Bellanger.

Figure 3: Archaeological and topographic environment of the site. Realisation: P. Bellanger.

agglomération laténienne. Elle évoque toutefois aussi la possibilité d'un établissement inséré dans un réseau de domaines agricoles à l'image de la ZAC Object'Ifs Sud (Le Goff, 2009).

Pour l'époque antique, on constate une concentration particulière dans le secteur de Beaulieu. Les fouilles de la rue de la Madeleine (Crapig, 1975), du Moulin de Beaulieu (Pithon, 1994) et du Clos Flaubert (Pirault, 1996) ont livré les éléments d'un ou plusieurs quartiers d'habitations organisés autour d'une voie. L'environnement rural s'identifie par des enclos et parcellaires attestés à Villejames (Devals, 1995), à Bréhadour (Devals, 1994) et au Moulin du Diable (Vacher, 2001). La présence d'un port a été évoquée à Clis, mais l'état des connaissances ne permet pas d'interpréter la fonction de ce site gallo-romain (villa(e)?). La fouille récente de La Maison Neuve, zone A, a révélé la présence d'un atelier de potier et de structures parcellaires qui pourraient être liés à une possible villa repérée par photographie aérienne à La Jalousie (Pirault, 2019). À proximité immédiate du site de La Maison Neuve, zone B, le diagnostic de Trébissin avait révélé la présence de constructions antiques (Le Boulaire, 2009a, 2009b).

L'hypothèse de l'existence d'une agglomération antique dans le secteur du Moulin de Beaulieu reste à confirmer (Monteil, 2012).

\section{LES VESTIGES D'UN MODESTE HABITAT OUVERT ANTÉRIEUR À L'IMPLANTATION DE L'ENCLOS PENTAGONAL}

Plusieurs structures fossoyées présentent une orientation et une disposition qui les distinguent des vestiges liés à l'enclos pentagonal. Certaines d'entre elles étant de plus recoupées par ces derniers, il apparaît envisageable de rattacher ces éléments à une première implantation d'habitat, datable du début de La Tène moyenne, mais dont l'organisation demeure lacunaire (fig. 4).

Quelques fossés (763/685/649/650, 830, 853/1191/1245/482, 552/750/811/1270/431, 551/546, 1387/1593, 459/1547/284 ou encore peut-être 220) sont antérieurs à l'enclos pentagonal mais leur organisation reste difficile à appréhender. De profil en U évasé, ces fossés montrent des dimensions modestes, présentant une largeur de 0,40 à $1,05 \mathrm{~m}$ de large et une profondeur conservée de 0,10 à $0,50 \mathrm{~m}$. Le creusement du petit fossé $286 / 1673$, à parois subverticales et fond plat, parait correspondre à une tranchée de palissade doublant le fossé 284. Les comblements, pour la plupart homogènes, sont constitués de limon sableux.

Dans l'angle sud-ouest, un possible chemin semble matérialisé par les fossés 50/47 et 1077/1076/605/46.

Les ensembles E.10, localisés dans la partie nord-ouest du terrain, E.32 et E.3, situés dans la partie centrale, pourraient constituer des unités d'habitation rattachables à cette première occupation. Ces ensembles sont composés de tranchées de faible puissance entourant partiellement ou complètement un espace d'une centaine de mètres carrés.

\section{L'enCLOS PENTAGONAL LATÉNIEN}

L'occupation principale du site de La Lande consiste en un vaste établissement de plan pentagonal composé d'une surface ceinturée par une double enceinte sur les flancs nord et nord-ouest, triplée sur les côtés est, sud et sud-ouest. L'établissement couvre une superficie globale d'environ 1,4 ha et une surface interne variable selon les phases d'occupation d'un minimum de $7500 \mathrm{~m}^{2}$. À l'intérieur s'observent de nombreux fossés qui dessinent des partitions structurant l'espace et dont les recoupements trahissent des états du site chronologiquement distincts.

\section{Évolution de l'établissement}

\section{Création de l'enclos pentagonal gaulois (La Tène C2)}

Le premier état de l'enclos 1 est fortement perturbé par les multiples reprises ultérieures, mais il a laissé suffi- 
samment de vestiges pour comprendre l'essentiel de son organisation (fig. 5). En effet, la plupart des fossés appartenant à cette phase ont été creusés plus profondément que leurs successeurs et ont ainsi échappé à une destruction complète.

La ceinture externe de l'établissement, dotée de ses cinq côtés, semble déjà intégralement en place. Elle se caractérise par des creusements atteignant au moins $2,50 \mathrm{~m}$ de large à l'ouverture et $1,75 \mathrm{~m}$ de profondeur sous le décapage et dont le profil montre un fond plat et des parois abruptes (fig. 6). Dans quelques sections transversales, la dissymétrie des strates de comblements permet de restituer un talus interne. Le pendage général du fond des fossés respecte la pente naturelle du terrain, vers le nordouest. Les fossés 114 et 1000 forment la façade orientale et encadrent l'accès au site. La présence d'une tranchée reliant les deux sections de fossé (1436) implique que cet accès principal devait être doté d'une passerelle. Deux grandes fosses jumelles attestent l'existence d'un système de porche monumental fixant le talus interne. Un chemin, délimité par le petit fossé bordier 115/110/112, conduit à l'entrée en longeant l'angle nord-est de l'enclos.
Les fossés 1647,1637 et 159/1491 constituent quant à eux les façades sud-ouest, nord-ouest et nord de l'enclos. La façade sud, hors emprise, demeure hypothétique.

La ceinture interne semble moins développée dans ce premier état. Sur le flanc oriental, seuls deux courts tronçons fossoyés, 1310 et 157, d'une largeur maximale à l'ouverture de $2,50 \mathrm{~m}$ et d'une profondeur conservée atteignant $1,50 \mathrm{~m}$ bordent l'entrée interne. Ils sont également dotés d'un talus du côté ouest. Ces fossés montrent un profil à fond plat et parois abruptes, similaire à celui des creusements de la ceinture externe. L'entrée interne est elle aussi munie d'un porche. Sur le flanc nord-ouest, les fossés 1640 et 1770 composent les autres éléments reconnus pour cet état de la ceinture interne. Si l'interruption du fossé 1640, outrepassant de peu l'angle sud-ouest, est avérée, la continuité du fossé 1770 vers l'est reste pour sa part incertaine. Le doublement de l'enclos à cet endroit précis peut s'expliquer par la volonté de protéger l'habitat des vents de nord-ouest.

Bien que particulièrement masquée par les reprises postérieures, une partition d'axe nord/sud est partiellement mise en place parallèlement et à une distance d'une

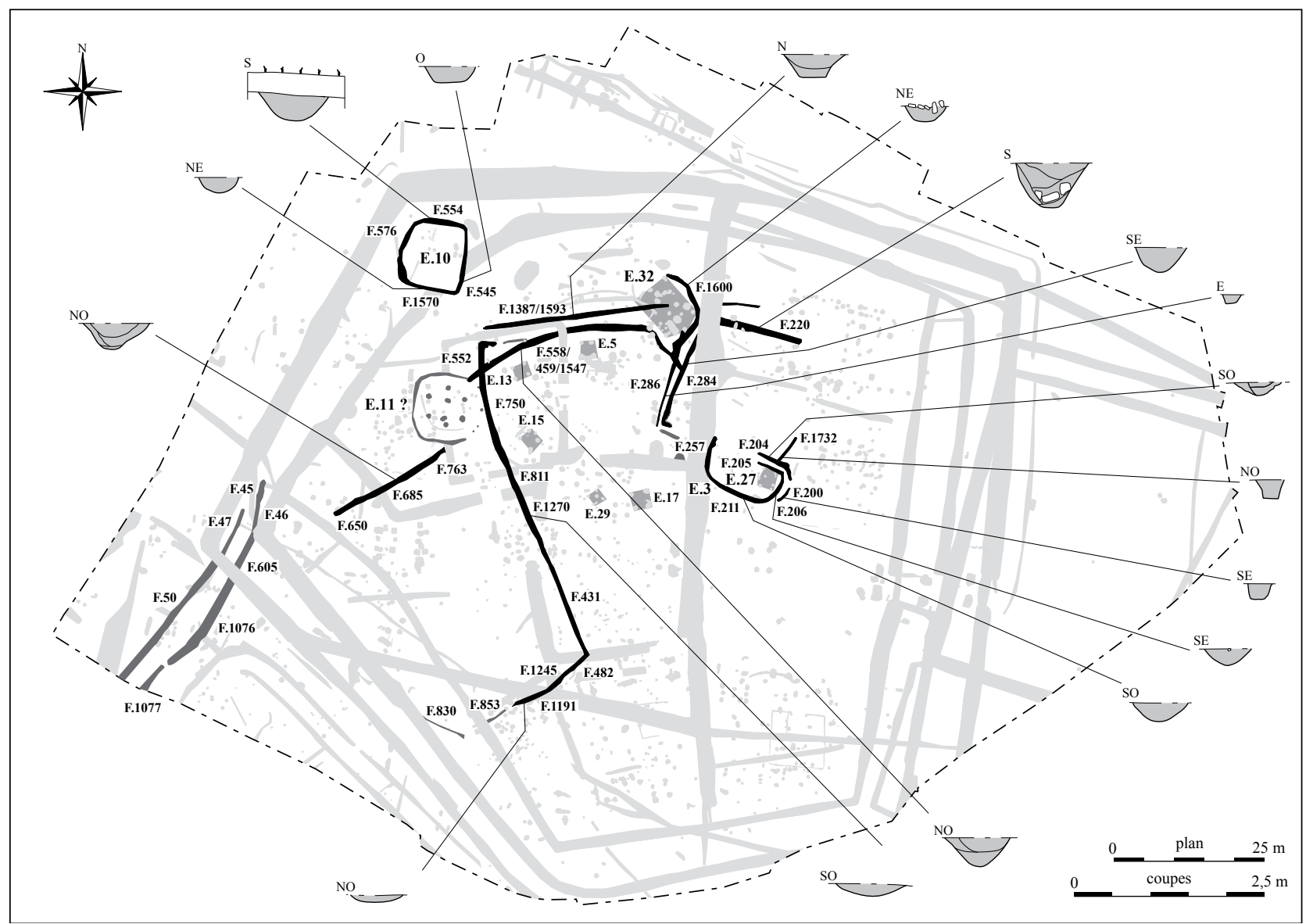

Figure 4 : Guérande, «La Lande » : plan et coupes des fossés attribués à la phase 1. DA0 : J.M. Richard, P. Bellanger.

Figure 4: Plan and sections of the ditches assigned to the phase 1. Realisation:J.-M. Richard, P. Bellanger. 


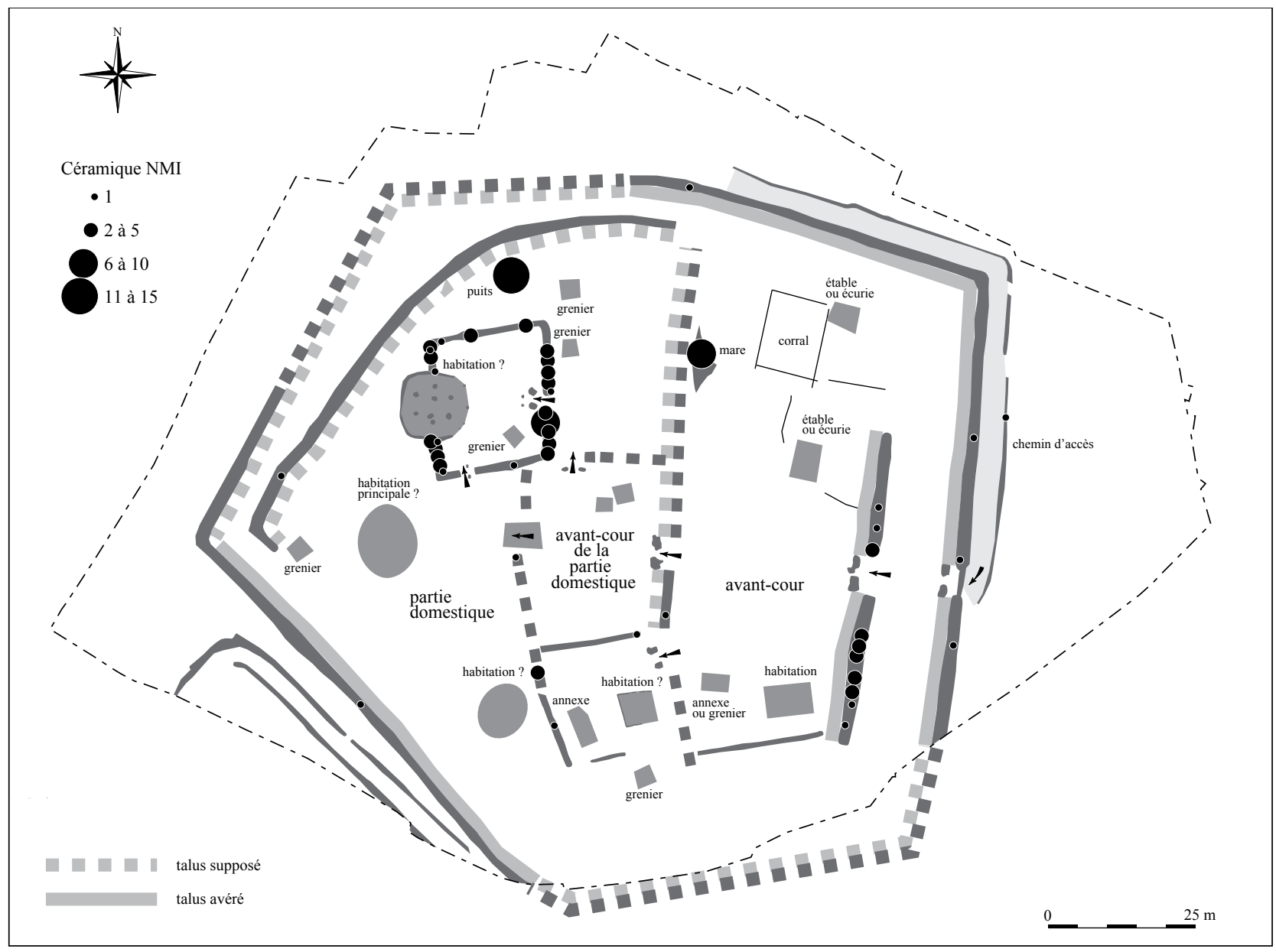

Figure 5 : Guérande, « La Lande » : plan interprétatif et répartition du mobilier céramique de la phase 2. DA0 : J. Cornec, P. Bellanger.

Figure 5: Interpretive plan and distribution of ceramic material of the phase 2. Realisation: J. Cornec, P. Bellanger.

trentaine de mètres à l'ouest de la clôture interne orientale (fig. 7). Cette délimitation sépare la partie orientale qui forme ainsi une avant-cour, et la partie occidentale à vocation vraisemblablement résidentielle et sans doute artisanale. De cette première partition, seul nous est parvenu le segment de fossé 1404, d'une largeur estimée de $1,40 \mathrm{~m}$ et d'une profondeur de $0,58 \mathrm{~m}$, bordant le côté méridional de l'entrée 2 accompagnée d'un porche identique à celui de l'entrée 1 mais de dimensions légèrement plus réduites. Matérialisée par l'interruption sud du fossé 1404 , son probable pendant 1406 au sud et par la présence de deux fosses de portail, une seconde entrée se signale (entrée 10). La section septentrionale de cette partition reste quant à elle hypothétique quoique très envisageable (1498?).

L'espace A, inscrit entre les fossés internes orientaux et ceux de la partition nord/sud, est délimité au sud par le fossé 1002. On observe entre les deux entrées une aire de circulation qui restera quasi exempte de structures durant toutes les phases d'occupation du site. Comme enclos (ensemble E.19), la partie nord de l'avant-cour sert très vraisemblablement au parcage. Dans ce même secteur, deux bâtiments à vocation agricole sont peut-être déjà édifiés (ensembles E.20 et E.24). Au sud de la cour, se trouve une construction (ensemble E.25) qui, de par ses dimensions et les rejets de mobilier mis au jour dans le comblement du fossé 157 voisin, peut être considérée comme une habitation.

Du côté occidental de la partition nord/sud, sitôt franchie l'entrée 2, l'espace B qui s'étend sur environ $660 \mathrm{~m}^{2}$ se voit circonscrit au sud par le fossé 302 et partiellement à l'ouest par le fossé 1264 . Face à l'entrée 2, un passage sans doute aménagé avec un porche couvert (entrée 9) permet l'accès à la partie ouest de l'enclos (espace D). Rejoignant le fossé de partition nord/sud, le fossé 1400 est peut-être également déjà creusé. Celui-ci s'interrompt à $5 \mathrm{~m}$ de distance de l'angle sud-est d'un petit enclos fossoyé (enclos 3), préservant ainsi la circulation (entrée 3) vers le nord-ouest de l'enclos (espace C).

L'enclos 3, de plan rectangulaire de $20 \mathrm{~m}$ par $24 \mathrm{~m}$ délimitant une surface interne de $380 \mathrm{~m}^{2}$, est constitué 


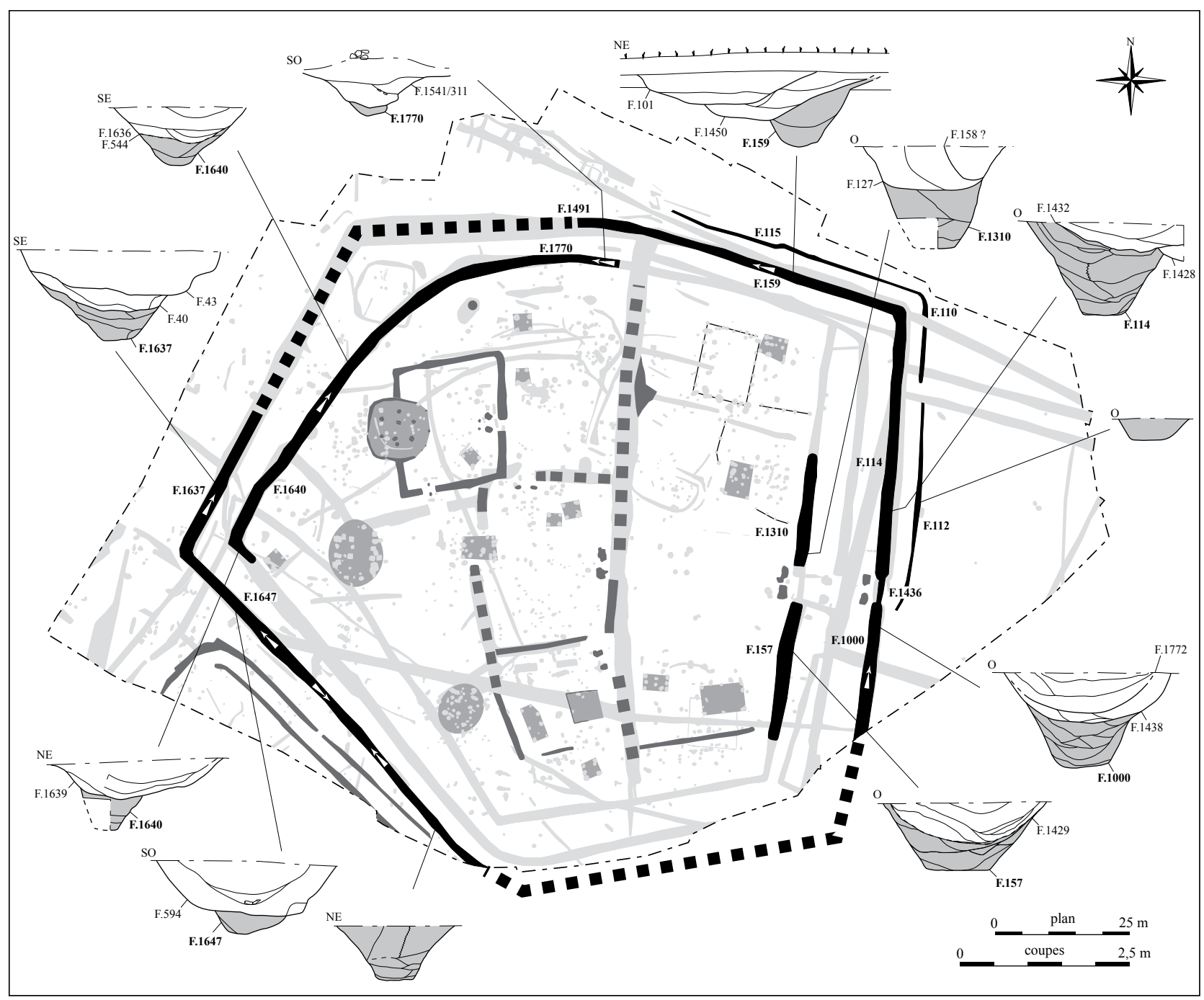

Figure 6 : Guérande, «La Lande » : plan et coupes des fossés de l'enclos attribués à la phase 2. DA0 : J.-M. Richard, P. Bellanger.

Figure 6: Plan and sections of the enclosure's ditches assigned to the phase 2. Realisation: J.M. Richard, P. Bellanger.

par des fossés à profil en $U$ évasé ou en $V$ qui offrent des dimensions conservées atteignant une largeur de $1,75 \mathrm{~m}$ à l'ouverture et une profondeur de $0,75 \mathrm{~m}$. Deux entrées sont ménagées dans les façades est et sud (entrées 4 et 7). L'existence d'un porche au niveau de l'entrée orientale, caractérisé par des fosses jumelles similaires quoique de taille inférieure à celles des entrées 1 et 2 , paraît témoigner qu'il s'agit là de l'entrée principale du petit enclos. La seconde entrée semble quant à elle munie d'une séparation transversale. L'insertion d'un bâtiment sur poteaux porteurs et tranchée périphérique dans la façade occidentale (ensemble E.11) ainsi que le mobilier recueilli au sein des comblements des fossés traduisent la vocation résidentielle de l'enclos 3. Une activité artisanale y est également attestée par la présence de soles perforées et de parois de fours dans les fossés 506 et 764 .

Dans l'angle ouest de l'enclos 1 (espace D), outre le grenier E.12, deux zones à multiples impacts pourraient constituer d'autres unités d'habitation. Un premier groupe de creusements de poteaux, pour la plupart de plan quadrangulaire, témoigne par le nombre de ces structures et leurs fréquents recoupements de la présence de bâtiments reconstruits au même endroit. L'existence d'un édifice à cet endroit dès la création de l'enclos pentagonal est fortement suggérée par sa situation face à l'axe principal de circulation est-ouest, matérialisé par les passages successifs (entrées 1, 2 et 9). Aucun plan certain ne peut toutefois être proposé pour cet état.

La seconde zone de concentration (ensemble E.33) se situe dans la partie sud de l'espace $\mathrm{D}$, mais la présence d'un bâtiment pour cette phase reste hypothétique.

L'espace $\mathrm{C}$, localisé au nord-ouest de l'enclos 3 résidentiel, comporte deux greniers qui ont pu fonctionner lors de la phase 2 (ensembles E.5 et E.6) ainsi qu'un puits (538). 


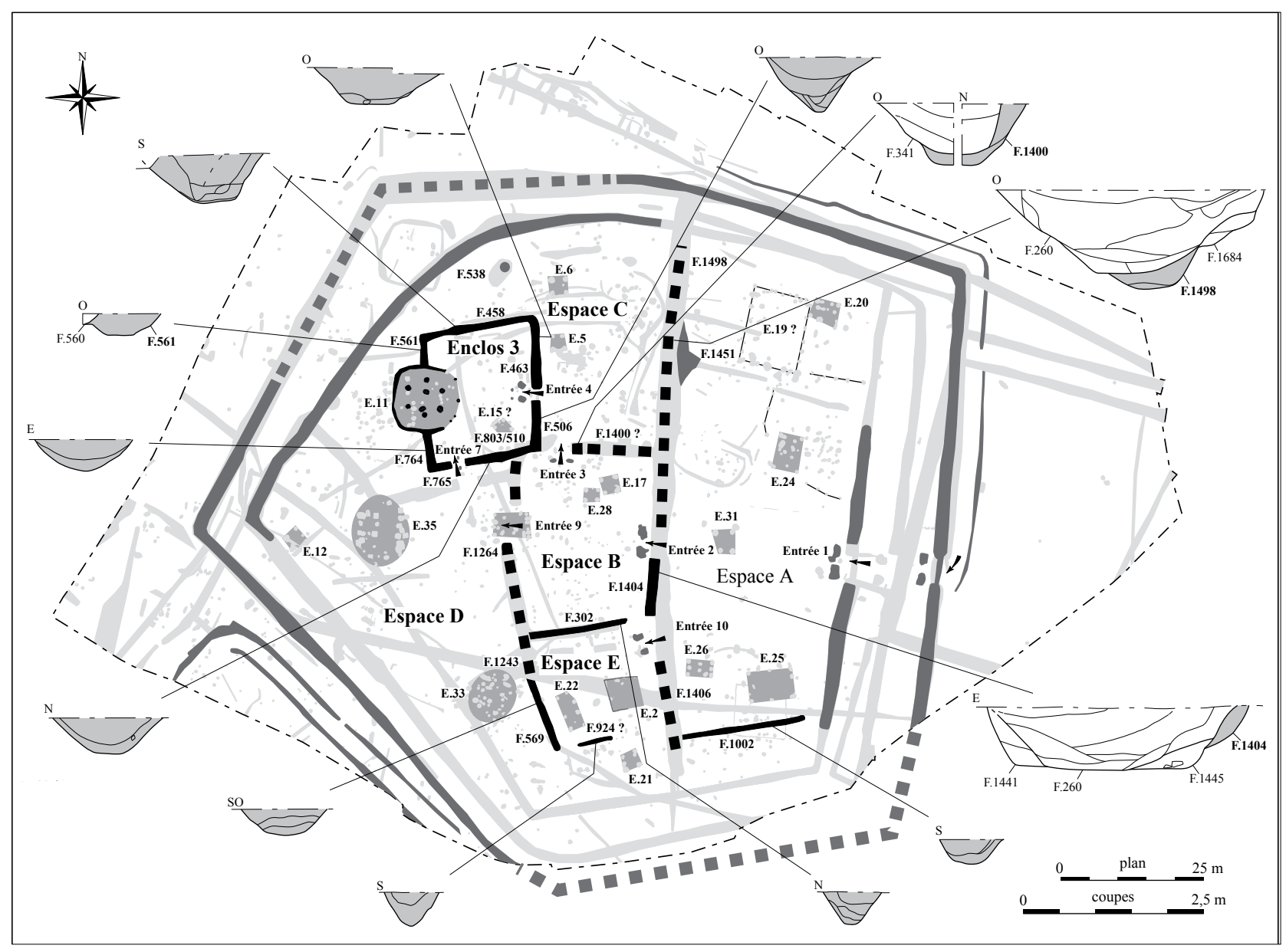

Figure 7 : Guérande, « La Lande » : plan et coupes des fossés internes attribués à la phase 2. DA0 : J.M. Richard, P. Bellanger.

Figure 7: Plan and sections of the internal ditches assigned to the phase 2. Realisation: J.-M. Richard, P. Bellanger.

Le fossé 1264 se poursuit vers le sud, au-delà de sa jonction avec le fossé 302, sur une longueur de $20 \mathrm{~m}$ (1243/569). Il forme, avec le petit fossé 924 au sud et le probable fossé 1406 à l'est, l'espace E d'une superficie d'environ $340 \mathrm{~m}^{2}$. Celui-ci est occupé (dès cette phase?) par deux édifices (ensembles E.2 et E.22), dont la fonction reste indéterminée (habitation et/ou annexe?). Le grenier E.21, tout près au sud, est peut-être lui aussi déjà bâti.

\section{Le chemin d'accès}

Un petit fossé externe, que l'on peut interpréter comme un fossé bordier de chemin ou une tranchée de palissade, longe l'angle nord-est de l'enclos pentagonal à une distance régulière située entre 2 et $2,80 \mathrm{~m}$ en rejoignant le côté sud de l'entrée de l'enclos. Son profil varie entre un U évasé et un fond plat à parois obliques. Il présente une largeur de $1 \mathrm{~m}$ au maximum et une profondeur conservée atteignant $0,35 \mathrm{~m}$. Le comblement de ce fossé a livré du mobilier attribuable à La Tène finale mais il reste probable qu'il soit aménagé dès la création de l'enclos.

\section{Un premier réaménagement interne de l'enclos (transition La Tène C2-D1)}

Cette phase apparaît comme une phase intermédiaire durant laquelle une nouvelle configuration de l'enclos est mise en chantier (fig. 8). La ceinture externe de l'enclos mise en place au cours du premier état ne semble pas être modifiée.

Cependant, l'établissement se voit désormais doté d'une triple enceinte sur trois de ses côtés, double sur les côtés nord et nord-ouest (fig. 9). Sur la façade orientale, en arrière de la ceinture externe, les fossés 118/126 et 1365/999/1064 encadrent l'entrée 1 entre les deux limites préexistantes. Un système de porche est installé en arrière de l'accès. Les reprises observées à la fouille des fosses du porche interne témoignent d'un réaménagement de l'entrée principale, soit sous la forme de deux, voire trois portails successifs (le maintien du troisième, celui de la ceinture externe restant incertain), soit sous la forme d'un porche monumental couvert, comme pourrait le suggérer l'alignement des six fosses d'ancrage. Au vu de l'absence 


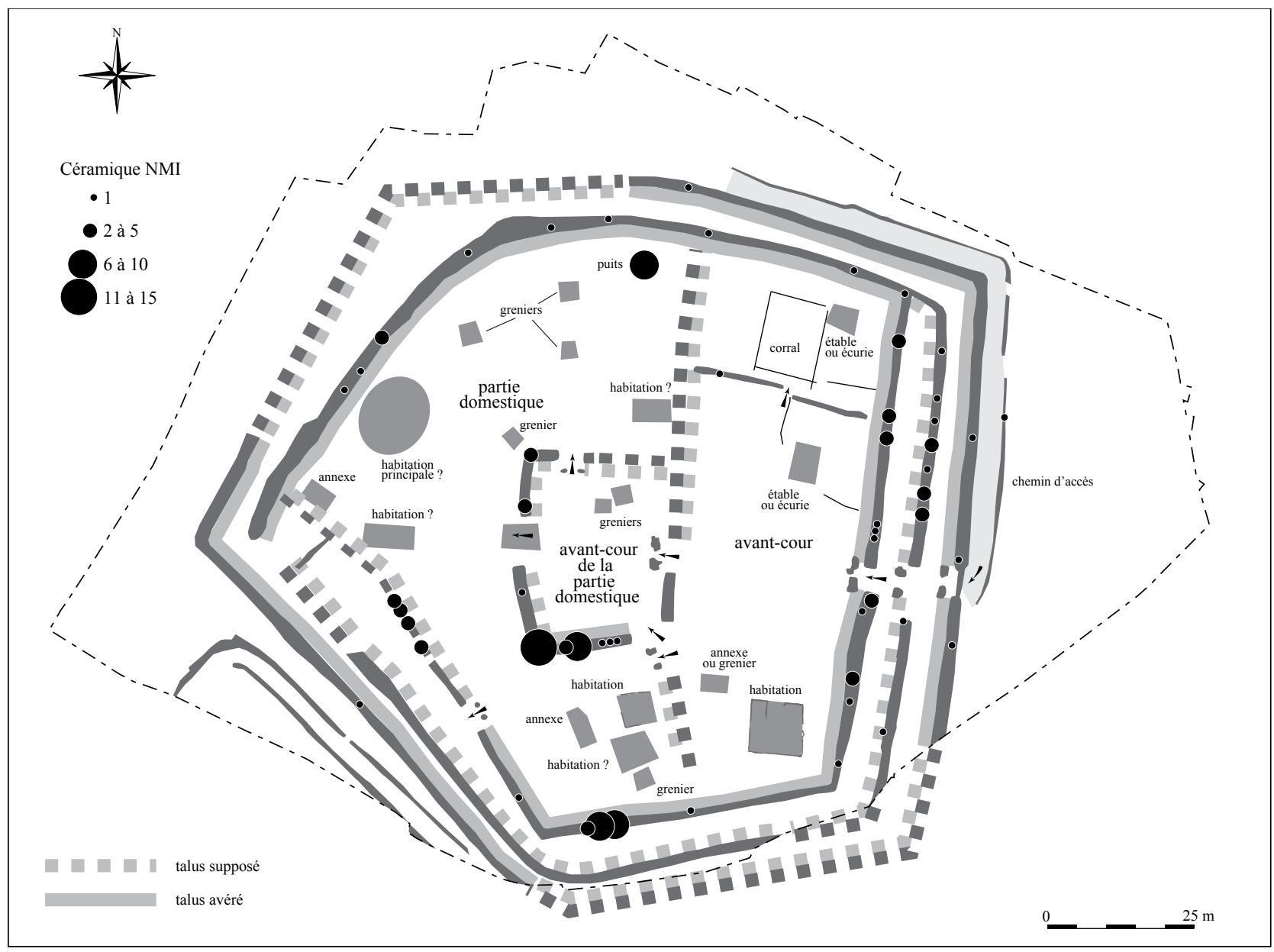

Figure 8 : Guérande, « La Lande » : plan interprétatif et répartition du mobilier céramique de la phase 3. DA0 : J. Cornec, P. Bellanger.

Figure 8: Interpretive plan and distribution of ceramic material of the phase 3. Realisation: J. Cornec, P. Bellanger.

de traces de poteaux intermédiaires, l'espace de $8 \mathrm{~m}$ entre chaque poteau latéral ne semble cependant pas plaider en ce sens. Ces fosses confirment également la localisation interne des talus. Le reste de la ceinture interne 1 se compose des fossés 593 pour la façade sud et 1771 pour la façade sud-ouest. Le tracé de ce dernier fossé est incomplet car perturbé par les creusements postérieurs dans son tiers nord-ouest. Les fossés 544, sans doute bordé d'un talus interne et s'interrompant dans l'angle sudouest (bordant un accès?), et 311/1541/124, constituent quant à eux les façades nord-ouest et nord de la ceinture interne 1. Le profil relevé varie entre un $U$ évasé et un fond plat et parois obliques et les dimensions peuvent atteindre 4,10 $\mathrm{m}$ de large à l'ouverture dans l'angle nordouest et $0,90 \mathrm{~m}$ de profondeur préservée. Comme pour la ceinture externe, le pendage général du fond respecte la pente naturelle du terrain.

La seconde ceinture interne, elle aussi dotée d'un talus du côté intérieur, reprend à l'est la partie supérieure des fossés 1310 et 157. Elle est composée sur ce flanc oriental par les fossés 127 , relié au nord à la ceinture interne 1, et 1429-1355 qui bordent l'entrée 1, comme dans l'état précédent. Le fossé 967 constitue le côté sud et, sur la façade sud-ouest, les deux sections 1407 et 1171, bien qu'observées de manière lacunaire en raison des reprises ultérieures, encadrent un accès (entrée 5). Ces fossés montrent tous un profil en $U$ évasé dont la largeur peut atteindre jusqu'à $4,10 \mathrm{~m}$ dans l'angle nord-ouest et une profondeur conservée de $0,85 \mathrm{~m}$.

À l'intérieur de l'enclos, le fossé de partition nord-sud perdure sous la forme de la courte section 1445, d'une largeur estimée aux alentours de $2 \mathrm{~m}$ et d'une profondeur maximale de $0,90 \mathrm{~m}$, en reprise du précédent fossé 1404 (fig. 10). Ce fossé borde lui aussi le côté sud de l'entrée 2 et le nord de l'entrée 10, tandis que les segments septentrional (1498 ?) et méridional (1406?) restent toujours supposés car masqués par les creusements postérieurs.

L'avant-cour constituée par l'espace A subit quelques modifications. Au nord, la mare 1451 est comblée et le creusement des fossés 1456 et 137 cloisonnent sans doute désormais l'extrémité septentrionale de l'avant-cour (espace F), apparemment encore vouée au parcage, sur une 


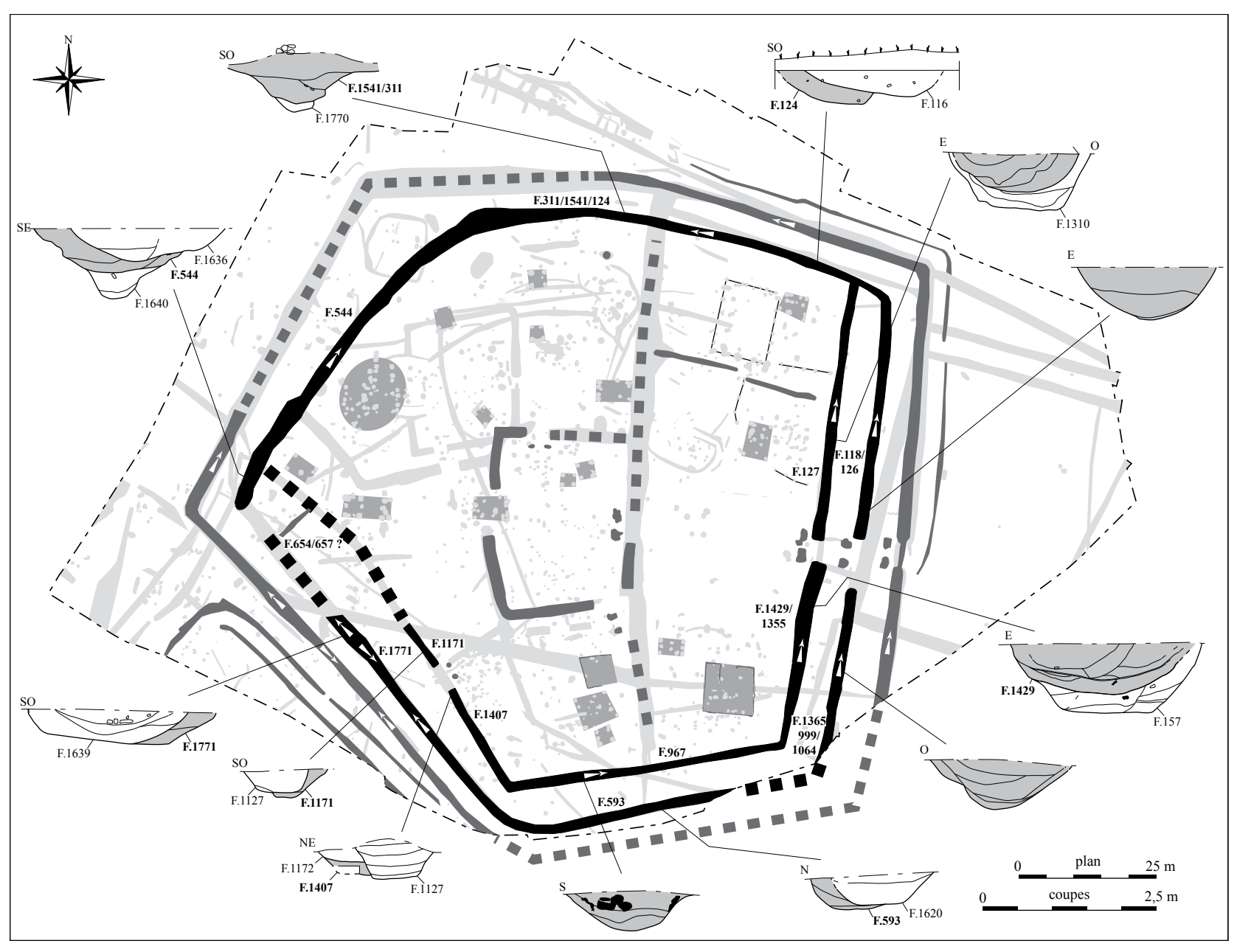

Figure 9: Guérande, «La Lande » : plan et coupes des fossés de l'enclos attribués à la phase 3. DA0 : J.M. Richard, P. Bellanger.

Figure 9: Plan and sections of the enclosure's ditches assigned to the phase 3. Realisation: J.-M. Richard, P. Bellanger.

surface d'environ $600 \mathrm{~m}^{2}$. On y accède par une entrée en chicane (entrée 11). Au sud, le fossé 1002 est condamné et le bâtiment E.25 est détruit pour être remplacé par une construction sur sablières basses (ensemble E.1) sans doute accompagnée d'une annexe (ensemble E.26). Les dimensions de cet édifice et les rejets dans le fossé voisin 157 tendent à indiquer qu'il s'agit d'une habitation.

L'espace B jouxtant l'entrée 2 du côté occidental est maintenu, entouré au nord par les fossés 505 et 1400 encadrant l'entrée 3, à l'ouest par les fossés 513 et 485 (en reprise du fossé antérieur 1264) bordant le large passage couvert (entrée 9) et au sud par le fossé 304 (en reprise du fossé antérieur 302), taluté sur le côté nord. Entre ce dernier et le fossé 1445 , l'écart est maintenant suffisant pour accéder à la fois à l'espace $\mathrm{E}$ et à l'entrée 10. Le profil de ces creusements varie entre un $\mathrm{U}$ et un $\mathrm{V}$ évasé et leurs dimensions maximales sont de $2,10 \mathrm{~m}$ de large à l'ouverture et de $0,70 \mathrm{~m}$ de profondeur. Deux greniers (ensembles E.18 et E.28) peuvent être construits dans la partie nord de cet espace au cours de cette phase.
Les fossés de l'enclos 3 sont comblés lors de cette phase d'occupation. Cette destruction génère une vaste surface non cloisonnée (espace D agrandi) autour de l'espace B. On peut toutefois présumer, au vu des nombreux trous de poteau (ensemble E.34) qui jalonnent les environs de l'ancien édifice E.11, qu'une nouvelle construction de grande taille succède à ce dernier. La partie nord de l'espace D apparait vouée au stockage avec la présence de plusieurs greniers (ensembles E.14, E.6, E.5 et E.15) et d'un puisard (329). Il semble aussi qu'une possible habitation (ensemble E.4) soit édifiée près de l'angle formé par le fossé de partition nord-sud et le fossé 1400. Dans l'angle sud-ouest, le grenier E.12 disparait certainement tandis que le bâtiment E.16 s'appuie maintenant contre le talus du fossé de ceinture interne. La conservation d'un bâtiment remplaçant l'ensemble E. 35 ne peut qu'être supposée pour cette phase.

Les fossés 569 et 924 comblés, aucun fossé ne sépare plus les espaces $\mathrm{D}$ et $\mathrm{E}$. Ce dernier reste une zone fortement construite, avec peut-être la création d'un nouvel édifice 


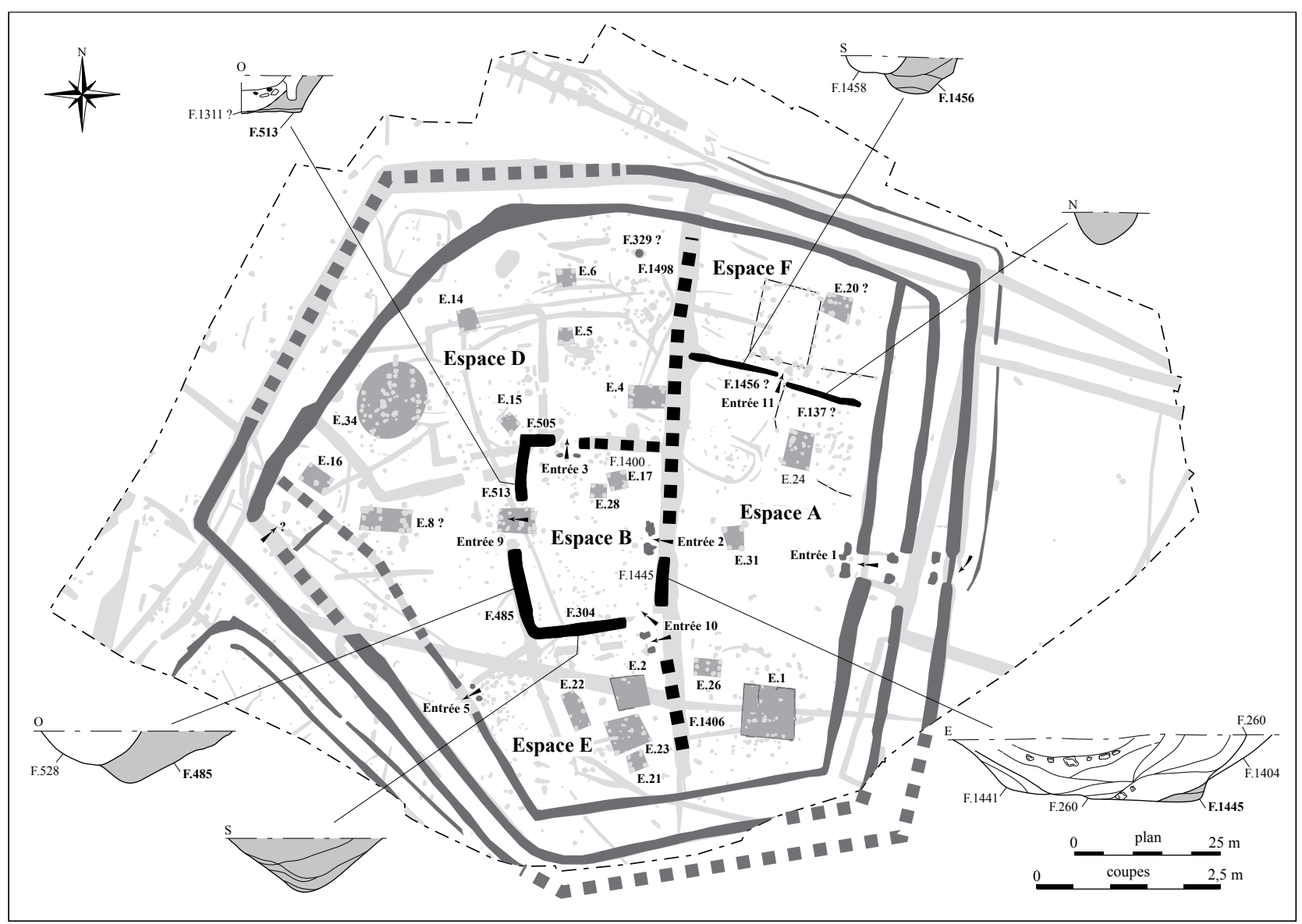

Figure 10 : Guérande, « La Lande » : plan et coupes des fossés internes attribués à la phase 3. DA0 : J.M. Richard, P. Bellanger.

Figure 10: Plan and sections of the internal ditches assigned to the phase 3. Realisation:J.-M. Richard, P. Bellanger.

(ensemble E.23) qui jouxte au sud l'axe de circulation entre les entrées 10 et 5 . La répartition du mobilier céramique montre des concentrations au nord et au sud de l'espace $\mathrm{E}$ évoquant des rejets d'habitats (ensembles E.2 et E.23 ?). Une activité artisanale est également attestée par la présence de soles de fours perforées dans le fossé interne sud (967).

Une modification importante des partitions occidentales : troisième état de l'enclos pentagonal gaulois (La Tène D1)

Peu de modifications sont apportées sur le pourtour de l'enclos au cours de cette phase (fig. 11 et 12). La ceinture interne 1 se referme désormais intégralement dans l'angle sud-ouest. De même, l'entrée 5 aménagée au cours de l'état précédent dans la façade sud-ouest de la ceinture interne 2 est abandonnée au profit de deux états successifs de fossés continus : 1172, peu marqué et observé seulement au niveau de l'obturation de l'entrée, puis 1127/775/616. Ce dernier état consiste en un creusement au profil en U évasé, conservé sur une largeur maximale de 1,60 m et une profondeur n'excédant pas 0,60 m.
La partition nord-sud se prolonge du côté méridional en condamnant l'entrée 10 avec le creusement du fossé 1441 qui offre un profil à fond plat et à parois obliques, une largeur à l'ouverture avoisinant $2 \mathrm{~m}$ et une profondeur maximale de $0,85 \mathrm{~m}$. Par contre, l'interruption de ce fossé au nord et la présence d'une autre extrémité de fossé qui constitue la section septentrionale de la partition, 1682, témoignent de la perduration de l'entrée 2. À l'image de l'entrée 1 , cet accès comporte une petite tranchée, 1449 , visiblement elle aussi destinée à l'écoulement des eaux entre les deux sections, dispositif qui nécessite l'usage d'une passerelle. La continuité du fossé de la section nord jusqu'à la façade septentrionale de l'enclos, fortement perturbée par la reprise postérieure, reste hypothétique mais largement envisageable comme en attestent les vestiges ponctuels de creusements anciens 1684 et 1498 . Les changements les plus importants concernent en fait essentiellement les partitions internes occidentales.

L'espace B perdure mais de petites modifications lui sont apportées. Outre les fossés 341,1311 et 528 qui reprennent respectivement les tracés des fossés 1400,513 et 385 , le côté méridional est vraisemblablement légèrement décalé 


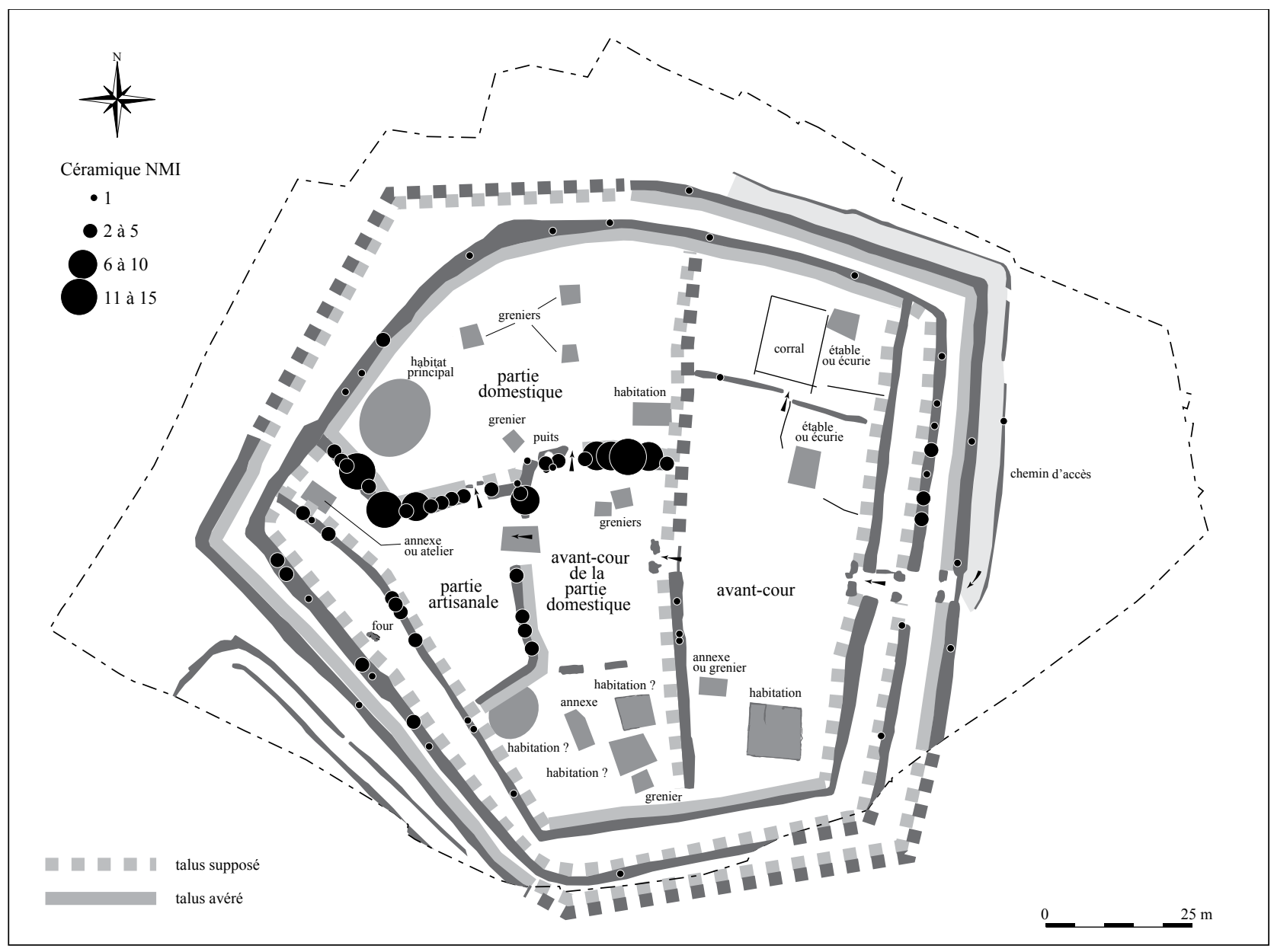

Figure 11 : Guérande, "La Lande » : plan interprétatif et répartition du mobilier céramique de la phase 4. DA0 : J. Cornec, P. Bellanger.

Figure 11: Interpretive plan and distribution of ceramic material of the phase 4. Realisation: J. Cornec, P. Bellanger.

vers le sud, les creusements 84 et 433 y formant une limite en pointillé qui remplace l'ancien fossé 304 . Cette délimitation, complétée par un nouveau fossé taluté à l'est (851 en retour de 528) qui ferme le côté ouest de l'espace $\mathrm{E}$ préexistant, confere ainsi à ce dernier une surface d'environ $620 \mathrm{~m}^{2}$. Les bâtiments présumés occupant cet espace accède toujours par l'entrée 9, de l'espace G qui s'étend dans la partie nord-ouest de l'enclos 1 .

Ce vaste espace d'environ $1300 \mathrm{~m}^{2}$ comporte une entrée au sud, entrée 6 , ici encore associée à des fosses jumelles qui indiquent l'existence d'un probable portail. Les greniers supposés en phase 3 peuvent subsister, de même que le logis principal (ensemble E.34) et le bâtiment E.4. L'existence de ceux-ci semble d'ailleurs confirmée par l'abondant mobilier recueilli à leur voisinage au sein des comblements des fossés de démarcation.

Il est enfin possible que le puits 1342 soit creusé au cours de cette phase.

\section{Le déclin de l'établissement (La Tène D1)}

Cette phase présente désormais une configuration simplement bipartite (fig. 13 et 14). La deuxième ceinture interne est comblée et au niveau de l'entrée 1, à l'est, le petit fossé F.158/131/1356 matérialise une entrée en chicane.

La reprise de la partition nord-sud se traduit par le creusement des fossés 1440 au sud et 1676 au nord qui 


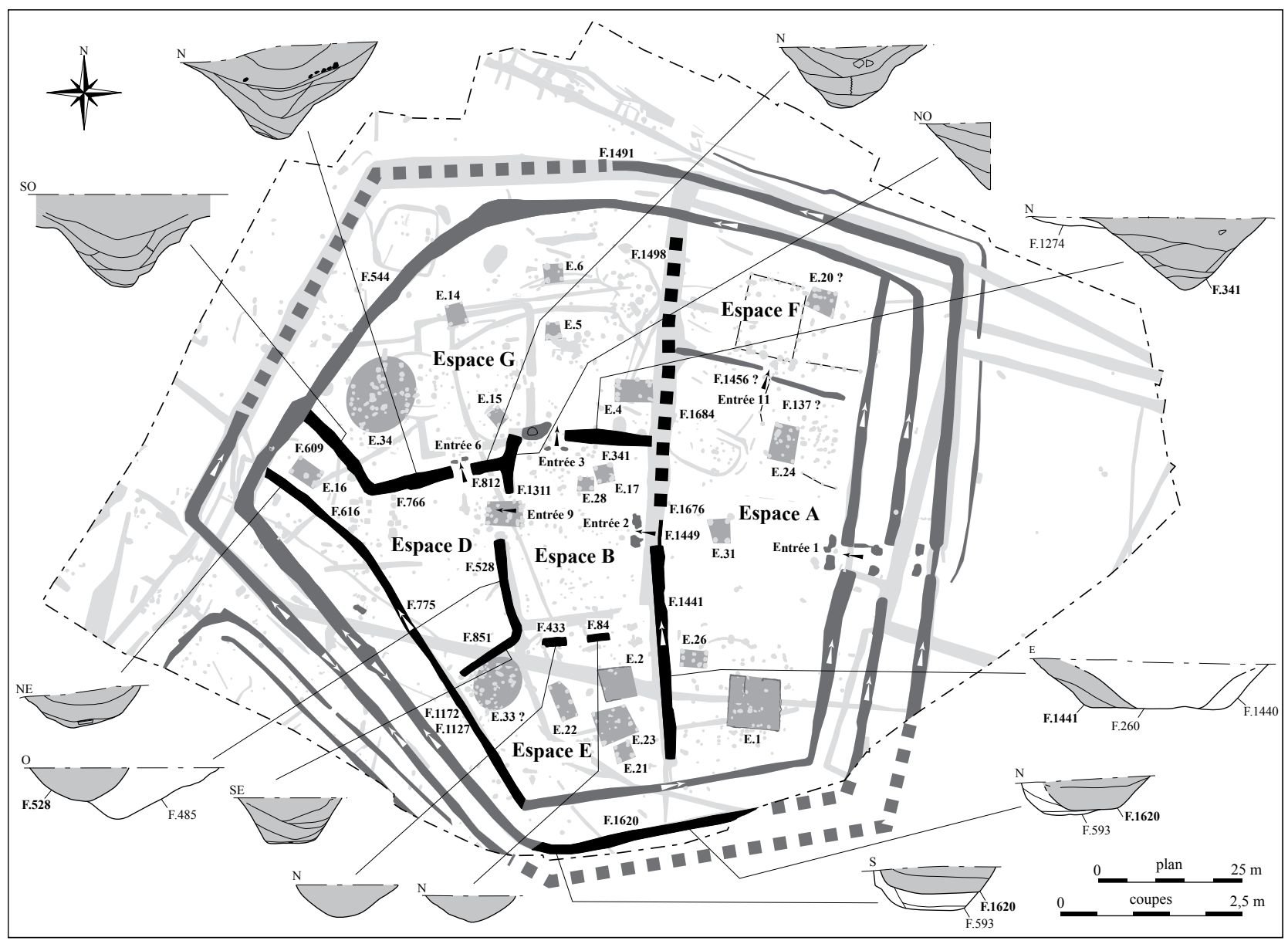

Figure 12 : Guérande, "La Lande » : plan et coupes des fossés attribués à la phase 4. DA0 : J.M. Richard, P. Bellanger.

Figure 12: Plan and sections of the ditches assigned to the phase 4. Realisation: J.-M. Richard, P. Bellanger.

préservent l'entrée 2. Ceux-ci sont légèrement décalés $d u$ côté ouest par rapport aux fossés précédents.

Les autres subdivisions internes disparaissent et le seul nouveau creusement aménagé dans la partie occidentale de l'enclos est le court tronçon de fossé 698/728/776. Une quantité importante de rejet mobilier se note dans son comblement, indiquant le possible déplacement de l'habitation principale (ensemble E.8/E.9).

L'existence des autres constructions lors de cette phase demeure hypothétique.

\section{LE MOBILIER DE L'ÂGE DU FER}

\section{Le mobilier céramique}

Avec 7051 fragments pour un nombre minimum d'individus-bord de 629, le mobilier céramique de l'âge du Fer du site de La Lande reste un des sites ayant livré un des corpus le plus important de la région. Par comparaison, le site aristocratique des Natteries à Cholet (49) (Maguer, 2000) a produit 10751 tessons. En Vendée, au Grand-Paisilier à Pouillé (Nillesse, 1993), on compte plus de 4900 fragments et sur Les Genâts à Fontenay-le-Comte (Nillesse, 1997) on en dénombre 3447 . Ce corpus se décompose en cinq lots principaux correspondant aux cinq contextes dégagés par l'étude des relations stratigraphiques (phases 1 à 5). Ces dernières illustrent des reprises multiples des fossés principaux (enclos et fossés de partition) consécutives des réorganisations successives de l'espace. Ces restructurations multiples ont de fait généré un taux de fragmentation élevé (40 vases archéologiquement complets sur un NMI de 629) et une résidualité importante au sein des assemblages qu'il est difficile de quantifier. Seul le mobilier du fossé 341 a échappé à ce phénomène en livrant un quart des vases archéologiquement complets (10 sur 40) issus de la fouille. Les types de récipients rencontrés seront mis en regard de la typochronologie de la céramique des Pays de la Loire établie en 2015 et publiée en 2018 (Menez, 2018).

\section{Le mobilier de la phase 1 (fig. 15)}

Les formes basses sont essentiellement représentées par les écuelles en " $S$ » apparentées au morpho- 


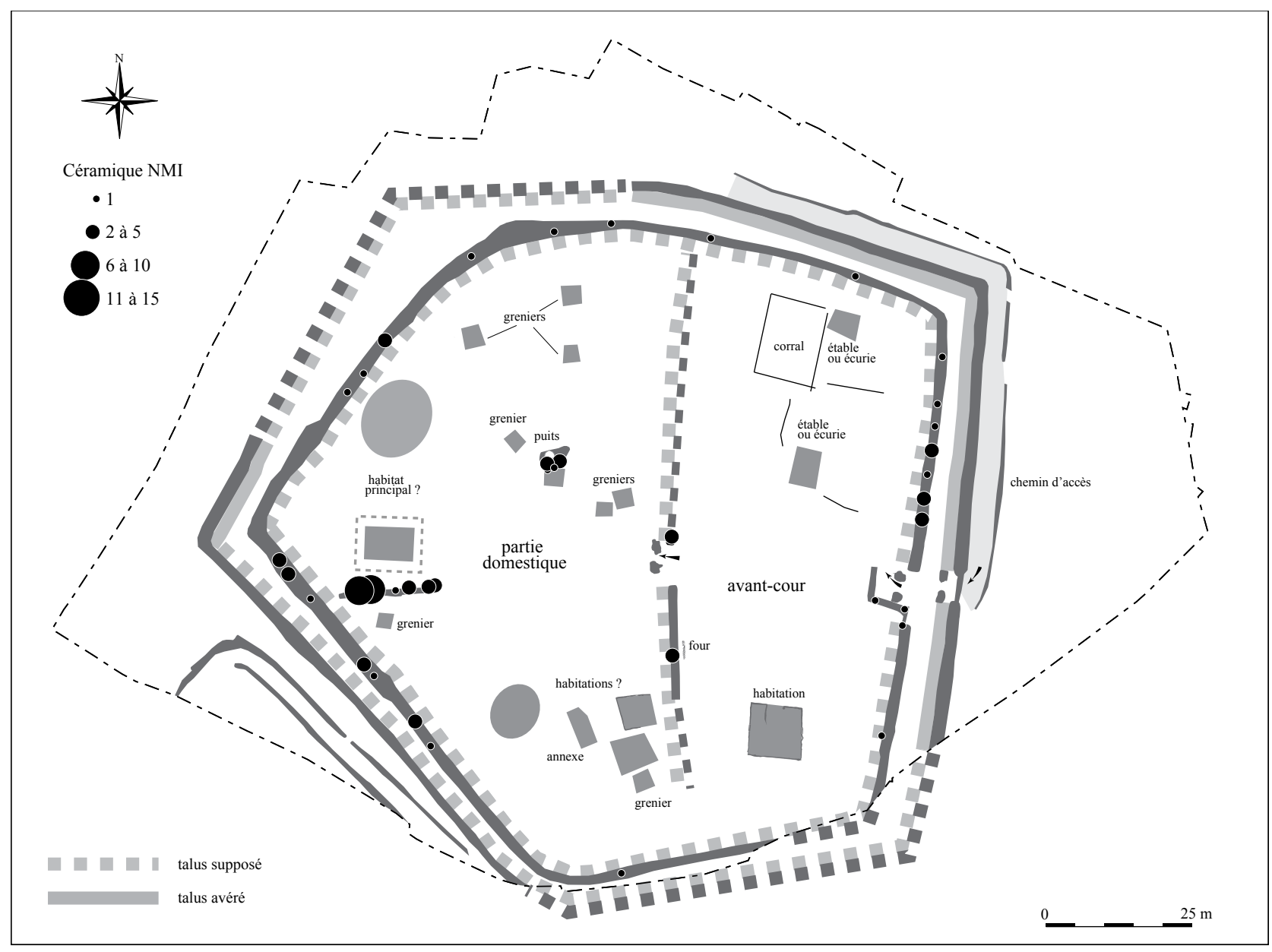

Figure 13 : Guérande, « La Lande » : plan interprétatif et répartition du mobilier céramique de la phase 5. DA0 : J. Cornec, P. Bellanger.

Figure 13: Interpretive plan and distribution of ceramic material of the phase 5. Realisation: J. Cornec, P. Bellanger.

type 44-PDL. Plusieurs déclinaisons sont présentes au sein de cet assemblage. Le $\mathrm{n}^{\circ} 1$ s'apparente au type $44 \mathrm{~b}-$ PDL, le $n^{\circ} 2$ au $44 c-P D L$, le $n^{\circ} 7$ au $44 j$ et le $n^{\circ} 8$ au 44-d. Les types $44 \mathrm{~b}$ et d-PDL sont bien représentés dans les contextes régionaux de La Tène moyenne et finale. Le site des Natteries à Cholet (Maguer, 2000) offre de données typologiques incitent à placer cet ensemble à La Tène moyenne sans plus de précision.

\section{Le mobilier de la phase 2 (fig. 16)}

Les écuelles en " $S$ " sont largement représentées à cette phase ( $\mathrm{n}^{\text {os }} 16$ à 24). On y rencontre des exemplaires des types PDL $44 \mathrm{a} 1$ et a2, b, c, f1, g2 et 1 qui couvrent un horizon assez large allant de La Tène $\mathrm{C} 1$ à La Tène D1. Le $\mathrm{n}^{\circ} 24$ est doté, sur la paroi interne du fond, d'un décor de lignes rayonnantes lustrées. Ce principe décoratif apparaît en Pays de la Loire au même titre qu'en Bretagne dès le début du $\operatorname{III}^{\mathrm{e}} s$. av. J.-C. et perdure jusqu'à la fin du I ${ }^{\mathrm{er}} s$. av. J.-C.

Les formes basses sont également figurées par trois jattes à cordons de type $38 \mathrm{~b} 1-\mathrm{PDL}$ ( $\mathrm{n}^{\text {os }} 25$ à 27 ) et un du type 38g2-PDL ( $\left.\mathrm{n}^{\circ} 28\right)$. Les chronologies retenues pour ces deux types couvrent une période allant de La Tène C2 à La Tène $\mathrm{D} 1$. La répartition des jattes 38b1 semble suivre l'axe ligérien comme l'attestent les exemplaires découverts à La Savinière 1 à Ancenis (Pétorin, 2009), Les Natteries à 


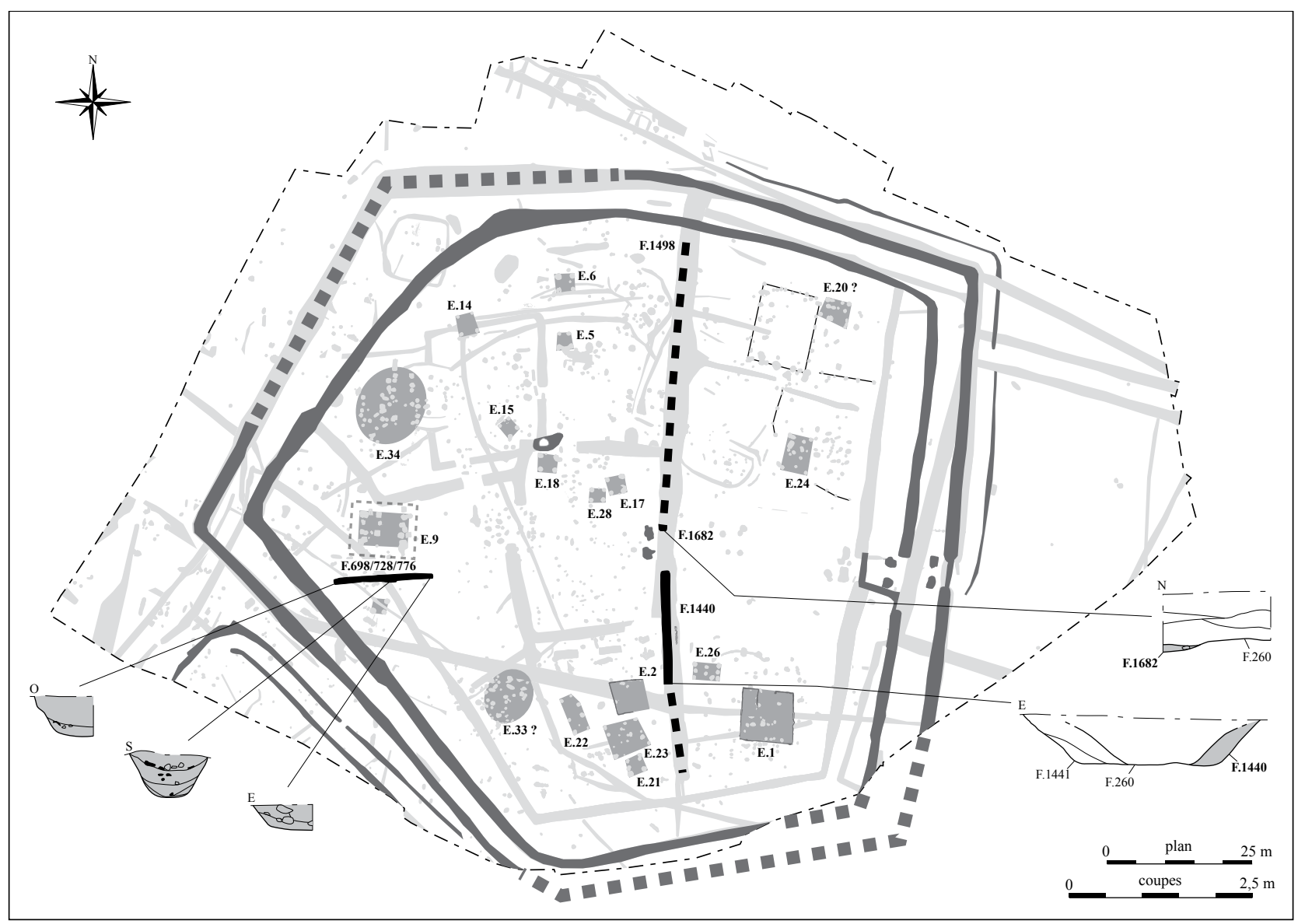

Figure 14 : Guérande, " La Lande » : plan et coupes des fossés attribués à la phase 5. DA0 : J.-M. Richard, P. Bellanger.

Figure 14: Plan and sections of the ditches assigned to the phase 5. Realisation: J.M. Richard, P. Bellanger.

Cholet (Maguer, 2000) ou encore à Carquefou, Le Clouët (Le Goff, 1998).

Parmi les formes hautes de cet assemblage, dont la majorité sont des récipients à profil sinueux plus ou moins marqués à bords obliques ou plus rarement droits relativement ubiquistes et non datant, on remarque l'apparition de deux types. Les vases à ressaut de type $54 \mathrm{~d}-\mathrm{PDL}$ $\left(\mathrm{n}^{\text {os }} 30\right.$ à 33$)$ et les grands vases de stockage des types $58 \mathrm{~b}$ et c-PDL ( $\mathrm{n}^{\text {os }} 34$ et 35 ). Les premiers, largement diffusés dans toute la région, marquent La Tène $\mathrm{D} 1$ (Cornec et al., 2018) et les vases de stockage signalent la transition entre La Tène $\mathrm{C}$ et $\mathrm{D}$. Un auget à bords parallèles, associé aux fours à grille en fonction à partir du III ${ }^{\mathrm{e}}$ jusqu’à la fin du $\mathrm{I}^{\text {er }}$ s. apr. J.-C. (Levillayer, 2018), est issu du fossé 506. Ce dernier a également livré un fragment de vase (sans doute en position résiduelle) de type 44j-PDL (n²9). L'épaule est ornée d'un décor estampé constitué d'une ligne discontinue de rectangle placée au-dessus d'un registre de trois ocelles disposées en triangle pointe en bas surmontant un triolet de cupules elles-mêmes disposées en triangle. Cette organisation générale s'accorde avec le thème en pendentif défini par G. Cabanillas de La Torre qui est caractéristique de La Tène C1 (Cabanillas de La Torre, 2015, fig. 3.70, p. 340). Le site de La Glannerie à Athée (Meuret, 1998) fournit, en contexte de La Tène $\mathrm{C} 1$, un vase à décor estampé similaire.

Ce contexte a également révélé une fibule complète en fer à ressort bilatéral à 8 spires de type Feugère 1a1 (fin du $\mathrm{III}^{\mathrm{e}} /$ début du II ${ }^{\mathrm{e}}$ s. av. J.-C.). L'apparition à cette phase des jattes de type 38b1 et g2-PDL, des vases ressaut $54 \mathrm{~d}-$ PDL et des vases de stockage 58-PDL permet de placer cet assemblage, comme le suggère la fibule, à la transition de La Tène C2-La Tène D1.

\section{Le mobilier céramique de la phase 3 (fig. 17)}

Cet assemblage est représenté par trois formes hautes de type 51a-pdl ( $\mathrm{n}^{\text {os }} 36$ et 37$)$ et $58 \mathrm{a}\left(\mathrm{n}^{\circ} 38\right)$ ubiquistes difficilement attribuables à une période particulière. L'écuelle profonde $\mathrm{n}^{\circ} 39$ s'apparente au type $44 \mathrm{~m}$-PDL, la $\mathrm{n}^{\circ} 42$ au type $441-\mathrm{PDl}$. Cette dernière, dotée d'un décor lustré rayonnant au même titre que le fragment de fond $\mathrm{n}^{\circ} 40$, renvoie à une datation de la première moitié $\mathrm{du}$ $\mathrm{II}^{\mathrm{e}}$ s. av. J.-C. Un tesson ( $\left.\mathrm{n}^{\mathrm{o}} 41\right)$, est décoré d'une bande 


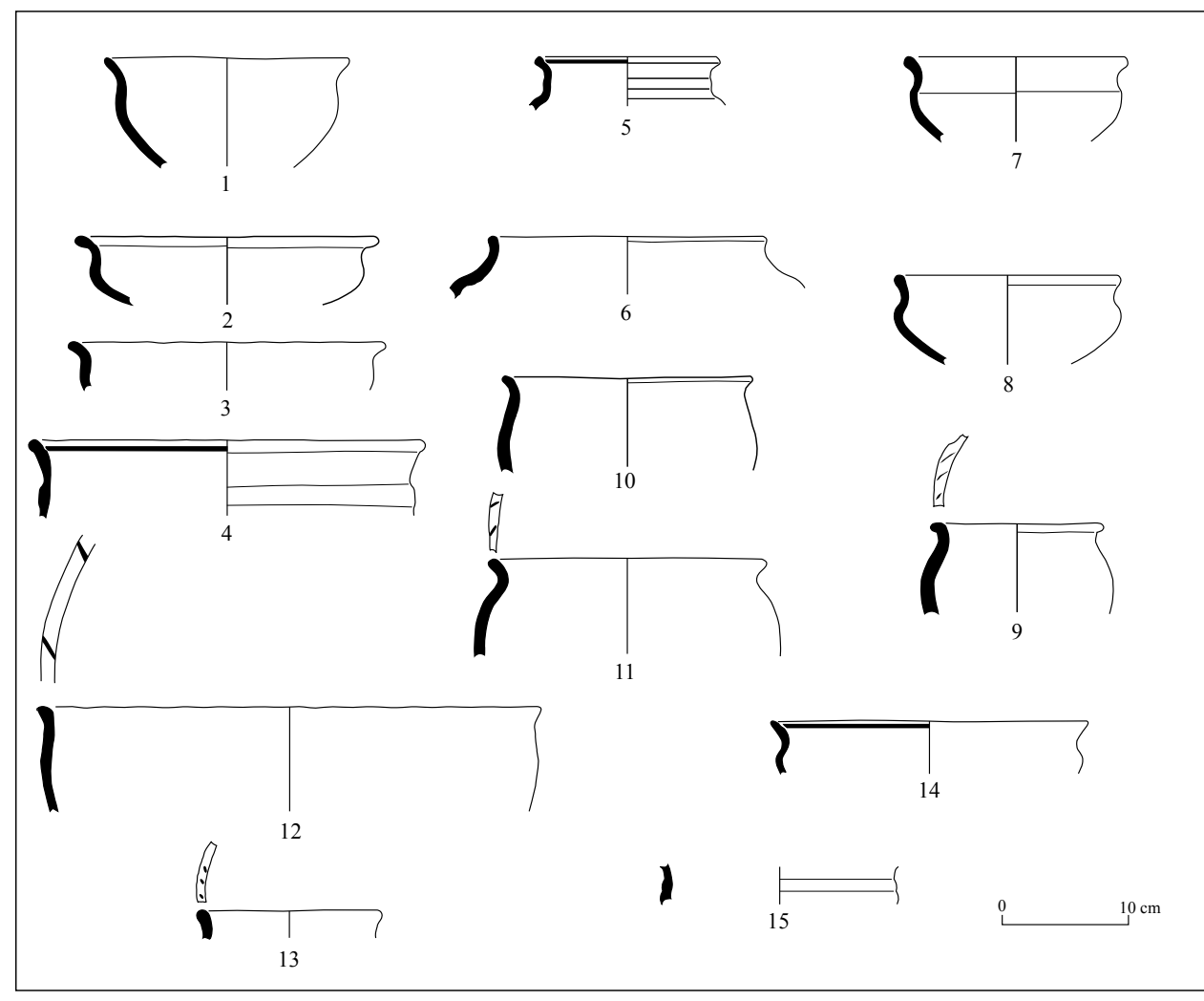

Figure 15 : Guérande, " La Lande $»$ : mobilier céramique de la phase 1. DA0 : J. Cornec.

Figure 15: Ceramic material of the phase 1. Realisation: J. Cornec. enduite à la peinture rouge encadrée par de fines cannelures. Ce principe décoratif d'enduction partielle des récipients est attribuable à la fin du $\mathrm{III}^{\mathrm{e}}$-début du $\mathrm{II}^{\mathrm{e}} \mathrm{s}$. av. J.-C. (Le Goff, 1994). Localement, on note qu'un fragment de lèvre et un autre de panse décorés à la peinture rouge sont issus du diagnostic de l'extension ZAC de Villejames à Guérande (Pirault, 2010).

Cette phase n'a pas livré de réel marqueur chronologique permettant une attribution chronologique fiable à cet assemblage.

\section{Le mobilier céramique de la phase 4 (fig. 18)}

Les contextes de cette phase sont marqués par un appauvrissement du répertoire typologique. On note ainsi la quasi-disparition des formes basses (écuelles et jattes) au profit des écuelles profondes de type 44b-PDL $\left(\mathrm{n}^{\circ} 46\right)$ et des formes moyennes de type 45-PDL ( $\left.{ }^{\circ} 44\right)$. Les récipients des types 54 et $56-\mathrm{PDL}$ ( ${ }^{\circ} 50$ à 53 ) dominent la catégorie des formes hautes. Les vases de stockage de type $58 \mathrm{~b}$ et e-PDL ( ${ }^{\text {os }} 54$ et 55 ) sont également bien représentés. Tous ces types sont relativement ubiquistes et couvrent une large période allant de La Tène moyenne à La Tène finale. Au sein de cet assemblage apparaissent des céramiques fine tournées ( $\mathrm{n}^{\text {os }} 55$ à 58 ). Celles-ci sont notamment représentées par une céramique fumigée ( $\left.\mathrm{n}^{\circ} 56\right)$. Ce récipient à col éversé est doté d'un décor au peigne placé sous la jonction épaule-col. Il consiste en une ligne ondée encadrée par deux fines cannelures. Des décors semblables sont présents sur les séries de céramiques fumigées produites dans la basse vallée de l'Allier (Lallemand, 2005) où cette production débute dès le milieu du II $^{\mathrm{e}}$ s. av. J.-C. (La Tène D1a). Localement, l'horizon 1 de l'oppidum du château d'Angers daté de La Tène $\mathrm{D} 1 \mathrm{~b}$ a fourni « un fragment de pot en céramique fumigée à décor ondé au peigne " (Bouvet et al., 2003). Le site des Pichelots, Les Alleuds (Gruet et Passini, 1985) a également livré un vase à l'architecture et au décor identique en contexte couvrant La Tène C2 à La Tène D1a. Le col $\mathrm{n}^{\mathrm{o}} 57$ à pâte fine grise est à rapprocher des vases à décor de baguettes. Ces productions se rencontrent en moyenne vallée de la Loire en contexte D1b - D2a et semble disparaître des assemblages à La Tène D2b (Riquier, 2005). On note que le site voisin du parc de Villejames (Devals, 2008) a livré un vase similaire en terra nigra. La similitude des pâtes des fragments $\mathrm{n}^{\text {os }} 58$ et 59 avec le $\mathrm{n}^{\circ} 57$ ainsi que le décor de cordon appliqué au $\mathrm{n}^{\circ} 58$ permet sans doute de les intégrer au même horizon chronologique.

Les faits de cette phase ont livré les seuls trois hauts de récipients graphités découverts sur le site. Le n ${ }^{\circ} 60$ est partiellement enduit sur les deux parois du col. Le col no 61 est enduit sur les deux parois, le $\mathrm{n}^{\circ} 62$ uniquement en partie externe. Ces deux derniers, dotés d'une fine cannelure labiale, sont trop fragmentaires pour se prononcer sur leur enduction partielle ou totale. Dans les assemblages du Boisanne à Plouër-sur-Rance, le graphitage est relativement 
Figure 16 : Guérande, "La Lande ": mobilier céramique de la phase 2. DA0 : J. Cornec.

Figure 16: Ceramic material of the phase 2. Realisation:J. Cornec.
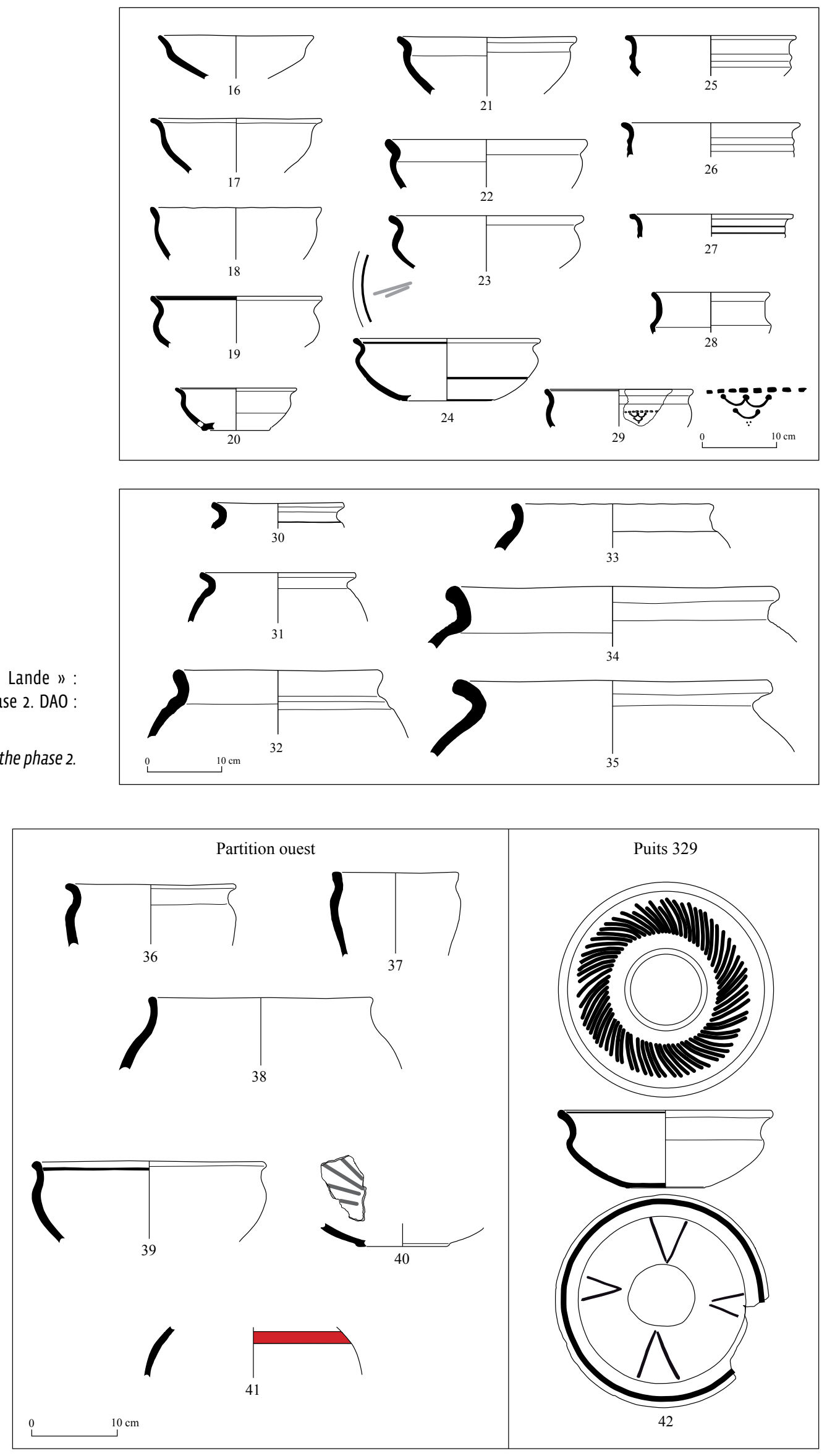

Figure 17 : Guérande, "La Lande " : mobilier céramique de la phase 3. DAO : J. Cornec.

Figure 17: Ceramic material of the phase 3. Realisation:J. Cornec. 


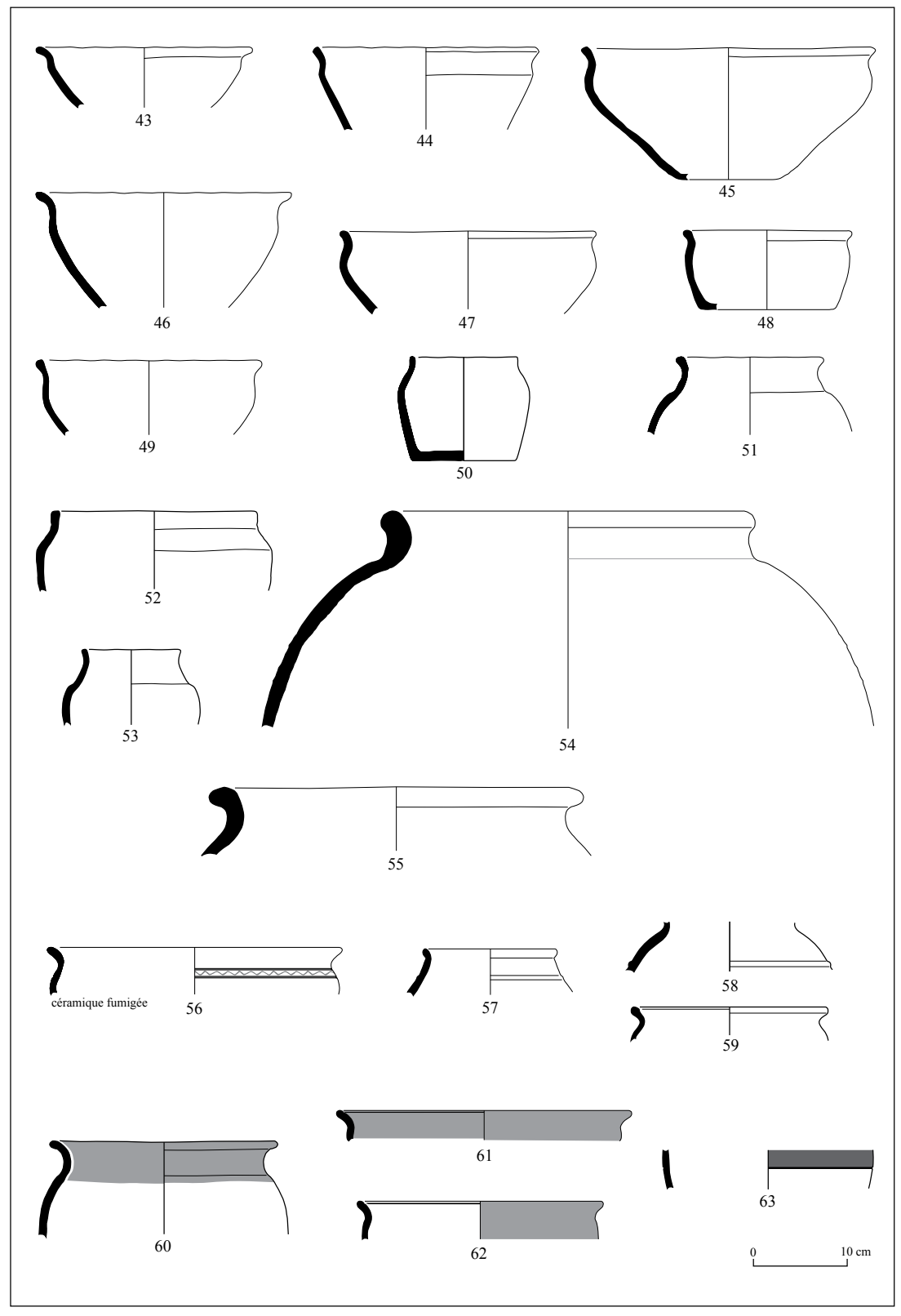

Figure 18 : Guérande, "La Lande " : mobilier céramique de la phase 4. DAO : J. Cornec.

Figure 18: Ceramic material of the phase 4. Realisation: J. Cornec. fréquent à partir de la seconde moitié du $\mathrm{III}^{\mathrm{e}}$ et au $\mathrm{II}^{\mathrm{e}} \mathrm{s}$. av. J.-C. pour disparaître progressivement au $\mathrm{I}^{\mathrm{er}} \mathrm{s}$. av. J.-C. (Menez, 1996, p. 130). Dans les Pays de la Loire, ce type de décor se rencontre rarement mais sa répartition couvre tous les départements (Cornec et al., 2018). À Guérande, le parc de Villejames (Devals, 2008) a livré un fond de vase graphité. Le principe d'enduction partielle, dans ce cas à l'aide de peinture rouge, est aussi illustré par le fragment $n^{\circ} 63$ au même titre que le tesson $n^{\circ} 41$ de la phase précédente.

\section{La partition centrale ouest (fig. 19)}

Le fossé 341 a livré à lui seul le quart des récipients complets (10 sur 40 individus) issus de la fouille, illus- majoritairement des formes fermées moyennes à profil sinueux à rapprocher des type 45-PDL ( ${ }^{\text {os }} 62$ à 69) ou hautes du morphotype 51a-PDL ( ${ }^{\text {os }} 70$ à 72 ). Seul le $\mathrm{n}^{\circ} 73$ au profil tronconique simple se singularise du reste du lot. Ce sont des récipients non tournés, les parois sont le plus souvent grossièrement régularisées et n'offrent pas de critères chronologiques fiables. Ce contexte a également révélé une céramique fine tournée $\left(\mathrm{n}^{\circ} 74\right)$ à décor de cordons similaire aux vases $n^{\text {os }} 57$ à 59).

L'apparition à cette phase d'une céramique fumigée $\left(\mathrm{n}^{\circ} 56\right)$ et des céramiques fines et à décor de baguette $\left(\mathrm{n}^{\text {os }} 57,58,59\right.$ et 74 ) est déterminante au sein de cet assemblage et permet d'attribuer cette phase à une chronologie comprise entre la fin du $\mathrm{II}^{\mathrm{e}} \mathrm{s}$. et la première moitié du ir s. av. J.-C. (La Tène D1b-D2a). 


\section{Le mobilier céramique de la phase 5 (fig. 20)}

Le mobilier de cette phase est marqué par une forte résidualité (vase de stockage $\left(\mathrm{n}^{\circ} 82\right)$, vase à ressaut $\left(\mathrm{n}^{\circ} 81\right)$ ou illustré par des types de récipients ubiquistes $\left(\mathrm{n}^{\text {os }} 79\right.$, 80) non datant.

\section{Synthèse}

Avec un des corpus les plus abondant des Pays de la Loire, le mobilier céramique de La Lande illustre une occupation continue du site du début de La Tène moyenne jusqu’à la fin de la période gauloise.
Se succèdent à partir du début de l'occupation les jattes à haut col (La Tène C1-C2), les vases de stockage (La Tène C2-D1), les jattes à cordons et vase à ressaut (La Tène $\mathrm{D} 1$ ) et enfin la céramique fumigée et les vases à cordons (La Tène D1b/D2a). Les éléments typologiques caractéristiques de La Tène D2b comme les assiettes, les vases bobines, certains modèles de gobelets-tonnelets ou les vases balustres sont absents ici. Cette absence peut être le reflet d'un abandon de l'occupation à la fin de la période gauloise (La Tène D2b) ou d'une limitation des échanges de l'espace guérandais avec le domaine ligérien. Celui-ci est cependant suggéré par la présence dans les assemblages des phases 2 et 4 des jattes de type $38 \mathrm{~b} 1$ et
Figure 19 : Guérande, " La Lande $"$ : mobilier céramique de la phase 4. DAO : J. Cornec.

Figure 19: Ceramic material of the phase 4. Realisation: J. Cornec.

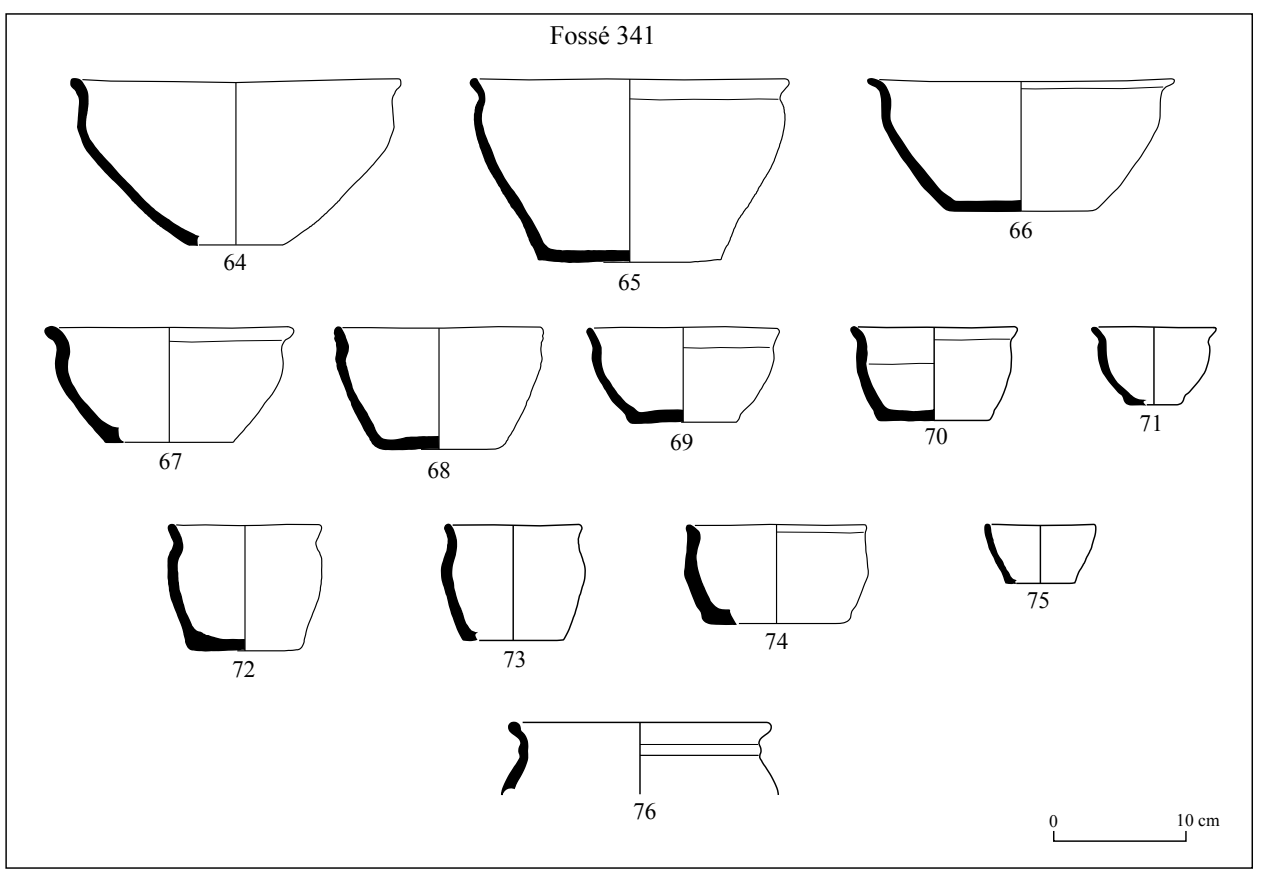

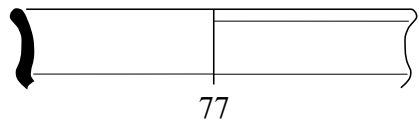
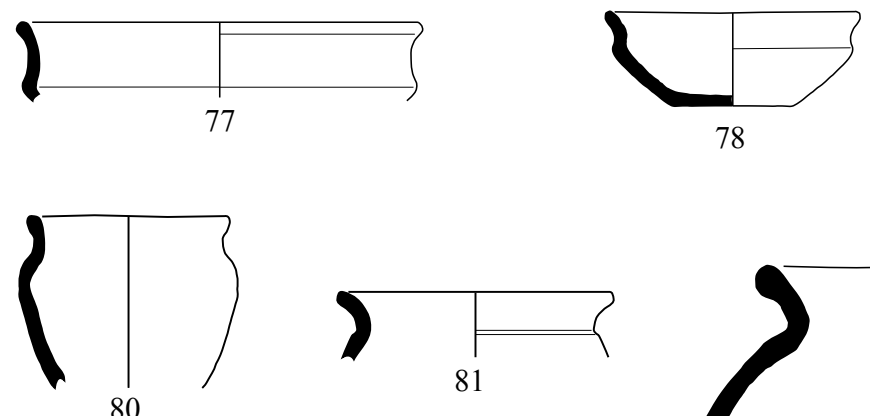

$10 \mathrm{~cm}$

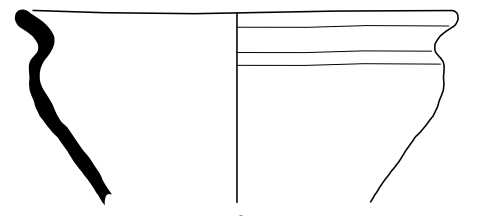

79

Figure 20 : Guérande, « La Lande » : mobilier céramique de la phase 5. DAO : J. Cornec.

Figure 20: Ceramic material of the phase 5. Realisation: J. Cornec. 
du vase fumigé à décor peigné et des vases à cordons. Du mobilier illustrant La Tène D2b a été découvert, certes en quantité limité, sur les sites guérandais appartenant à la phase de transition protohistoire - époque romaine. Une assiette en terra nigra du type 35b1-PDL a été découverte au Clos-Flaubert à Guérande (Pirault, 1996), un vase tonnelet provient du site de Villejames (Devals, 2008) et plusieurs fragments de vases balustre (3 NMI) et de vase bobine (1 NMI) ont été mis au jour sur l'extension du parc de Villejames (Pirault, 2010). Ces quelques indices plaideraient plutôt en faveur d'un hypothétique abandon de l'occupation du site de La Lande à La Tène D2a.

Dans les assemblages de toutes les phases, on note la présence de jattes à haut col, d'écuelles en " $S$ » à décor lustré rayonnant, de cols dotés de cannelures labiales internes, de quelques exemplaires d'anses en œillet (non représentées), de décor de couverte partielle à la peinture rouge ou au graphite et de décor estampé. Ces quelques traits morphologiques ou décoratifs sont, sans en être l'aire de diffusion exclusive, caractéristiques des productions armoricaines. Ils témoignent sans doute des liens que la péninsule guérandaise pouvait entretenir avec le pourtour des actuelles côtes bretonnes et du sud de l'Angleterre (Bouvet, 2004).

Le mobilier de La Lande est également caractérisé par la rareté du mobilier amphorique (type gréco-italique ou Dressel 1a) mis au jour. Celui-ci se résume à trois individus pour une centaine de fragments. Par comparaison, cinq sondages réalisés dans un fossé de l'opération de diagnostic de l'extension du parc de Villejames (Pirault, 2010) ont livré un total de 52 individus d'amphore grécoitalique ou Dressel 1 sur un total de 2720 restes.

\section{Les autres mobiliers}

\section{Les éléments de parure en verre (fig. 21)}

Trois éléments de parure en verre ont été découverts sur le site de La Lande.

Une perle en pâte de verre gris clair présente un diamètre externe de $20 \mathrm{~mm}$ pour une hauteur de $15 \mathrm{~mm}$. Le diamètre interne de $8,5 \mathrm{~mm}$ est légèrement ovalisé. Si la couleur ne trouve pas d'équivalent dans les séries de R. Gebhard (Gebhard, 1989), sa section en « D » allongé évoque certains exemplaires découverts à Bibracte datés de La Tène C1-D2.

Le $\mathrm{n}^{\circ} 2$ est un fragment de bracelet en verre violet foncé à section ovalaire $(5,5 \times 4,5 \mathrm{~mm})$ d'un diamètre interne restitué de $64 \mathrm{~mm}$. Ce bracelet, d'un type relativement courant, correspond à la série 36 de R. Gebhard et est daté de La Tène D. La synthèse de M. Dinard (Dinard et al., 2011) affine cette datation en plaçant ce type de bracelet à La Tène D1.
Le dernier élément de parure est un fragment de bracelet en verre d'un diamètre interne restitué de $64 \mathrm{~mm}$ $\left(n^{\circ} 3\right)$. De couleur bleu cobalt, il est orné de quatre filets blancs, deux sur la face interne et un sur chaque côté. Sa face externe est parée d'un filet rapporté, installé en zigzag et rehaussé de deux filets blancs. Il s'accorde avec la série 8 de R. Gebhard datée de La Tène C2.

\section{Le mobilier lithique (fig. 22)}

Le mobilier lithique issu du site de La Lande se résume à 12 artéfacts divers.

\section{- Le mobilier de mouture}

Cinq éléments liés au travail de mouture ont été mis au jour sur le site de La Lande. Ils se divisent en deux groupes : trois moulins va-et-vient et deux moulins rotatifs manuels.

\section{- Le mobilier lithique autre}

Un disque ou palet en quartzite $\left(n^{\circ} 1\right)$ présente un diamètre de $70 \mathrm{~mm}$, pour une épaisseur de $9 \mathrm{~mm}$. Sa forme circulaire est obtenue par épannelage du bord. Une encoche de $10 \mathrm{~mm}$ de large, installée à environ 45 degrés par rapport à son axe central, semble avoir été réalisée sur son flanc. Aucune trace d'usure visible pouvant témoigner de l'installation d'un lien dans cette encoche n'est observable.

Le $\mathrm{n}^{\circ} 2$ est un fragment de disque en aplite (granite à grains fins) d'un diamètre estimé à $90 \mathrm{~mm}$ pour une épaisseur de $22 \mathrm{~mm}$. Le polissage de ses deux faces, légèrement convexes, et de sa tranche indique une probable utilisation comme broyeur ou polissoir.

Le comblement d'un trou de poteau a livré un petit objet manufacturé en serpentine $\left(\mathrm{n}^{\circ} 3\right)$. D'un poids de $44 \mathrm{~g}$, il se présente sous la forme d'un carré de $37 \mathrm{~mm}$ de côté pour une épaisseur de $11 \mathrm{~mm}$. Il est percé de trois trous d'environ $3 \mathrm{~mm}$ de diamètre et d'un non débouchant de même diamètre. La serpentine est un minéral tendre, rayable à l'ongle, et d'une densité moyenne (comprise entre 2,55 et $3,5 \mathrm{~kg} / \mathrm{dm}^{3}$ ) supérieure à beaucoup d'autres minéraux. À notre connaissance, aucun objet similaire n'a été découvert dans les Pays de la Loire. Sa fonction reste donc énigmatique.

Le $\mathrm{n}^{\circ} 4$, réalisé en aplite est tronconique (hauteur : $10,5 \mathrm{~cm}$ ) à section ronde (diamètre moyen : $11,5 \mathrm{~cm}$ ). Il est muni de deux perforations opposées non perforantes (perçage non abouti ?) sur ces faces supérieure et inférieure. Un objet assez semblable (forme et dimensions) a été découvert sur le site de Paule (Menez, 2008). Ce dernier présente une perforation traversante sur la paroi 
de laquelle des restes métalliques témoignent de la présence d'un probable système de suspension et permet de l'identifier comme un poids.

Enfin un unique fragment de bracelet en roche noire (lignite?) à section légèrement ovale $(10 \times 9 \mathrm{~mm})$ pour un diamètre interne restitué est de $56 \mathrm{~mm}$ a été mis au jour sur le site.

\section{Le mobilier métallique (fig. 23)}

\section{- Phase 1}

Hormis 14 fragments de scories, aucun objet métallique n’a été mis au jour dans les faits de la phase 1.

\section{- Phase 2}

Le comblement du fossé 506 a livré une fibule en fer à ressort bilatéral à 8 spires de type Feugère $1 \mathrm{a} 1\left(\mathrm{n}^{\circ} 1\right)$ datable de la fin du III $^{\mathrm{e}}$ ou du début du II $^{\mathrm{e}}$ s. av. n. è. (Feugère, 1985).

Un probable fragment de faucille est issu du fossé 803 $\left(\mathrm{n}^{\circ} 2 ; \mathrm{L}: 98 \mathrm{~mm}\right)$.

\section{- Phase 4}

Pour cette phase, on relève la présence dans le remplissage du fossé 609 d'une fibule en fer trop incomplète pour identification $\left(\mathrm{n}^{\circ} 3\right)$. Deux spires sont visibles à la
Figure 21 : Guérande, "La Lande »: mobilier en verre. DAO : J. Cornec.

Figure 21: Glass artefacts. Realisation: J. Cornec.
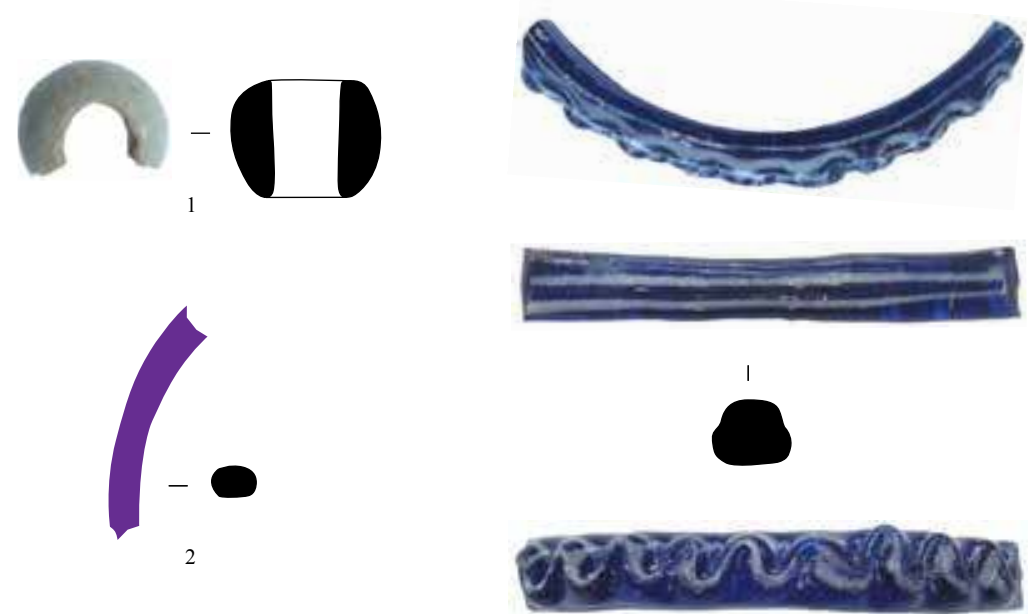

$1 \mathrm{~cm}$

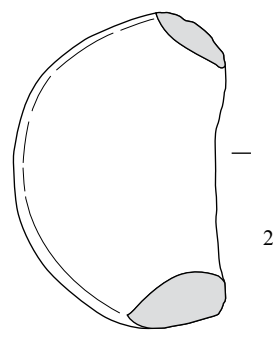

Figure 22 : Guérande, " La Lande » : mobilier lithique. DAO : J. Cornec.

Figure 22: Lithic material. Realisation: J. Cornec.
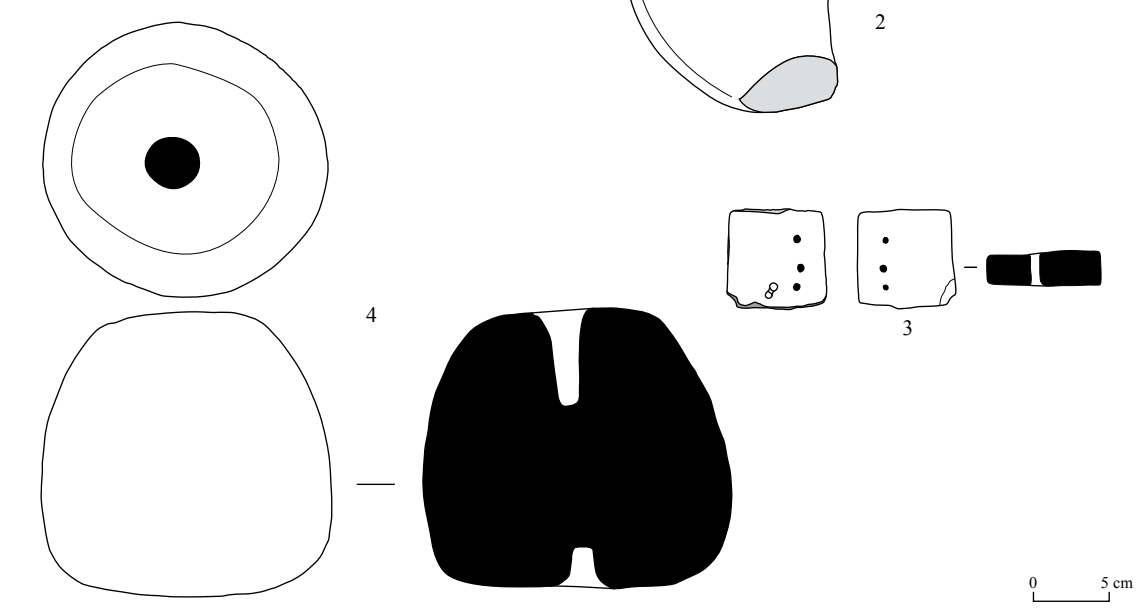


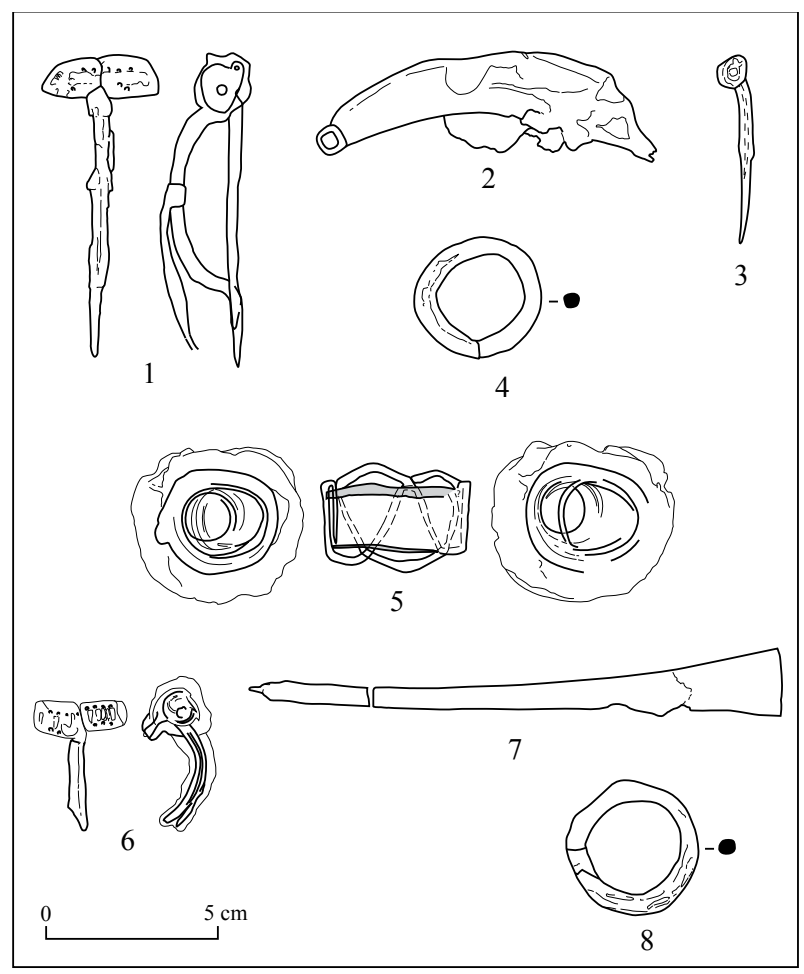

Figure 23: Guérande, « La Lande » : mobilier métallique. DA0 : J. Cornec.

Figure 23: Metal artefacts. Realisation: J. Cornec.

radiographie. Il pourrait s'agir du type Feugère 1a, datable de la fin du $\mathrm{III}^{\mathrm{e}}$ ou du début du $\mathrm{II}^{\mathrm{e}} s$. av. n. è.

Un anneau légèrement ovale de 36 par $32 \mathrm{~mm}$ et de section ronde de 5 à $6 \mathrm{~mm}$ a été trouvé dans le comblement du fossé $1441\left(\mathrm{n}^{\circ} 4\right)$.

Un ressort bilatéral de fibule en fer à 6 spires provient du fossé 528 . Le nombre de spires indique vraisemblablement le type Feugère 1a1.

\section{- Phase 3 ou 4}

Le fossé 124 a livré un objet indéterminé ( $\left.\mathrm{n}^{\circ} 5\right)$.

Dans le fossé 1355 a été découvert un ressort de fibule en fer à 8 spires $\left(n^{\circ} 6\right)$ correspondant sans doute à un type Feugère $1 \mathrm{a} 1$.

\section{- Phase 3,4 ou 5}

Deux fragments d'une tige conique se terminant en pointe (L : $154 \mathrm{~mm}$, section : 5 à $20 \mathrm{~mm}$ ) proviennent du fossé $544\left(n^{\circ} 7\right)$.

\section{- Faits isolés}

Un anneau de diamètre externe de $37 \mathrm{~mm}$ et de section circulaire de 4 à $5 \mathrm{~mm}$ est issu du fait $83\left(\mathrm{n}^{\circ} 8\right)$.

\section{Le mobilier en terre cuite}

\section{- Les creusets (fig. 24)}

Les creusets découverts sur le site se divisent en quatre types morphologiques distincts. Le $\mathrm{n}^{\circ} 1$, dont seule une petite partie du haut du récipient manque, présente une forme générale ovoïde, d'une hauteur estimée à $100 \mathrm{~mm}$ pour un diamètre maximal de $80 \mathrm{~mm}$. Le fond est sphérique et très épais (un tiers de la hauteur). La pâte, blanche à grise, est très sableuse. La paroi externe est entièrement recouverte de restes vitrifiés qui présentent localement des boursouflures. Cette vitrification prend une couleur noire, rouge, verte ou jaune selon les zones.

Le deuxième type est représenté par deux fragments $\left(\mathrm{n}^{\circ} 2\right)$ à pâte blanche formant un possible petit creuset (diamètre : $28 \mathrm{~mm}$ ) à fond hémisphérique. Sa paroi externe porte des traces de résidus oxydés. Sa paroi interne, très altérée, montre un gradient de chauffe allant du rose pâle au gris.

Le troisième type est figuré par des creusets en forme de coupelle à bord rond. Le $\mathrm{n}^{\circ} 3$ est muni d'un aplatissement de la lèvre facilitant l'écoulement d'un liquide. Leurs diamètres oscillent entre 71 et $74 \mathrm{~mm}$. Les pâtes, toujours très sableuses, varient du beige clair au gris clair. Le haut des récipients est le plus souvent scoriacé et/ou vitrifié.

Le dernier type (type 4) s'illustre par des récipients aux bords épais (environ $30 \mathrm{~mm}$ ), légèrement inclinés vers l'extérieur. Le $\mathrm{n}^{\circ} 6$ est doté d'un raccourcissement de la lèvre facilitant le versement d'un liquide. Les diamètres sont plus variables que le groupe précédent et varient de $100 \mathrm{~mm}\left(\mathrm{n}^{\circ} 7\right)$ à $165 \mathrm{~mm}\left(\mathrm{n}^{\circ}{ }^{5}\right)$ jusqu'à un maximum de $219 \mathrm{~mm}$ pour le $\mathrm{n}^{\circ} 6$.

\section{- Des restes de parois scoriacées associés aux creusets?}

Associés aux creusets, dix éléments s'apparentent à des fragments de fond ou parois de foyer. La morphologie générale de ces quelques fragments est hémisphérique. La pâte, très sableuse, varie du beige à l'orange foncé de l'intérieur vers l'extérieur. La paroi interne est recouverte d'une superposition de croûtes scoriacées $(5$ à $10 \mathrm{~mm}$ ) de couleur noire violacée et d'argile beige $(10 \mathrm{~mm})$ marquant des opérations de rechapages successives.

Des analyses ont été réalisées sur trois échantillons (un creuset de type 3 , un de type 4 et un sur un fragment de paroi scorifiée) par le laboratoire Arc'Antique selon la méthode du microscope à balayage couplée à la spectrométrie à énergie dispersive (MEB-EDS). Elles ont détecté majoritairement les éléments Cuivre-Étain-Plomb. Les proportions de ces éléments varient mais sont présents sur les trois échantillons. 
Figure 24 : Guérande, « La Lande » : creusets. DAO : J. Cornec.

Figure 24: Crucibles. Realisation:J. Cornec

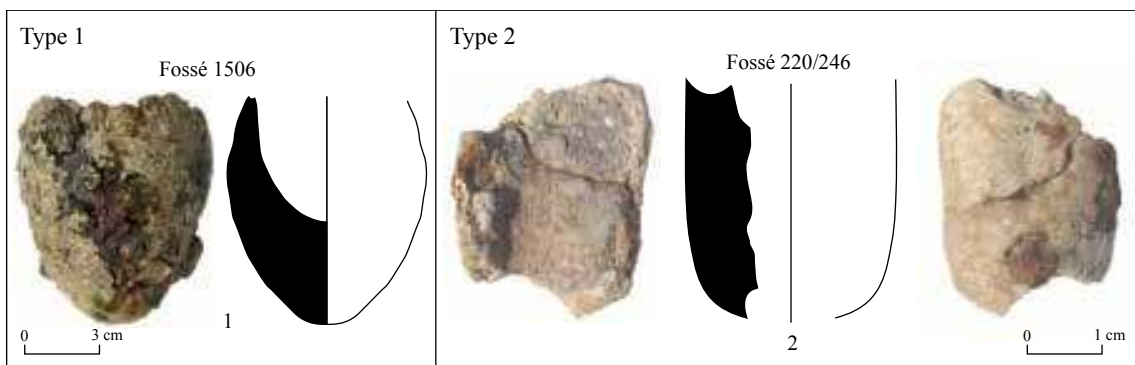

Type 3

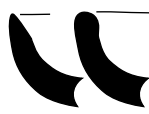

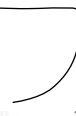

3

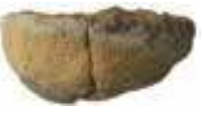

Fossé 609

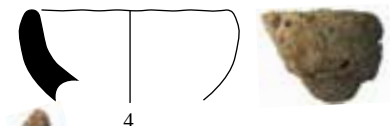

$3 \mathrm{~cm}$

Bec verseur

Type 4
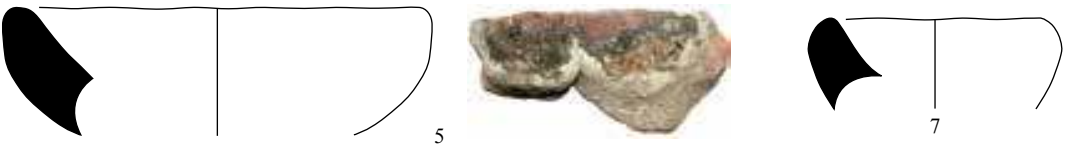

Fossé 609
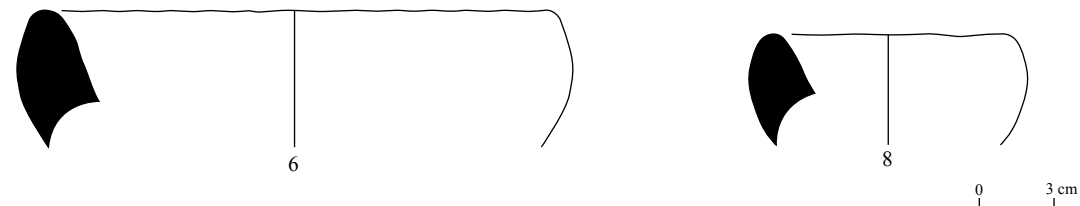

La présence de creusets sur un site illustre le plus souvent la présence momentanée d'artisans spécialisés dans la métallurgie des alliages de cuivre (Menez, 1996; Hamon, 2005).

\section{- Les fragments de soles perforées et de parois de four}

Des fragments de soles perforées ont été mis au jour dans plusieurs fossés et représentent un ensemble de 355 fragments pour un poids total de $26,587 \mathrm{~kg}$. Ces soles sont percées de trous de 5 à $6 \mathrm{~cm}$ de diamètre espacés de $9 \mathrm{~cm}$. Une ossature de baguettes d'environ $1 \mathrm{~cm}$ de diamètre assurait la cohérence mécanique de l'ensemble. Associés à ces soles, les restes de parois de four ont été découverts dans deux fosses $(6,250$ et $43,360 \mathrm{~kg})$. Ils présentent un gradient de chauffe allant du jaune pâle (couleur de l'encaissant) au rouge. À notre connaissance, par comparaison au niveau régional, les quantités de soles découvertes ici sont inhabituelles. Le site des Natteries (Maguer, 2000) a livré 20 fragments de soles perforées, un fragment est issu du site de La Colleraye à Savenay (Sélèque, 2010) et à Guérande, sur le diagnostic de l'ex- tension de la ZAC de Villejames (Pirault, 2010), ce sont 69 fragments de soles perforées et non perforées qui ont été mis au jour. Pour ces trois exemples, aucune activité artisanale particulière n'a pu être mise en évidence.

Ces deux types de restes associés (soles perforées et parois de four) sont des indices qui permettent d'envisager une activité de potier sur ou à proximité du site. Dans la mesure où ces artéfacts peuvent matérialiser des fours domestiques comme sur l'habitat de l'île de Martigues (Nin, 2000), considérer l'hypothèse d'une activité potière sur le site reste sans doute imprudent.

\section{- Les éléments de torchis}

Les fragments de torchis issus de la fouille forment un lot de 752 fragments pour un poids total de $39,246 \mathrm{~kg}$. Le torchis étant élaboré à partir de terre crue plaquée sur un entremêlât de fines branches est un matériau périssable. C'est le contact avec une forte source de chaleur (incendie) qui permet leur conservation dans le temps. 
L'évaluation du nombre de bâtiments et de leur taille sur un site est donc assujettie à ce type d'accident, par nature difficile à mettre en évidence. Trois éléments se singularisent du reste du lot par la présence sur la surface visible d'une fine couche d'enduction (environ $1 \mathrm{~mm}$ d'épaisseur) de couleur blanche ou ocre. Un individu se distingue par une première enduction de couleur blanche directement appliquée sur la terre crue et elle-même recouverte par une seconde enduction de couleur ocre. Ces quelques fragments permettent d'envisager la présence sur le site de bâtiments aux murs en torchis " peint » et régulièrement entretenus.

\section{- Les plaques foyères}

Les plaques foyères amovibles présentes sur le site de La Lande constituent un ensemble de 321 restes pour un poids total de $21,307 \mathrm{~kg}$. Malgré quelques recollages possibles, aucune longueur ou largeur n'a pu être constatée. Les épaisseurs varient de 14 à $37 \mathrm{~mm}$ pour les extrêmes, la moyenne se situant autour de $25 \mathrm{~mm}$. Ces restes montrent tous une cuisson régulière. Trois fragments sont dotés d'un rebord légèrement rehaussé. D'autres se distinguent par un bord circulaire. Des exemplaires similaires (bord rehaussé et circulaire) ont été mis au jour sur le site du Clouët à Carquefou (44) [Le Goff, 1998].

\section{- Les pesons et fusaïole}

L'artisanat du tissage est illustré par la découverte de huit pesons de métier à tisser et d'une fusaïole. Les pesons sont tronc-prismatiques à perforation horizontale. La morphologie générale des pesons est tronc-prismatique à perforation unique. La fusaïole est de section ovale pour un diamètre d'environ $34 \mathrm{~mm}$.

\section{- Les balles de fronde (fig. 25)}

Deux balles de fronde en terre cuite aux dimensions semblables sont respectivement issues des comblements des fossés 505 (phase 3) et 775 (phase 4). D’une longueur moyenne de $40 \mathrm{~mm}$, leur forme évoque une olive. Ces balles de fronde étaient utilisées notamment pour la chasse (Feugère, 1992).

\section{- Lartisanat du sel}

La fouille de l'enclos n'a livré que quelques fragments (42 NR) d'augets fins. Un seul élément au profil complet est à classer parmi les augets dits "à bords parallèles " ou " barquette ». Ce type d'auget est utilisé sur des fours à grille dont la mise en œuvre apparaîtrait au début du $\mathrm{III}^{\mathrm{e}}$ s. av. J.-C. pour perdurer jusqu'aux phases finales de
La Tène (Daire, 2003). Ces quelques témoins recueillis dans l'habitat reflètent la consommation de sel mais une fosse de rejet d'éléments de four à grille (fragments de voûtains, d'entretoises et d'augets en grande quantité), découverte à $150 \mathrm{~m}$ au sud du site au cours de l'opération de diagnostic effectuée en 2006 (Devals, 2008), pourrait témoigner d'une activité artisanale de production salicole. On signalera la découverte de deux fragments de pilier " trompette " associés à des fours à piliers (Gouletquer, 1970) dont l'utilisation a vraisemblablement duré de la fin de l'âge du Bronze à La Tène ancienne.

\section{Perduration et MOdifications DE L'ENCLOS À L'ANTIQUUITÉ}

\section{Phase 6 : cinquième état de l'enclos, 15 -10 av. J.C. à 50 apr. J.C.}

Une bonne partie de la ceinture externe de l'enclos originel est conservée, caractérisée par un recreusement plus ou moins profond et situé à peu près dans l'axe des fossés antérieurs (fig. 26).

Les fossés 1428 et 1438, encadrant toujours l'accès à l'établissement, constituent ainsi la façade orientale, les fossés 1450-1492 la façade nord, et 40 la façade nordouest. L'enclos subit toutefois une modification notable sur le côté méridional, traduite par l'abandon de la partie sud et qui réduit sa surface interne à environ 1 ha. Le fossé 594 préserve un court tronçon de la façade sud-ouest mais il se raccorde avec un nouveau creusement, 700-95

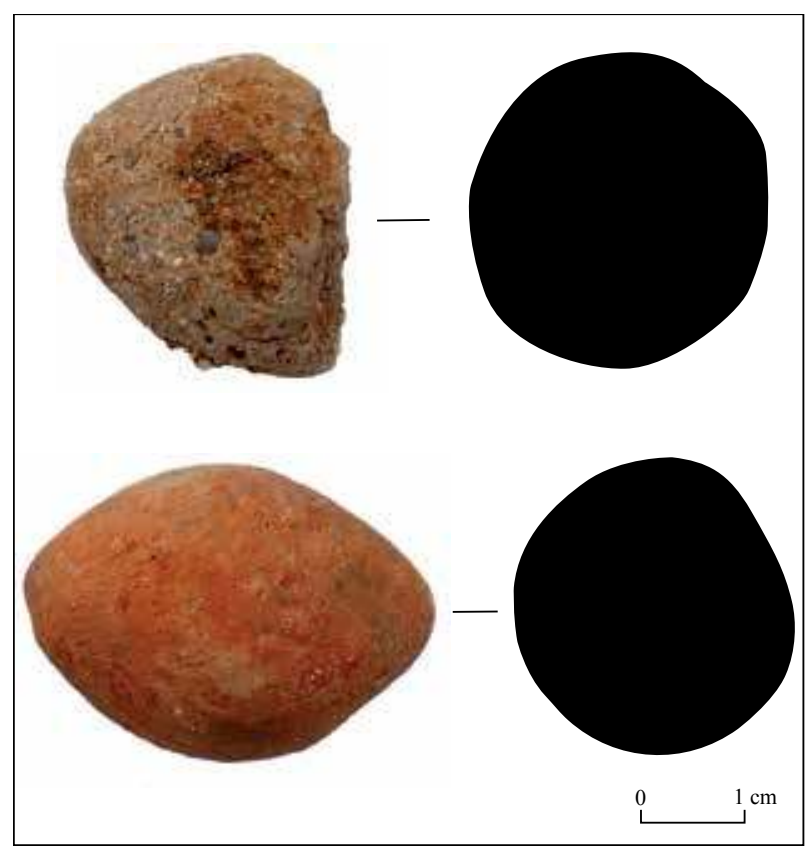

Figure 25 : Guérande, « La Lande » : balles de fronde. DA0 : J. Cornec.

Figure 25: Sling balls. Realisation: J. Cornec. 
qui, avec le fossé 1040-1063, referment désormais l'enclos du côté sud. L'interruption à l'ouest du fossé 1040-1063 pourrait trahir l'existence d'un accès vers le sud.

Ces fossés adoptent un profil en U fortement évasé ou à large fond plat. Leur largeur à l'ouverture oscille généralement entre 1,35 et $3 \mathrm{~m}$ mais elle atteint $5 \mathrm{~m}$ dans la partie nord-ouest de la ceinture. La profondeur maximale quant à elle n'excède pas 1,15 m. Le pendage des fonds de fossés respecte la pente naturelle du terrain, vers le nord-ouest.

De la ceinture interne (fig. 27), seule subsiste la partie occidentale reprise par les fossés 1636 et 1639, ce dernier se raccordant sur la nouvelle façade méridionale. Ils montrent un profil en U très évasé avec une largeur pou- vant atteindre 3,50 $\mathrm{m}$ à l'ouverture et une profondeur de $0,50 \mathrm{~m}$.

La partition nord-sud est également conservée sous la forme du fossé 260 qui, comme les fossés de ceinture, offre un profil en $\mathrm{U}$ très évasé et un fond plat. Sa largeur varie entre $1,15 \mathrm{~m}$ au sud et $4,30 \mathrm{~m}$ au nord et sa profondeur atteint un maximum de 1,15 m. L'entrée initiale (entrée 2) est abandonnée au profit d'un nouvel accès, entrée 8 , décalé de quelques mètres au nord. Cet accès se caractérise par un passage empierré doté d'un évidement transversal préservant le passage d'eau du fossé.

Un bâtiment (ensemble E.30), dont ne subsistent que deux solins formant un angle, est peut-être installé dès

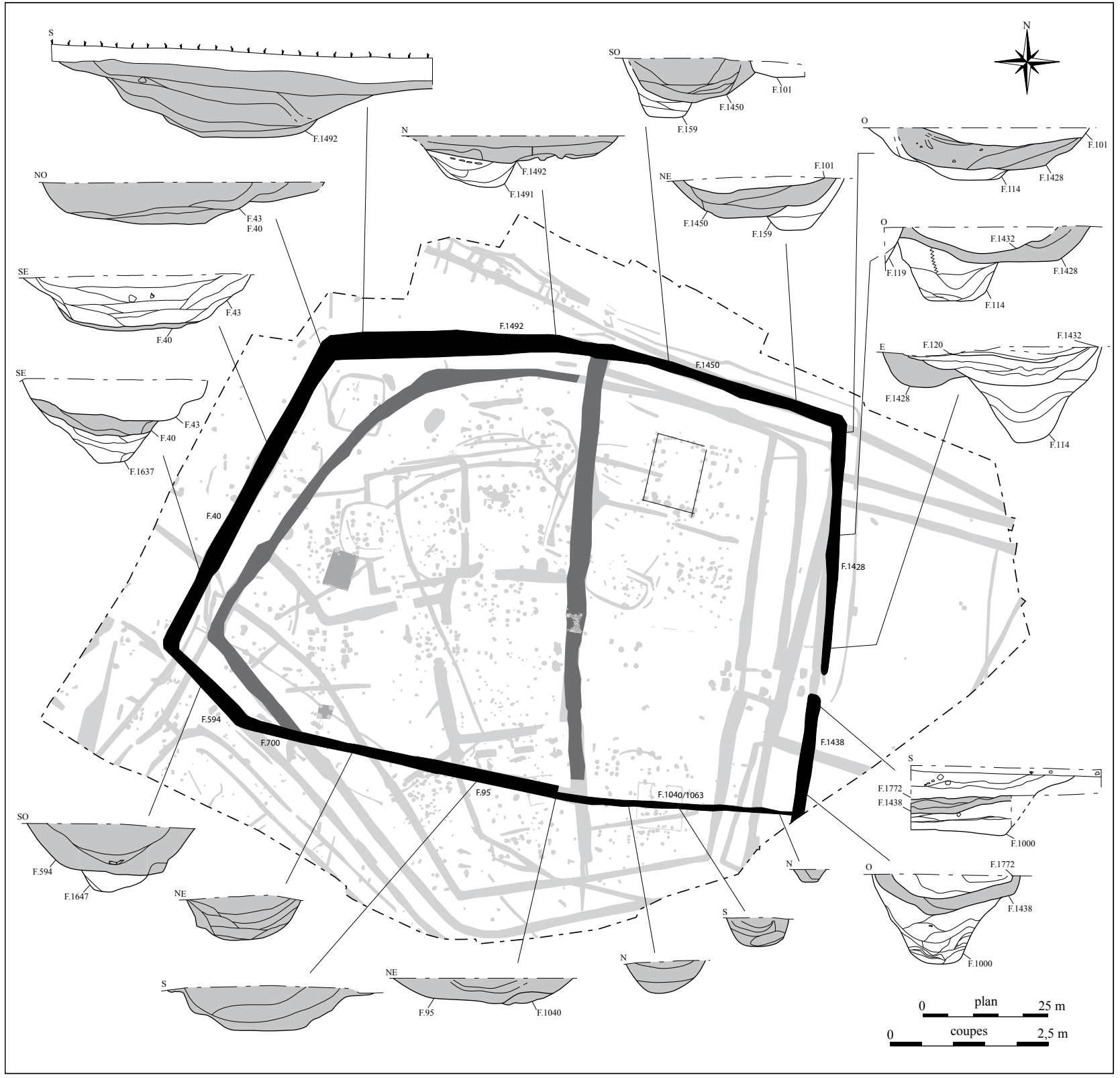

Figure 26 : Guérande, « La Lande » : plan et coupes des fossés de l'enclos attribués à la phase 6. DA0 : J.-M. Richard, P. Bellanger.

Figure 26: Plan and sections of the enclosure's ditches assigned to the phase 6. Realisation: J.-M. Richard, P. Bellanger. 


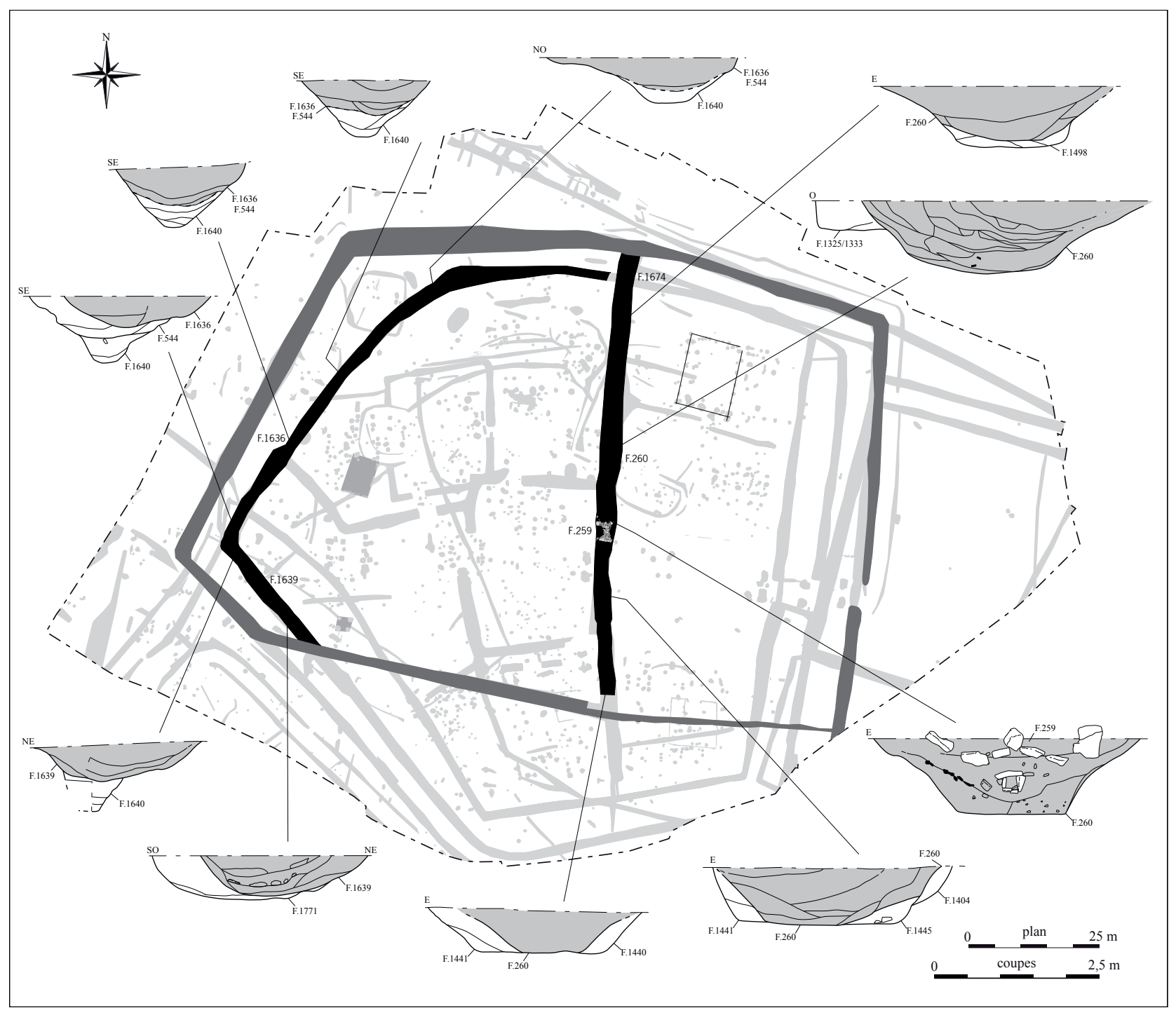

Figure 27 : Guérande, "La Lande » : plan et coupes des fossés internes attribués à la phase 6. DA0 : J.M. Richard, P. Bellanger.

Figure 27: Plan and sections of the internal ditches assigned to the phase 6. Realisation:J.M. Richard, P. Bellanger.

cette phase du côté ouest de l'enclos. La fonction résidentielle de ce bâtiment reste incertaine. En effet, le mobilier recueilli, en rejet et de caractère très fragmenté, et l'absence de certaines catégories de vaisselles usuellement trouvées sur les sites d'habitat ruraux tels que gobelets ou mortiers pourraient indiquer que l'enclos à vocation d'habitat à l'époque gauloise devient un simple enclos à fonction agro-pastorale à l'époque antique.

Dans l'angle nord-ouest de l'avant-cour, plusieurs trous de poteau appartenant à l'ensemble E.19, identifié comme une probable clôture de type corral, ont livré du mobilier antique.

Le mobilier indique pour cette phase une datation s'étageant entre les années 15-10 av. J.-C. et le milieu du i ${ }^{\text {er }} s$. apr. J-C.

\section{Phase 7 : sixième et dernier état de l'enclos, 50 à 70-80 apr. J-C.}

Comme dans l'état précédent, la façade orientale de l'enclos est maintenue (fig. 28), alors constituée par les fossés 1432 et 1772, légèrement moins profonds que les creusements antérieurs mais qui bordent encore l'entrée principale. En revanche, une modification affecte la ceinture nord, désormais décalée de $3 \mathrm{~m}$ vers le sud et, de plus, l'avant-cour s'agrandit du côté méridional avec le comblement du fossé 1040-1063. On ne connaît cependant pas de retour de ce côté, celui-ci se trouvant hors emprise, dans un secteur qui n'a pu être diagnostiqué en raison de l'avancée précoce des aménagements de voiries de la ZAC. Il semble toutefois que les fossés orientaux de cette avant-cour soient rapidement comblés car un four (120), 


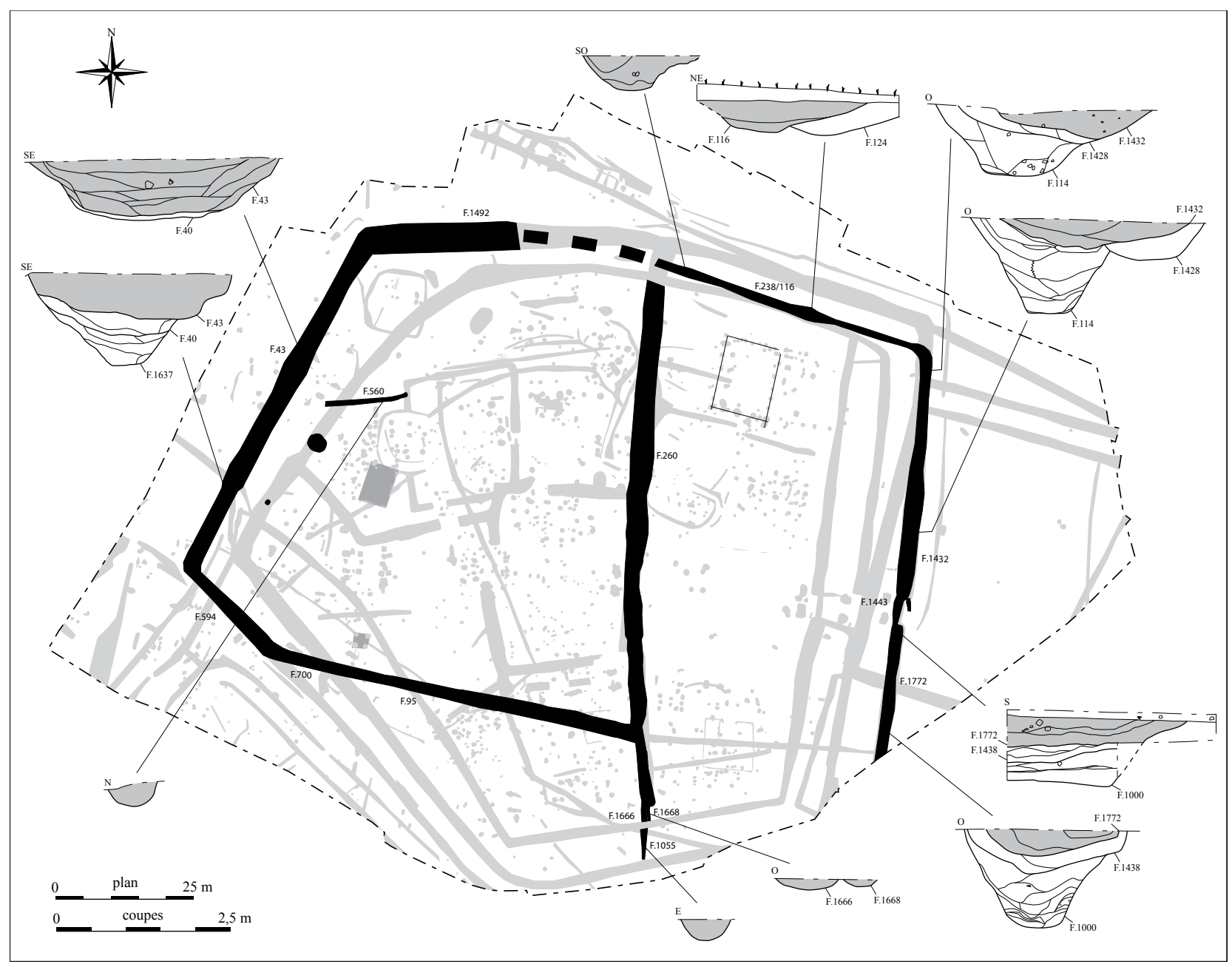

Figure 28 : Guérande, « La Lande » : plan et coupes des fossés attribués à la phase 7. DA0 : J.-M. Richard, P. Bellanger.

Figure 28: Plan and sections of the ditches assigned to the phase 7. Realisation: J.M. Richard, P. Bellanger.

installé dans le comblement du fossé 1432 et dont la fonction reste indéterminée, a livré des charbons de bois qui ont été datés par radiocarbone entre 46 av. J.-C. et 74 apr. J-C (Archéolabs réf. ARC10/R3764C) : Datation ETH-40021, Age ${ }^{14} \mathrm{C}$ AMS conventionnel : $1985 \pm 30$ $\mathrm{BP}\left(\delta^{13} \mathrm{C}\right.$ mesuré de $-24,6 \pm 1,1 \%$ vs $\left.\mathrm{PDB}\right)$; date $14 \mathrm{C}$ calibrée : $46 \mathrm{cal} \mathrm{BC}-74 \mathrm{cal} \mathrm{AD}$ (courbe de calibration "IntCal04 », Reimer et al., 2004, Radiocarbon, 46).

La façade nord-ouest est reprise en ceinture externe par le fossé 43, légèrement moins profond mais dans le même axe que son prédécesseur, tandis que le fossé de ceinture interne est colmaté. Un puits (606) ainsi qu'une petite structure de combustion (1638), tous deux implantés dans le comblement du fossé 1636, en témoignent. L'analyse palynologique d'un prélèvement de sédiments issu du comblement du puits montre la continuité d'un environnement de type agropastoral.

De même, le petit fossé 560, que l'on peut interpréter comme une tranchée de palissade destinée à abriter le bâtiment E.30, recoupe cette ceinture interne abandon- née. Le pendage général des fossés de l'enclos demeure en direction du nord-ouest.

Le fossé de partition nord-sud 260 est quant à lui prolongé du côté sud et se raccorde maintenant au fossé 700 95 de la façade méridionale.

Cette phase d'occupation peut être datée par le mobilier de la seconde moitié du $\mathrm{I}^{\text {er }}$ s. apr. J-C.

\section{ABANDON DE L'ENCLOS ORIGINEL ET OCCUPATION POSTÉRIEURE, PHASE 8 : 70-80 À 150 APR. J.-C.}

Cette phase se traduit par l'abandon complet de l'enclos 1 d'origine gauloise et la création de l'enclos 2, implanté à l'est (fig. 29). Celui-ci chevauche en partie l'ancienne façade orientale de l'enclos 1 et se développe hors emprise, raison pour laquelle il n'a pu qu'être incomplètement étudié. L'absence d'éléments internes pourrait indiquer une vocation de type agro-pastorale. 


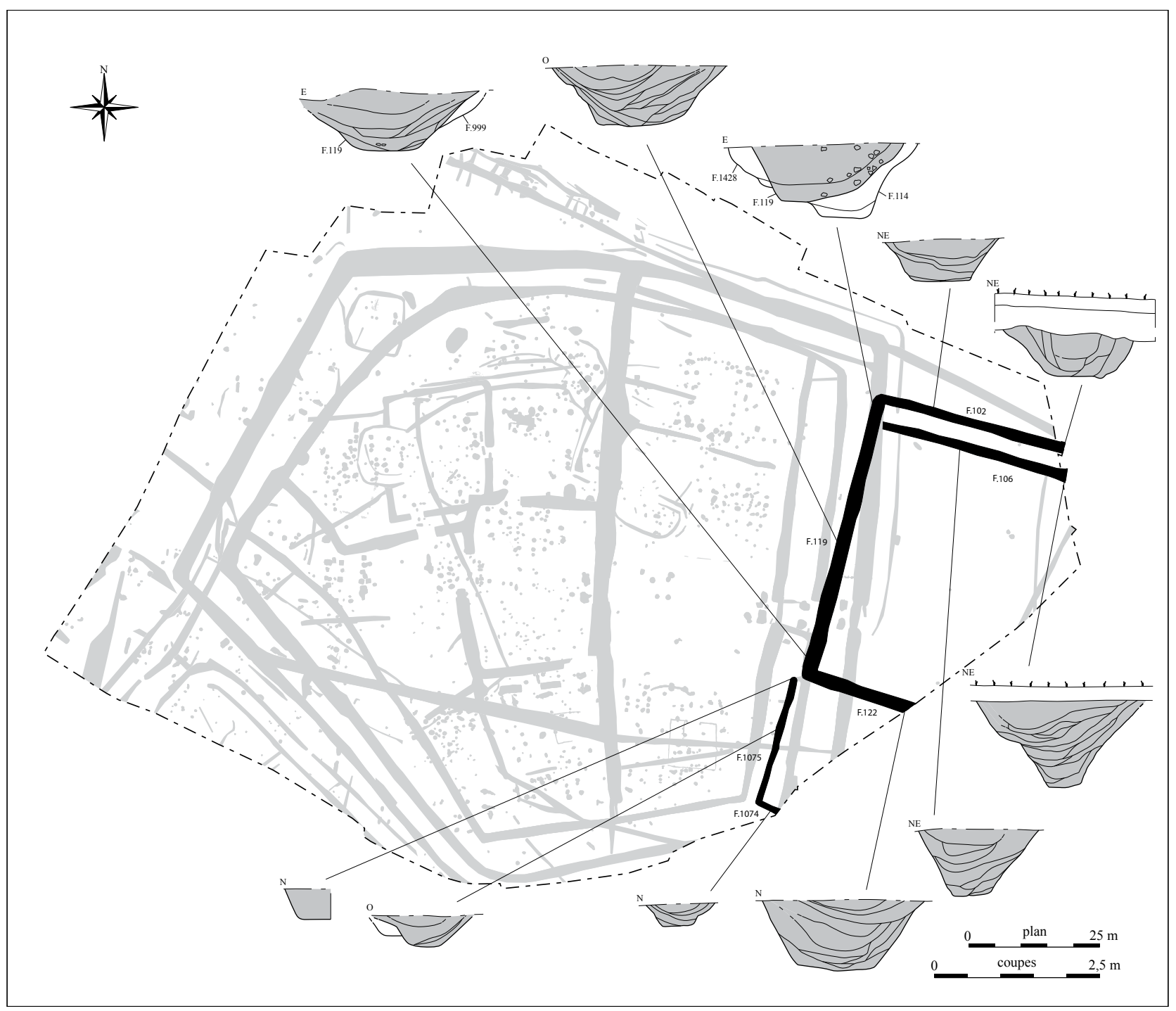

Figure 29: Guérande, « La Lande » : plan et coupes des fossés attribués à la phase 8. DA0 : J.-M. Richard, P. Bellanger.

Figure 29: Plan and sections of the ditches assigned to the phase 8. Realisation: J.M. Richard, P. Bellanger.

Les niveaux d'abandon du puits 606 ainsi que le mobilier recueilli au sein du comblement des fossé de l'enclos 2 fiés au gré du temps mais on constate que l'établissement garde sa morphologie originelle durant les quelque deux siècles de l'occupation gauloise.

L'espace occupé par l'enclos atteint dès sa création une superficie globale que l'on peut estimer aux alentours d'1,4 ha, la surface utile avoisinant quant à elle $7500 \mathrm{~m}^{2}$.

Implanté selon un axe rectilinéaire nord-sud, un fossé partage l'intérieur de l'enclos en deux parties inégales. Il sépare une zone d'occupation très dense à l'ouest, couvrant environ $4350 \mathrm{~m}^{2}$, d'un secteur oriental présentant une moindre densité de vestiges et qui occupe une superficie proche de $2950 \mathrm{~m}^{2}$.

L'entrée de l'enclos, située à l'est et dotée de portails, offre un aspect monumental. Elle permet d'accéder à la partie orientale de l'établissement qui comporte un secteur d'habitat au sud et des systèmes de corrals associés à des bâtiments (étables ou écuries?) au nord. 
Un second passage, pratiqué dans le fossé de partition nord-sud et disposé dans l'axe de l'entrée principale, détermine l'accès, muni d'un porche, à la partie occidentale.

De multiples partitions, dont la situation évolue au fil de l'occupation protohistorique, divisent ce secteur en modules à vocations diverses. Les constructions et structures identifiées ainsi que les rejets de mobilier indiquent l'existence d'un lieu de résidence principale, de secteurs de stockage ou artisanaux et d'habitats et autres édifices annexes.

Des passages, fréquemment eux aussi dotés d'un porche, relient les différents modules.

La cartographie des espaces vides complète la vision de l'organisation au sein de l'enclos.

Outre les espaces exempts ou quasi-exempts de creusements dus à la présence de talus, on relève dans la partie orientale un vaste secteur qui correspond à une cour ménagée entre les deux accès de l'établissement qui sépare la zone vouée au parcage du bétail de la zone d'habitat.

Dans la partie occidentale, s'observent d'autres espaces assimilables à des cours ou des zones de circulation. Au nord, la rareté des structures s'explique par l'humidité de ce secteur localisé en bas de pente.

À l'époque antique, l'enclos subit une modification de sa façade sud qui lui confère un plan sub-rectangulaire mais la division entre les parties a priori résidentielle et agropastorale subsiste avec le fossé de partition nord-sud. Celui-ci est également muni d'un passage, mais alors empierré et déplacé vers le nord.

Le peu de vestiges attribuables à l'Antiquité semble traduire la poursuite du déclin ou du moins du changement de statut de l'établissement observé à la fin de la période gauloise, à moins qu'il reflète un déplacement de l'occupation.

\section{Les activités de l'établissement}

Malgré l'absence de restes animaux à cause de l'acidité du terrain, phénomène malheureusement récurrent en Bretagne et dans une grande partie des Pays de la Loire, la pratique de l'élevage demeure fortement envisageable de par la présence de solides portails d'entrée et de probables enclos à bestiaux associés à une mare observés dans la partie nord-est de l'établissement.

Hormis l'élevage, la découverte de deux balles de fronde pourrait attester de la pratique de la chasse, du moins au cours des premières phases de l'établissement.

Étonnamment, on note qu'aucun coquillage n'a été recueilli malgré la proximité du littoral.

Les constructions de type greniers, mises au jour en quantité relativement importante, témoignent d'une activité agricole, confirmée par l'analyse palynologique de deux échantillons prélevés dans le comblement du puits 538. Des indices de céréaliculture y sont visibles avec l'enregistrement de courbes de pollens de céréales et d'apophytes telles que Centaurea (Centaurée) et Rumex (Oseille) indiquant l'existence probable de parcelles cultivées à proche distance du puits ou du moins d'activités de céréaliculture (aire de battage, stockage...). La culture de lin (Linum usitatissimum) semble également attestée sur le site avec la présence d'un pollen de ce taxon dans chaque échantillon (artisanat textile?). Cependant, très peu de pesons ont été trouvés parmi les rejets du site. Il est possible que le lin cultivé ici ne fût pas tissé sur place mais commercé à l'état brut vers d'autres sites plus spécialisés.

Les échantillons palynologiques livrent d'autre part un environnement végétal très ouvert, constitué principalement par Quercus (chêne) et Corylus (noisetier) et des traces de Fagus (hêtre), Tilia (tilleul) et Ulmus (orme). Quelques petits ligneux arbustifs, Hedera (lierre), Lonicera (chèvrefeuille) et Ilex (houx) sont également décelés. Cet enregistrement pollinique, avec notamment le noisetier, taxon héliophile, traduit probablement la présence sur les coteaux environnants d'un couvert forestier très dégradé (bois clair, clairières), constitué des reliques d'une chênaie mixte.

Le paysage est donc dominé par un système prairial au sein duquel la présence d'un cortège de taxons rudéraux (Astéracées, Caryophyllacées, Chenopodiacées, Plantago, Artemisia, Arctium, Convolvulus...) témoigne d'activités humaines (habitat, élevage). Une légère augmentation du taux des Astéracées aux dépens des Poacées dans l'US. 1 pourrait traduire une augmentation des zones pâturées.

Plusieurs morceaux de parois de four ainsi que des fragments de soles perforées découverts en rejet pourraient indiquer une activité potière. Un fossé (fossé 341 , phase 4) a de plus livré un lot de céramiques pour la plupart complètes ou presque, et de formes analogues que l'on peut envisager issues d'une même production.

Une autre production artisanale, le travail des bronzes, se signale par la présence d'un nombre conséquent de creusets, associés à des fragments de parois de four. Le travail des fers est quant à lui illustré par la présence de scories (NR : 110).

\section{L'environnement du site}

Les nombreuses opérations de fouilles et de diagnostics archéologiques effectuées à Guérande montrent une occupation dense de ce territoire dès le Néolithique.

D'autre part, les analyses palynologiques effectuées sur le site du parc Savari attestent une forte anthropisation de ce secteur à la charnière du premier et du second âge du Fer (Bellanger, 2010) associant mises en culture et création de chemins. 
Dans le secteur même de Villejames, les interventions archéologiques réalisées au gré des aménagements ces vingt dernières années permettent d'appréhender l'environnement proche de l'établissement de La Lande (fig. 30).

Outre divers vestiges non datés mais pouvant être liés, du moins pour partie, à l'enclos du second âge du Fer, le diagnostic de La Métairie de La Lande (Devals, 2008) a livré une fosse contenant des rejets de four à sel accompagnés de mobilier datant de La Tène finale à environ $150 \mathrm{~m}$ au sud-ouest de l'enclos pentagonal. Cette fosse pourrait témoigner d'une activité salicole installée à l'écart de l'habitat, au sein d'un système d'enclos annexe, entrevu sur la fouille et vraisemblablement confirmé tant par le diagnostic que par les traces repérées par photointerprétation.

Létablissement de La Lande se situe à quelques centaines de mètres à l'est de l'enclos de Villejames qui a fonctionné simultanément. Celui-ci est également doté d'une double enceinte mais, si l'on en juge par les amé- nagements internes apparemment moins complexes, il ne semble pas disposer du même statut privilégié. On notera toutefois que tous deux sont situés sensiblement à la même altitude et à proximité du point culminant de Guérande. On ne peut éviter de s'interroger sur les relations que pouvaient entretenir les occupants de la ferme de La Lande et ceux de Villejames. La fouille de ce dernier a cependant montré son abandon avant l'époque antique (Devals, 1995 et 2009; Pirault, 2010).

La situation " en miroir " de ces deux établissements est comparable à celle observé sur le site de la ZAC de La Tourelle à Lamballe (Côtes-d'Armor) [Mentele, 2010].

Deux possibilités sont envisageables : soit il s'agit de propriétés distinctes implantées de part et d'autre d'un thalweg, soit elles constituent deux fermes faisant partie d'un domaine appartenant au même détenteur. D'autre part, la densité d'occupation à la fin de l'âge du Fer sur le territoire de Guérande s'apparente au vaste réseau d'établissements gaulois de la ZAC Object'Ifs Sud (Rémy, 2017).

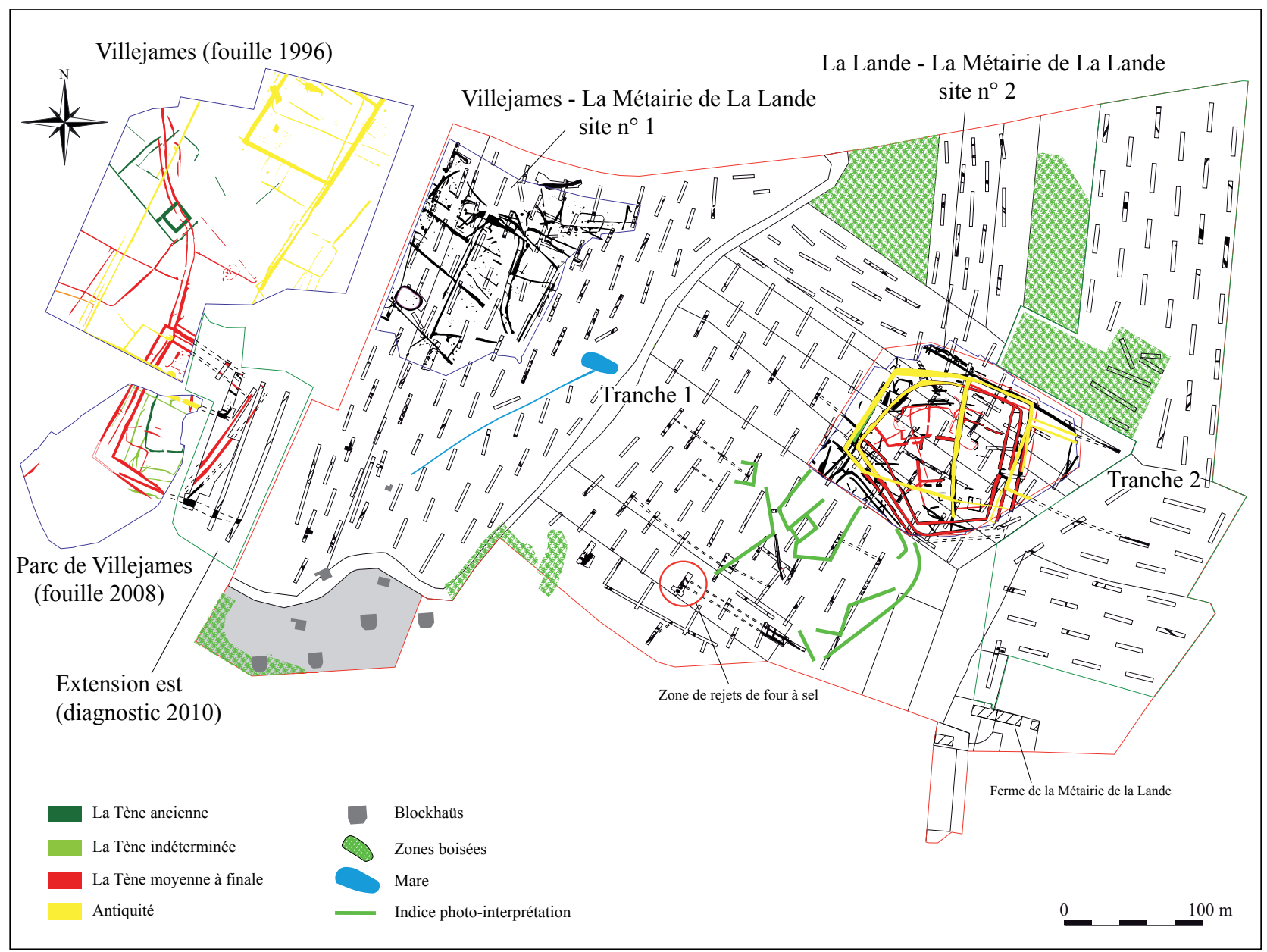

Figure 30 : Guérande, « La Lande » : données archéologiques autour du site. DAO : P. Bellanger. 


\section{Comparaisons régionales}

Le site de La Lande diffère par bien des aspects de la plupart des établissements ruraux datés de la fin de l'âge du Fer. Son plan pentagonal, en premier lieu, n'est pas fréquent à une époque au cours de laquelle on observe une standardisation de forme tendant vers un plan quadrangulaire (Maguer et al., 2009). À ce titre, il est possible que la modification mise en œuvre à la transition entre l'âge du Fer et l'époque antique, supprimant la partie méridionale de l'enclos, participe de cette volonté de standardisation.

Pour l'Ouest de la France, quelques enclos à fossés emboîtés de plan pentagonal, semblables à l'établissement de La Lande ont toutefois récemment fait l'objet d'une fouille (fig. 31).

L'établissement rural de Beauregard à Dissay-surCourcillon dans la Sarthe (Nillesse, 2004), occupé durant La Tène D, offre des points communs avec l'enclos de la Lande : un plan pentagonal composé de deux enclos emboîtés couvrant une surface de $12900 \mathrm{~m}^{2}$ et une partition interne centrale avec système de porche d'entrée. L'enclos interne s'étend cependant sur une surface moindre $\left(5770 \mathrm{~m}^{2}\right)$ et ne comporte pas d'autre partition.

Toujours dans la Sarthe, le gisement des Nouis à Coulans-sur-Gées (Mare, 2014) se caractérise par deux enclos emboîtés de plan hexagonal couvrant une superficie totale de $8047 \mathrm{~m}^{2}$. Sa disposition interne intègre des fossés de partition avec, à l'est, un dispositif d'accès centré qui comprend un possible portique. Les comblements des fossés ont livré du mobilier attribuable à La Tène finale mais une création du site à La Tène C est envisagée.

Succédant à un habitat ouvert daté du $\mathrm{IV}^{\mathrm{e}} \mathrm{s}$. av. J.-C. et à un premier enclos occupé entre la seconde moitié du $\mathrm{III}^{\mathrm{e}}$ s. et le $\mathrm{II}^{\mathrm{e}}$ s. av. J-C, l'établissement de La Grande Haie à Vitré, en Ille-et-Vilaine (Hamon, 2010) est délimité par une vaste enceinte de $18000 \mathrm{~m}^{2}$ de plan mixte (fossés rectilignes et curvilignes) proche de celui de La Lande. Un enclos interne, d'une surface de $4800 \mathrm{~m}^{2}$, délimite l'espace domestique. Son occupation est attribuée à La Tène finale.

En Ille-et-Vilaine également, la fouille de la Zac des Vairies à Saint-Sauveur-des landes (Sicard, 2016) a révélé la présence de trois occupations successives datée du second âge du Fer. À un premier enclos de plan ogival daté de La Tène moyenne, s'ensuit un enclos de forme mixte, doté de multiples partitions internes. Créé sans doute à la fin de La Tène moyenne, cet enclos a perduré jusqu'au début du $\mathrm{I}^{\mathrm{er}}$ s. av. J.-C. Durant la seconde phase, attribuée à La Tène finale, l'enclos est agrandi, adoptant un plan hexagonal qui atteint une superficie de plus d' 1 ha.

En Loire-Atlantique, mais de l'autre côté de l'estuaire de la Loire, l'établissement du Fief Clément à Pornic (Levillayer, 2018) connaît une première implantation à
La Tène $\mathrm{C} 1$, constituée par un enclos de forme trapézoïdale doté d'un fossé de partition. Durant la seconde phase, attribuable à La Tène C2-D1, l'adjonction d'une grande enceinte de plan plus ou moins pentagonal confere à l'ensemble une superficie totale de $11600 \mathrm{~m}^{2}$. De nombreuses restructurations internes s'observent durant la phase 2, puis dans la phase 3 (La Tène D1b-D2).

D'autres enclos à fossés emboîtés de plan pentagonal semblable à l'établissement de La Lande ont aussi été reconnus par photographie aérienne (Péridy, 1999).

Sur le site de La Rourie à Cholet (Maine-et-Loire), un enclos quadrangulaire comprend une triple enceinte sur trois de ses côtés ainsi qu'un enclos interne agrémenté au nord de fossés formant de multiples subdivisions.

À La Tuderrière à Apremont (Vendée) se trouve un enclos à enceinte unique mais dont le plan pentagonal rappelle beaucoup celui de La Lande. Il est doté, comme ce dernier à l'état 1 , d'une entrée centrale au sud-est et de deux sections de fossés internes qui flanquent cette entrée. Ces deux exemples montrent cependant des dimensions légèrement supérieures. Si des analogies se remarquent, en l'absence de fouille, il reste néanmoins impossible d'affirmer l'attribution chronologique et d'être certain de la contemporanéité des éléments fossoyés repérés.

Sur la commune même de Guérande, plusieurs enclos à double ou triple enceinte ont été repérés par photographie aérienne. À quelques centaines de mètres à l'ouest, l'enclos quadrangulaire à double fossé périphérique de Villejames a été partiellement étudié (Devals, 1995 et 2009; Pirault, 2010). Succédant à une occupation datée de La Tène ancienne à moyenne, cet établissement a livré du mobilier contemporain de celui de La Lande mais ne semble pas avoir perduré après la conquête. Sa surface, d'environ 1 ha, est inférieure à celle de l'enclos pentagonal.

Cette configuration à double ou triple enceinte est avérée sur certains sites laténiens.

La fonction défensive est incontestable pour de rares exemples au regard des dimensions particulièrement imposantes des fossés, comme c'est le cas sur les sites de Saint-Symphorien à Paule dans les Côtes-d'Armor (Menez, 2008) et des Natteries à Cholet dans le Maineet-Loire (Maguer, 2000) dont le caractère de résidence aristocratique est par ailleurs assuré.

Ici, à l'instar de l'établissement de Beauséjour à Angers, dans le Maine-et-Loire (Pétorin, 2010), la taille des fossés reste modeste, atteignant une profondeur maximum restituée de 2,20 m pour une ouverture que l'on peut estimer aux alentours de $3 \mathrm{~m}$ de large. Les matériaux extraits de leur creusement n'ont donc pas permis de bâtir des talus très importants et vraiment défensifs, d'autant plus que la fouille a montré la présence de talus toujours disposés en arrière du fossé et non cumulés dans l'espace défini par les fossés d'enceinte. 


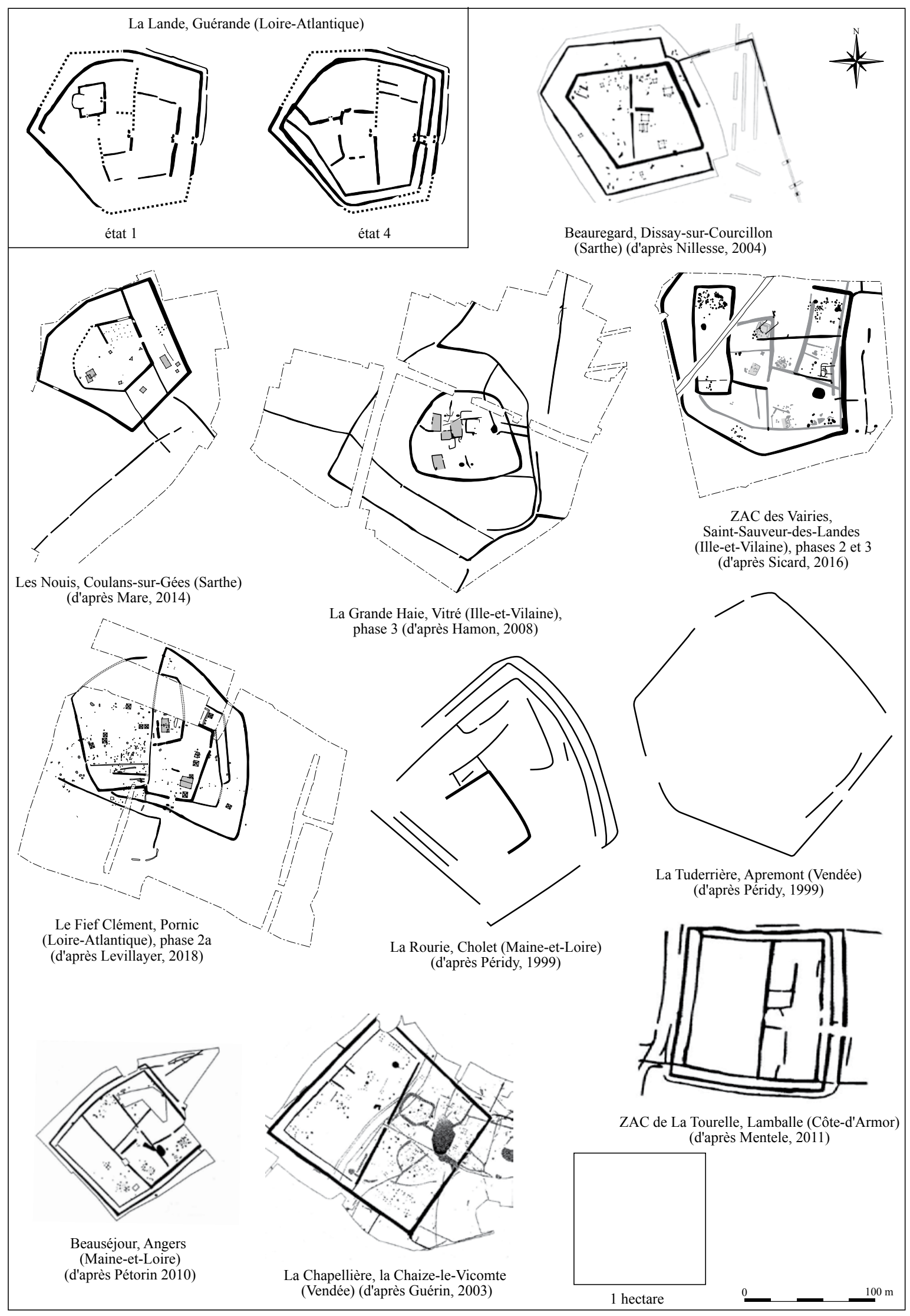

Figure 31 : Guérande, «La Lande » : établissements comparables. DA0 : P. Bellanger. 
Si l'on prend en compte la largeur réelle des fossés et l'emprise du talus, cet espace se restreint à un couloir d'environ $2 \mathrm{~m}$ de large n'autorisant qu'une circulation permettant tout au plus l'entretien de l'enclos. Il n'y a guère que dans la partie sud-ouest, entre les ceintures interne et intermédiaire, qu'une surface est suffisante pour y accueillir une quelconque activité, ce qui expliquerait l'existence d'un passage ménagé dans l'enceinte interne dans l'état 2 du site.

Les systèmes d'enclos emboîtés sont fréquemment associés à des partitions internes, contrairement aux fermes de plan simplifié. Il est possible que ce principe découle d'une volonté ostentatoire liée au statut particulier des propriétaires.

Une partition divisant l'enclos en deux parties principales avec un système de passage central se retrouve sur divers établissements protohistoriques tels que la ZAC de La Tourelle à Lamballe dans les Côtes-d'Armor (Mentele, 2010), La Chapellière à La Chaize-le Vicomte en Vendée (Guérin, 2003) ou Le Clos-Henry à Château-Gontier (Valais et al., 2008), parfois souligné par des vestiges de porche lorsque les fossés sont interrompus comme au Coq Hardy à Fontenay-le-Comte en Vendée (Nillesse, 2006), à Beauregard à Dissay-sur-Courcillon dans la Sarthe (Nillesse, 2004) et à Beauséjour à Angers dans le Maineet-Loire (Pétorin, 2010).

Cette division sépare en général une partie à vocation plutôt agricole d'un secteur résidentiel. Il s'agit d'une bipartition fonctionnelle qui préfigure l'organisation des établissements ruraux gallo-romains : pars urbana et pars rustica (Maguer et al., 2009).

La multiplication des subdivisions internes est plus rarement observée. Sur le site de Beauséjour, la dernière phase d'aménagement montre elle aussi une partition interne complexe constituée de cinq modules délimités de tailles variées. C'est également le cas des établissements laténiens de la ZAC de Bellevue à Thorigné-Fouillard dans l'Illeet-Vilaine (Le Goff, 2007) et du Fief Clément à Pornic (Levillayer, 2018).

De grandes fosses rectangulaires ont été aménagées par paires implantées selon un axe parallèle aux fossés sur le côté interne de chaque entrée. Ces dispositifs constituant des vestiges de porche ou portail se retrouvent relativement fréquemment sur les sites de La Tène finale parmi lesquels on peut citer Les Humelles à Mûrs-Érigné dans le Maine-et-Loire (Le Goff, 2000), la ZAC de La Tourelle à Lamballe dans les Côtes-d'Armor (Mentele, 2010) ou encore La Grande Haie à Vitré (Hamon, 2010) et le site de la ZAC de Bellevue à Thorigné-Fouillard en Ille-etVilaine (Le Goff, 2007).

Ces dispositifs d'entrée ne s'observent pas uniquement sur les sites d'habitat et peuvent se retrouver sur des accès d'enclos en lien avec des activités d'élevage (Lepaumier et al., 2018). La systématisation de l'installation de porches, y compris aux entrées des petites partitions internes, reste particulièrement exceptionnelle sur le site de La Lande.

Les petits fossés implantés au niveau des entrées, et destinés à évacuer le trop-plein des eaux pluviales trouvent une analogie sur les sites de La Tourelle (Mentele, 2010) et du Bois Hue à Nantes (Levillayer $e t$ al., 2017).

L'habitat protohistorique, organisé par modules, paraît témoigner dès le début de son implantation d'une occupation relativement groupée, comprenant un nombre d'individus dépassant certainement la famille nucléaire. On peut envisager la cohabitation de plusieurs cellules familiales comme sur le site de La Bleure à Cholet dans le Maine-et-Loire (Sandoz, 1999) où le nombre de bâtiments, notamment de greniers vraisemblablement contemporains, suggère un certain nombre d'occupants mais dont les liens sociaux restent indéterminés.

Sur l'établissement de La Lande, à partir de la création de l'enclos (phase 2) à La Tène moyenne, les aménagements des partitions successives reflètent une véritable hiérarchisation de l'habitat au sein de l'enclos.

À ce titre, la maison subcirculaire associée au petit enclos interne est exceptionnelle. Nous sommes là de toute évidence face à une mise en scène de la résidence principale.

L'hypothèse d'un propriétaire détenteur d'un statut relativement élevé, entouré de ses ouvriers agricoles, semble d'ailleurs se confirmer par les éléments de parure mis au jour, même si ce type de mobilier n'est pas l'apanage exclusif de l'aristocratie gauloise (Lepaumier et al., 2015).

Les bâtiments de plan quadrangulaire, encadrés par des tranchées périphériques, bien que plus rares que les constructions sur poteaux porteurs, sont reconnus pour l'âge du Fer et la période augustéenne dans le Nord-Ouest de la France (Maguer et Robert, 2013). On relève en effet la présence de bâtiments analogues sur les sites du Clouët à Carquefou en Loire-Atlantique (Le Goff, 1998), de Kerven Teignouse à Inguinel dans le Morbihan (Tanguy, 2000), de La Grande Haie à Vitré (Hamon, 2010) et des Vairies à Saint-Sauveur-des-Landes en Ille-et-Vilaine (Sicard, 2016), de La Chapellière à la Chaize-le-Vicomte (Guérin, 2003) et de La Pâquerie à Aubigny en Vendée (Pétorin, 2013), de La Boirie 1 à Chemillé (Guérin, 1999) et de La Chauvelière Neuve à Cholet dans le Maine-etLoire (Maguer, 2005) et de La Petite Némerie à Vivoin dans la Sarthe (Maguer et al., 2003). Les dimensions de ces constructions varient de 50 (La Petite Némerie) à $123 \mathrm{~m}^{2}$ (La Chauvelière Neuve).

Le développement des décapages extensifs a permis de vérifier l'existence de chemins d'accès aux fermes gauloises. Comme sur la ferme de La Lande, on retrouve sur les sites des Natteries à Cholet dans le Maine-et-Loire 
(Maguer et al., 2009) et du Clos-Henry à ChâteauGontier (Valais et al., 2008), en Mayenne, un chemin longeant un des côtés de l'enclos.

De nombreuses fermes gauloises connaissent un abandon avant la Conquête (Langouët, 1996; Maguer et al., 2009) ou du moins n'y subsistent que de faibles vestiges d'occupation.

Certains établissements ruraux de la fin de l'âge du Fer témoignent toutefois d'une pérennité d'occupation, à l'exemple du site de la Pâquerie à Aubigny en Vendée (Pétorin, 2013). La ferme de La Lande connaît pour sa part un décroissement progressif de son activité et très vraisemblablement un véritable changement de statut et de vocation. À La Tène finale, le mobilier révèle déjà un déclin certain du statut du site et probablement de l'activité qui pouvait s'y dérouler.

L'enclos lui-même ainsi que sa partition centrale perdurent au Haut-Empire, avec certes une modification de sa façade sud, sans discontinuité durant la transition et la première moitié du $\mathrm{I}^{\mathrm{er}}$ s. apr. J.-C. La présence d'un bâtiment associé à un puits soulève toutefois la question de la perduration de l'habitat lui-même. En effet, l'absence notable de certaines vaisselles généralement trouvées sur les établissements ruraux, tels que les mortiers, pourrait révéler un changement de fonction. Il est possible que l'établissement de type ferme évolue lors de la période de romanisation vers un enclos à vocation purement agricole dépendant d'un établissement voisin, peut-être celui de Villejames, fouillé en 1993 et 1994 (Devals, 1995). On constate d'ailleurs des profils et des dimensions analogues pour les deux sites.

Pour l'époque antique, l'aménagement de passerelle empierrée de l'entrée 8 trouve une comparaison flagrante avec le système de passage observé lors de la fouille de l'enclos gallo-romain de Villejames (Devals, 1995 et 2009), muni à l'identique d'un canal destiné à l'écoulement des eaux du fossé. Une différence réside toutefois dans les blocs parfaitement équarris bordant la passerelle de Villejames ainsi que sa largeur plus importante $(7 \mathrm{~m})$. Sur le site de La Gatellière à Angers dans le Maine-et-Loire (Hervé, 2004), un dispositif empierré assurant le passage sur un fossé de partition a également été mis au jour mais celui-ci présentait un canal d'écoulement en surface.

\section{CONCLUSION}

Succédant à un petit habitat ouvert du début de La Tène moyenne, l'occupation principale du site de La Lande consiste à La Tène $\mathrm{C} 2$ et $\mathrm{D} 1$ en une vaste ferme de plan pentagonal enclose dans une double enceinte sur les flancs nord et nord-ouest, triple sur les autres côtés. À l'intérieur s'observent de nombreux fossés attribuables pour la plupart à des partitions structurant l'espace et dont les imbrications trahissent des états du site chronologiquement distinct.

Ce site d'habitat rural réunit plusieurs des critères utilisés dans l'enquête nationale initiée en 2006 sous la direction de F. Malrain et G. Blancquaert pour caractériser les résidences aristocratiques (Menez, 2008). Ceux-ci ont depuis été affinés, rendant ainsi compte de la complexité de classer hiérarchiquement les sites d'habitat gaulois tant les critères peuvent varier selon les contextes locaux (Lepaumier et al., 2011; Fichtl, 2013).

En premier lieu, on soulignera les dimensions de l'enclos qui excèdent, avec une superficie globale d'environ 1,4 ha et une surface interne de quelque $7500 \mathrm{~m}^{2}$, le seuil d'1 ha retenu pour signaler un site remarquable.

Certes la taille des fossés de l'établissement de La Lande n'atteint pas celle observée sur des sites fortifiés comme Saint-Symphorien à Paule ou Les Natteries à Cholet mais le creusement, l'entretien et les remaniements des enceintes emboîtées ainsi que les aménagements internes successifs représentent des travaux conséquents qui ne sont possibles qu'avec une main-d'œuvre importante et un groupe d'individus organisés, soit communautairement comme dans le cas des habitats groupés, soit par un pouvoir fort détenu par un nombre restreint de personnes.

L'entrée monumentale dénote une volonté ostentatoire et un contrôle renforcé de l'entrée. De même les multiples partitions internes, constituées de fossés talutés qui divisent la partie résidentielle en cellules et formant une succession de cours et de clôtures, reflètent une mise en scène et une structuration peu fréquente. Chacune de ces cellules sont en outre pour la plupart pourvues d'un accès muni d'un portail ou d'un porche.

Le plan de l'habitat principal, clairement identifié pour la phase 2, montre une superficie de $130 \mathrm{~m}^{2}$, ce qui lui confere un caractère monumental en accord avec l'enclos à deux entrées dans lequel il s'insère.

Les réaménagements successifs de l'habitat sur une courte période de deux siècles révèlent d'autre part une détermination de changer de façon conséquente l'aspect du lieu de vie. Ces restructurations impliquent elles aussi une main-d'œuvre nombreuse qui témoigne du statut social prééminent du propriétaire du lieu.

Comme en atteste le nombre relativement élevé de greniers, le site de La Lande possède une capacité de stockage de récoltes importante peu souvent observée.

Au travers du mobilier recueilli peu fréquent sur les fermes gauloises, du moins à l'échelle locale, qu'il s'agisse des éléments de parure tels que les fibules, les deux bracelets en verre et la perle, des céramiques fines décorées ou des balles de fronde en terre cuite, sans doute destinées à la chasse (activité vraisemblablement réservée aux " notables»), se distingue une certaine richesse des habitants. 
En revanche, la faible représentativité des amphores dans les phases d'occupation datées de La Tène finale pourrait confirmer le changement de statut du site à cette période.

Enfin, l'abondance de creusets destinés à la fonte de bronze et de fragments de fours associés indique la présence à demeure d'un atelier spécialisé.

L'établissement de La Lande reflète une prospérité notable, particulièrement dans son état attribué à La Tène C2, mais sa situation hiérarchique reste incertaine. En effet, si certains critères usuellement utilisés pour définir l'aristocrate gaulois sont bien présents sur le site (surface, aménagements des entrées), beaucoup manquent (dimensions des fossés, qualité des mobiliers, en particulier les importations - amphores - et l'armement).

\section{Bibliographie}

Bellanger P. (dir.), 2010, Guérande, ZAC de Bréhadour, Le Parc Savari. Occupations du Néolithique moyen 1 et de la transition des deux âges $d u$ Fer, rapport final d'opération, Cesson-Sévigné, Inrap Grand Ouest, 3 vol. (221 p., 150 p. de pl., 113 p.).

Bellanger P. (dir.), 2013, Guérande, ZAC de La Métairie de La Lande, site 2. Une ferme aristocratique du second âge $d u$ Fer au Haut Empire, rapport final d'opération, Cesson-Sévigné, Inrap Grand-ouest, 2 vol. (502 p., 394 p.).

Bellanger P. (dir.), 2019, Guérande, ZAC de La Maison Neuve, zone B. Atelier de sauniers et occupation antique (Léchet 2 et 3), rapport final d'opération, Cesson-Sévigné, Inrap Grand Ouest, $194 \mathrm{p}$.

Bouvet J.-P., Brodeur J., Chevet P., Mortreau M. et Siraudeau J., 2003, "Un oppidum au château d'Angers (Maine-et-Loire) ", Les marges de l'Armorique à l'âge du Fer - Archéologie et Histoire : indices matériels et sources écrites, Actes du XXII colloque de l'Association française pour l'étude de l'âge du Fer (Nantes, 1999), $10^{\mathrm{e}}$ supplément à la Revue archéologique de l'Ouest, p. 173-187.

Bouvet J.-P., 2004, « Les âges du Fer dans la région de Guérande (800 à 30 av. J.-C.) : de la nature de l'occupation humaine à la constitution d'horizons chronologiques et culturels ", Cahiers du Pays de Guérande, 44, p. 31-46.

Cabanillas de La Torre G., 2015, «L'esthétique au quotidien dans l'âge du Fer européen : pour une nouvelle approche de l'art laténien ", dans Wilczex J., Cannot A., Le CozaNet T., Remy J., Macháčex J. et K. J., Interdisciplinarité et nouvelles approches dans les recherches sur l'âge du Fer, 1, vydání Brno : Masarykova univerzita, p. 147-150.

Centre De Recherches Archéologiques De La Presqu'île Guérandaise, 1975, Guérande, Route de la Madeleine, rapport de fouille, Nantes, Crapig.

Cherel A.-F., 2012, "Chronologie de la fin de l'âge du Fer
(III ${ }^{\mathrm{e}}-\mathrm{I}^{\mathrm{er}}$ s. av. J.-C.) dans la Plaine de Caen : le cas de « ZAC Object'Ifs Sud " à Ifs (Calvados)", dans Barral P. et FichtL S. (dir.), Regards sur la chronologie de la fin de l'âge du Fer (III--Ir s. av. J.-C.) en Gaule non méditerranéenne, Actes de la table ronde de Bibracte, Centre archéologique européen (Gluxen-Glenne, 15-17 octobre 2007), Glux-en-Glenne, Bibracte, 342 p., 149 ill.

Cornec J., Le Goff E., Le Guevellou R., Levillayer A., Moreau C., Mortreau M. et Thebaud S., 2018, " La céramique du $\mathrm{VI}^{\mathrm{e}}$ au I ${ }^{\mathrm{er}} s$. av. n. è. en Pays de la Loire : Évolution des formes, des décors et mobiliers associés ", dans Menez Y. (dir.), Céramiques gauloises d'Armorique. Les dessiner, les caractériser, les dater. Rennes, Presses universitaires de Rennes (Archéologie \& Culture), p. 357-450.

Daire M.-Y., 2003, Le sel des Gaulois, Paris, Errance, 152 p.

Devals C. (dir.), 1994, Guérande, Bréhadour, rapport final d'opération, Cesson-Sévigné, Afan Grand Ouest.

Devals C. (dir.), 1995, Guérande, Villejames, rapport final d'opération, Cesson-Sévigné, Afan Grand Ouest.

Devals C. (dir.), 2008, Guérande, ZAC de la Métairie de la Lande, Tranche 1, rapport final de diagnostic, Cesson-Sévigné, Inrap Grand Ouest, 1 vol. (non paginé, 34 p. de pl.).

Devals C. (dir.), 2009, Guérande, Le Parc de Villejames, rapport final d'opération, Inrap Grand Ouest, 3 vol. (116 p., 150 p. de pl., non paginé).

Dinard M., Gratuze B. et Cherel A.-F., 2011, " Les bracelets protohistoriques en verre de Bretagne ", dans Revue archéologique de l'Ouest, 28, p. 149-166.

Feugère M., 1985, Les fibules en Gaule méridionale de la conquête à la fin du ve apr. J.-C., $12^{\mathrm{e}}$ supplément à la Revue archéologique de Narbonnaise, Paris, CNRS.

Feugère M., 1992, "Les instruments de chasse, de pêche et d'agriculture ", dans Py M. (dir.), Recherches sur l'économie vivrière des Lattarenses, Lattara 5, Lattes, p. 139-162.

FichtL S., 2013, "À propos des résidences aristocratiques de la fin de l'âge du Fer : l'exemple de quelques sites du Loiret ", dans Krausz S., Colin A., Gruel K., Ralston I. et Dechezleprêtre T., dans L'âge du Fer en Europe, Mélanges offerts à Olivier Buchsenschutz, Bordeaux, Ausonius (Mémoire 32), p. 329-343.

Gebhard R., 1989, Der Glasschmuck aus dem Oppidum von Manching, Stuttgart, Steiner, 290 p. (Die Ausgrabungen in Manching, 11).

Gouletquer P.-L., 1970, Les briquetages armoricains, technologie protohistorique du sel en Armorique, Travaux du laboratoire d'anthropologie préhistorique, Rennes, CNRS, $186 \mathrm{p}$.

GuÉrIn F. (dir.), 1999, Chemillé, La Boirie 1 (Maine-et-Loire), rapport final d'opération, Inrap Grand Ouest, $92 \mathrm{p}$.

Gú́rIn F. (dir.), 2003, La Chaize-le-Vicomte, La Chapellière, rapport final d'opération, Inrap Grand Ouest, 180 p., 145 p. de pl. 
Guillier G. (dir.), 1999, Vivoin, La Gaudine, rapport final d'opération, Inrap Grand Ouest, 82 p., 27 p. de pl.

Gruet M., Passini B., 1985, Le village ouvert des Pichelots. La Tène III, journées d'étude de l'association PROLOG (Angers, 20-21 avril), Direction Régionale des Antiquités Historiques des Pays de la Loire, $21 \mathrm{p}$.

Hamon A.-L. (dir.), 2005, Corps-Nuds (Ille-et-Vilaine), Le Petit Chambière, Un enclos d'habitat de second âge du Fer, Inrap Grand Ouest, 99 p.

Hamon A.-L. (dir.), 2010, La ferme laténienne de la GrandeHaie : Vitré, Boulevard de Laval, rapport final d'opération, Inrap Grand Ouest, 246 p.

Hervé M.-L. (dir.), 2004, Angers, La Gatellière, rapport final d'opération, Inrap Grand Ouest, 59 p., 79 p. de pl.

Lallemand D., 2005, "L'origine et l'évolution de la terra nigra dans la basse vallée de l'Allier ", Actes du Congrès de Blois, Blois, Société Française d'Étude de la Céramique Antique en Gaule, p. 39-60.

LANGOUET L., 1996, Le passage du pré-romain au gallo-romain dans les campagnes de la haute Bretagne, dans Revue archéologique de Picardie, numéro spécial 11, p. 233-243.

Le Boulaire A., 2009a, Guérande, Tromartin, rapport final de diagnostic, Inrap Grand Ouest.

Le Boulaire A., 2009b, Guérande, Trébissin, les Hauts de Trébissin, rapport final de diagnostic, Inrap Grand Ouest, 71 p., 22 p. de pl.

Le Goff E., 1994, Datation et caractérisation d'ensemble homogène de mobilier : le fossé de l'avant-cour de l'habitat fortifié de Saint-Symphorien à Paule (22), Mémoire de DEA, université de Rennes 2, 137 p., 54 p. de pl., inédit.

Le Goff E. (dir.), 1998, Carquefou, Le Clouët, Les Mazères, rapport final d'opération, Afan Grand Ouest, 138 p.

Le Goff E. (dir.), 2000, Mûrs-Érigné, Les Humelles, habitat fortifié de l'âge du Fer, rapport final d'opération, Afan Grand Ouest, 93 p.

Le Goff E. (dir.), 2007, Thorigné-Fouillard, ZAC de Bellevue, un habitat gaulois du bassin rennais (III- - ${ }^{e r}$ s. av. J.-C.), rapport final d'opération, Inrap Grand Ouest, $147 \mathrm{p}$.

Le Goff E., 2009, " Habitats, terroir et paysage rural : aménagement et structuration du territoire et de la campagne gauloise. Ifs, ZAC "Object'Ifs Sud " (Calvados) ", dans Bertrand I., Duval A., Gomez de Soto J. et Maguer P. (dir.), Habitats et paysages ruraux en Gaule et regards sur d'autres régions du monde celtique : actes du XXXI' colloque international de l'AFEAF (Chauvigny, 2007), tome 2, Chauvigny, Association des Publications Chauvinoises, p. 93-107.

Lepaumier H., Vauterin C.-C., Le Goff E. et Villaregut J., 2011, Un réseau de fermes en périphérie caennaise. L'âge du Fer en Basse-Normandie. Gestes funéraires en Gaule au second âge du Fer. Actes du XXXIII colloque international de l'AFEAF (Caen 2009), Presses universitaires de Franche-
Comté, Annales littéraires de l'université de Franche-Comté, 881, série "Environnement, sociétés et archéologie ", 14, vol. 1, p. 139-158.

Lepaumier H., Besnard-Vauterin C.-C., Chanson K. et ZaOur N., 2015, «Fonction et statut des habitats enclos de la fin de l'âge du Fer, une question de mobilier? L'exemple du réseau d'établissements du sud-est de l'agglomération caennaise ", Revue archéologique de l'Ouest, 32, p. 285-316.

Lepaumier H., Giraud P. et Leroux G., 2018, “ Les clôtures et portes sur les établissements ruraux du second âge du Fer à partir de quelques réflexions issues d'exemples du Grand Ouest ", dans Villard-Le Tiec A., Menez Y. et Maguer P. (dir.), Architectures de l'âge du Fer en Europe occidentale et centrale. Actes du $40^{\circ}$ colloque international de l'AFEAF (Rennes, 2016), Presses universitaires de Rennes (Archéologie \& Culture), p. 187-202.

Levillayer A., Audé V., Baron A. et Mens E., 2017, « Le site du Bois Hue à Nantes (Loire-Atlantique) et le second âge du Fer dans l'interfluve Erdre-Loire ", Revue archéologique de l'Ouest, 34, p. 177-210.

Levillayer A., 2018, Pornic (Loire-Atlantique), Le Fief Clément, rapport final d'opération, Inrap Grand Ouest, 3 vol. (74 p., 583 p., 226 p.).

Lorho T. et Monteil M., 2013, "Entre Loire et baie du Mont-Saint-Michel (Pays de la Loire et Bretagne, France) : modes d'occupation du littoral au Haut-Empire ", dans Daire M.-Y., Dupont C., Baudry A., Billard C., Large J.-M., Lespez L., Normand E. et Scarre C. (dir.), Ancient Maritime Communities and the Relationship between People and Environment along the European Atlantic Coasts, Actes du colloque international HOMER "Anciens peuplements littoraux et relations Homme/Milieu sur les côtes de l'Europe Atlantique " (Vannes, 27 septembre$1^{\text {er }}$ octobre 2011), Londres, BAR (coll. BAR International Series, 2570), p. 347-358.

Maguer P. (dir.), 2000, L'établissement rural des Natteries à Cholet (Maine-et-Loire), rapport final d'opération, Afan Grand Ouest, 2 vol. (259 p., 66 p. de pl., non paginé).

Maguer P., Cherel A.-F. et Auxiette G., 2003, " Nouvelles données sur les habitats de l'âge du Fer dans le nord de la Sarthe (commune de Vivoin, autoroute A 28) ", Revue archéologique de l'Ouest, supplément n ${ }^{\circ} 10$, p. 213-234.

Maguer P., 2005, "L'architecture des bâtiments de La Tène dans le sud du Maine-et-Loire et en Vendée : études de cas ", dans Buchsenschutz O. et Mordant C. (dir.), Architectures protohistoriques en Europe occidentale du Néolithique à l'âge du Fer, Actes des congrès nationaux des sociétés historiques et scientifiques, 127e, (Nancy 2002), Paris, CTHS, p. 331-345.

Maguer P., Lusson D. et Troubady M., 2009, "Fermes, hameaux et résidences aristocratiques entre Loire et Dordogne ", dans Bertrand I., Duval A., Gomez De Soto 
J. et Maguer P. (dir.), Les Gaulois entre Loire et Dordogne, Actes du XXXIe colloque international de l'Association Française pour l'Étude de l'áge du Fer (Chauvigny, 2007), Chauvigny, Associations des publications chauvinoises, p. 423459.

Maguer P. et Robert G., 2013, "La maison gauloise dans l'Ouest et le Centre de la France ", dans Krausz S., Colin A., Gruel K., Ralston I. et Dechezleprêtre T., dans L'âge du Fer en Europe, Mélanges offerts à Olivier Buchsenschutz, Bordeaux, Ausonius (Mémoire 32), p. 247-258.

Mare E. (dir.), 2014, Coulans-sur-Gée (Sarthe), Les Nouis, LGV Bretagne - Pays de la Loire : exploitation agricole gauloise en pays cénoman et occupation médiévale, rapport final d'opération, Inrap Grand Sud-Ouest, $173 \mathrm{p}$.

Menez Y. (dir.), 1996, Une ferme de l'Armorique gauloise, Le Boisanne à Plouër-sur-Rance (Côtes-d'Armor), Paris, Maison des Sciences de l'Homme (Documents d'Archéologie Française, 58), $266 \mathrm{p}$.

Menez Y., 2008, Le camp de Saint-Symphorien à Paule (Côtesd'Armor) et les résidences de l'aristocratie du second âge du Fer en France septentrionale, thèse de doctorat, Paris, université de Paris 1 (Panthéon-Sorbonne), 2 vol. (559 p., 548 fig.).

Menez Y. (dir.), 2018, Céramiques gauloises d'Armorique. Les dessiner, les caractériser, les dater, Rennes, Presses universitaires de Rennes (Archéologie \& Culture), 496 p.

Mentele S. (dir.), 2010, Lamballe, ZAC de La Tourelle. La mise en valeur agraire du terroir du plateau de La Tourelle aux If et $I^{e r}$ s. av. J.-C., rapport final d'opération, Inrap Grand Ouest, $540 \mathrm{p}$.

Meuret J.-C., 1998, La Glanerie, Athée (Mayenne), rapport de fouille programmée, Nantes SRA des Pays de la Loire.

Monteil M., 2012, Contribution à l'étude des agglomérations secondaires des Gaules romaines. Les cités de l'ouest de la province de Lyonnaise (Bretagne et Pays de la Loire), vol. II, mémoire inédit, HDR, Tours, université François-Rabelais, non publié, $363 \mathrm{p}$.

Nillesse O. (dir.), 1993, Pouillé (Vendée), Le Grand Paisilier, autoroute $A 83$ Nantes-Niort, rapport final d'opération, Inrap Grand Ouest, 2 vol. (non paginé, 127 p. de pl.).

Nillesse O. (dir.), 1997, Fontenay-le-Comte (Vendée), L'établissement rural des Genâts, rapport final d'opération, Inrap Grand Ouest, 6 vol. (197 p., 244 p. de pl., non paginé).

Nillesse O. (dir.), 2004, L'établissement rural gaulois de La Tène finale de Beauregard à Dissay-sur-Courcillon, rapport final d'opération, Inrap Grand Ouest, 51 p., 80 p. de pl.

Nillesse O. (dir.), 2006, L'établissement rural de la fin de l'áge du Fer et occupation gallo-romaine du Coq Hardy à Fontenayle-Comte, rapport final d'opération, Inrap Grand Ouest, 108 p., 91 p. de pl.
NIN N., 2000, «La maison protohistorique : espace fonctionnel, espace vécu ", dans Chausserie-Lapree J. (dir.), Le temps des gaulois en Provence, Martigues, p. 43-50.

PÉRIDY P., 1999, « Archéologie aérienne du bocage vendéen (France). État des recherches ", Revue archéologique de Picardie, Actes du colloque international d'archéologie aérienne (Amiens, 15-18 octobre 1992), $\mathrm{n}^{\circ}$ spécial 17, Hommage à Roger Agache pour trente-cinq ans de prospections aériennes dans le Nord de la France, p. 373-386.

Pétorin N. (dir.), 2009, Ancenis (Loire-Atlantique), La Savinière 1-2, rapport final d'opération, Inrap Grand Ouest, $97 \mathrm{p}$.

PÉTORIN N. (dir.), 2010, Angers, Beauséjour : établissement rural de La Tène finale, rapport final d'opération, Inrap Grand Ouest, $77 \mathrm{p}$.

PÉtorin N. (dir.), 2013, Aubigny, La Pâquerie : établissement rural, La Tène finale- $\mathrm{t}^{\text {er }}$ s. A. D., rapport final d'opération, Inrap Grand Ouest, $401 \mathrm{p}$.

Pirault L. (dir.), 1996, Guérande, Le Clos Flaubert, rapport final d'opération, Afan Grand Ouest, 45 p., 102 p. de pl.

Pirault L. (dir.), 2010, Guérande, Extension est du parc de Villejames, rapport final de diagnostic, Inrap Grand Ouest, 2 vol. (41 p., 33 p.).

Pirault L. (dir.), 2019, Guérande, ZAC de la Maison Neuve, Zone $A$, rapport final d'opération, Inrap Grand Ouest, 2 vol. (214 p., 178 p.).

Pithon M. (dir.), 1994, Guérande, Le Moulin de Beaulieu, rapport final d'opération, Afan Grand Ouest, 18 p., 71 p. de pl.

RÉmY J., 2017, L'organisation des territoires du quart nord-ouest de la Gaule (Bretagne et Pays de la Loire) à la fin de l'âge du Fer (II - Ir $^{r}$ s. av. n. è.), thèse de $3^{\mathrm{e}}$ cycle, université de Tours, vol. 1, texte, $452 \mathrm{p}$.

SAndoz G. (dir.), 1999, Cholet, La Bleure, rapport final d'opération, Afan Grand Ouest, $85 \mathrm{p}$.

Seleque J. (dir.), 2010, Savenay (Loire-Atlantique), La Colleraye, rapport final d'opération, ArchéoLoire, 2 vol. (180 p.).

SICARD S. (dir.), 2016, Un établissement rural gaulois en milieu humide, ZAC des Vairies, Les Croisés, Saint-Sauveur-desLandes, (Ille-et-Vilaine), rapport final d'opération, Inrap Grand-Ouest, 2 vol. (919 p.).

Tanguy D., 2000, «Le site d'habitat de l'âge du Fer de Kerven Teignouse à Inguiniel (Morbihan) ", dans Revue archéologique de l'Ouest, 17, p. 143-173.

Vacher S., 2001, Guérande, Giratoire du Moulin du Diable, rapport final de diagnostic, Afan Grand Ouest, 11 p., 13 p. de pl.

Valais A., Meuret J.-C. et Nauleau J.-F., 2008, « Le ClosHenry : une ferme de La Tène finale à Château-Gontier (Mayenne) ", Revue archéologique de l'Ouest, 25, p. 139-161. 


\section{Das grabenumhegte Gehöft von La Métairie de la Lande bei Guérande (Loire-Atlantique): ein aristokratisches Gehöft der jüngeren Eisenzeit?}

Das Gehöft von La Lande, das sich am östlichen Rand der Hochebene von Guérande und am rechten Ufer eines Tälchens befand, wurde im Jahr 2009 im Rahmen einer Rettungsgrabung archäologisch untersucht, die eine Fläche von $19.500 \mathrm{~m}^{2}$ umfasste. Insgesamt konnten acht Siedlungsphasen ermittelt werden, die einen Zeitraum vom 4. Jh. v. Chr. bis zum Beginn des 2. Jh. v. Chr. umfassen. Die erste Siedlungsphase entspricht möglicherweise einer kleinen, offenen Siedlung, die an das Ende der Frühlatènezeit oder an den Anfang der Mittellatènezeit datiert wird. In den folgenden vier Phasen, die der Mittel- und Spätlatènezeit zuzuweisen sind, entwickelte sich ein großes Gehöft, das eine Grundfläche von etwa 1,4 Hektar einnahm und einen fünfeckigen Grundriss aufwies sowie verschiedene Umbauten erkennen ließ. Dieses Gehöft wies an seiner Nord-und Nordwestseite eine doppelte Grabenumbegung auf; an den anderen Seiten wurden dreifache Umfassungsgräben festgestellt. Das grabenumhegte Gehöft besaß von Beginn an einen Eingang mit Toranlage im Osten. Im Innenbereich konnten zahlreiche unterteilende Gräben beobachtet werden, die die Innenfläche in miteinander kommunizierende Einheiten gliederte, bei denen die Verbindungspassagen häufg mit Toren ausgestattet waren. Die bemerkenswerte Gliederung der Anlage in dieser Periode wirft sofort die Frage nach ihrem sozialen Status auf, möglicherweise handelte es sich um ein aristokratisches Gehöft. Die fünfte Siedlungsphase, die der Spätlatènezeit zugewiesen werden kann, scheint einen Niedergang des Status des Gehöftes anzuzeigen. Obwohl die südliche Fassade verändert wurde, wurde die Gehöftanlage weiterhin während der beiden folgenden Siedlungsphasen, die dem 1. Jh. n. Chr. zugewiesen werden können, genutzt. Schließlich wurde die Anlage am Ende des 1. Jh. n. Chr. zugunsten einer Einhegung von agro-pastoralem Charakter aufgegeben, die sich mit der ehemaligen östlichen Fassade überschnitt.

Schlagwortindex: Loire-Atlantique, Eisenzeit, Frührömische Zeit, Keramik.

\section{El recinto de La Métairie de la Lande en Guérande (Loire-Atlantique): un posible establecimiento rural aristocrático de la Segunda Edad del Hierro}

El establecimiento de La Lande, situado en el borde oriental de la llanura de Guérande, en la margen derecha de la cabecera de un pequeño valle, fue objeto de una excavación preventiva en 2009, sobre un total de $19500 \mathrm{~m}^{2}$. Se identificaron ocho fases de ocupación entre el siglo IV antes de nuestra era e inicios del siglo II de nuestra era. La primera fase corresponde probablemente a un pequeño poblado abierto del final de la fase antigua o inicios de la fase media de La Tène. Durante las cuatro fases siguientes, de mediados a finales del periodo de La Tène, se desarrolla un gran establecimiento rural de 1,4 ha, de planta pentagonal, con varias reorganizaciones. Está delimitado por un doble recinto en las zonas norte y noroeste, y triple en el resto. El recinto posee desde su creación una entrada oriental con un porche. En el interior se observan numerosos fosos divisorios que estructuran el espacio en módulos, conectados por pasajes generalmente aportalados. La estructuración del espacio interno durante este periodo es tal que se plantea la cuestión de su estatus, potencialmente aristocrático. La quinta fase, al final del periodo de La Tène, parece marcar el declive del estatus del poblado. Aunque se modifica su fachada sur, el establecimiento sigue ocupado durante dos fases más, fechadas durante el siglo I de nuestra era, antes de abandonarse al final de este siglo a favor de otro recinto de tipo agropecuario que se superpone a la antigua fachada oriental.

Palabras clave: Loire-Atlantique, Edad del Hierro, época alto-imperial, cerámica. 